\title{
Warm perfusion : a potential solution to the organ shortage
}

Citation for published version (APA):

Brasile, L. (2002). Warm perfusion : a potential solution to the organ shortage. [Doctoral Thesis, Maastricht University]. Datawyse / Universitaire Pers Maastricht. https://doi.org/10.26481/dis.20020627lb

Document status and date:

Published: 01/01/2002

DOI:

10.26481/dis.20020627lb

Document Version:

Publisher's PDF, also known as Version of record

\section{Please check the document version of this publication:}

- A submitted manuscript is the version of the article upon submission and before peer-review. There can be important differences between the submitted version and the official published version of record.

People interested in the research are advised to contact the author for the final version of the publication, or visit the DOI to the publisher's website.

- The final author version and the galley proof are versions of the publication after peer review.

- The final published version features the final layout of the paper including the volume, issue and page numbers.

Link to publication

\footnotetext{
General rights rights.

- You may freely distribute the URL identifying the publication in the public portal. please follow below link for the End User Agreement:

www.umlib.nl/taverne-license

Take down policy

If you believe that this document breaches copyright please contact us at:

repository@maastrichtuniversity.nl

providing details and we will investigate your claim.
}

Copyright and moral rights for the publications made accessible in the public portal are retained by the authors and/or other copyright owners and it is a condition of accessing publications that users recognise and abide by the legal requirements associated with these

- Users may download and print one copy of any publication from the public portal for the purpose of private study or research.

- You may not further distribute the material or use it for any profit-making activity or commercial gain

If the publication is distributed under the terms of Article $25 \mathrm{fa}$ of the Dutch Copyright Act, indicated by the "Taverne" license above, 


\section{Warm Perfusion}

A potential solution to the organ shortage 
(c) L. Brasile, Maastricht 2002

ISBN 9090158855

Vormgeving en druk: Datawyse | Universitaire Pers Maastricht 


\section{Warm Perfusion \\ A potential solution \\ to the organ shortage}

\section{Proefschrift}

ter verkrijging van de graad van doctor aan de Universiteit Maastricht, op gezag van de Rector Magnificus

Prof. dr. A.C. Nieuwenhuijzen Kruseman, volgens het besluit van het College van Decanen, in het openbaar te verdedigen op donderdag 27 juni 2002 om 14.00 uur

door

Lauren Brasile 


\section{Promotor}

Prof.dr. G. Kootstra

\section{Co-promotor}

Dr. B.M. Stubenitsky

\section{Beoordelingscommissie}

Prof.dr. J.P. van Hooff (voorzitter)

Prof.dr. T.M. van Gulik (Academisch Medisch Centrum, Amsterdam)

Dr. E.M. van Heurn

Prof.dr. J.G.R. De Mey

Prof.dr. M.L. Nicholson (Leicester General Hospital, United Kingdom) 


\section{Contents}

CHAPTER 1

Introduction -

The major obstacles facing clinical transplantation

CHAPTER 2

The cadaveric kidney and the organ shortage -

A perspective review

CHAPTER 3

Solving the organ shortage -

Potential strategies and the likelihood of success

CHAPTER 4

Exsanguineous Metabolic Support technology

CHAPTER 5

Hypothermia -

A limiting factor in using warm ischemically damaged kidneys

CHAPTER 6

Amelioration of reperfusion injury by ex vivo warm perfusion

CHAPTER 7

Overcoming severe renal ischemia -

The role of ex vivo warm perfusion

CHAPTER 8

The culture of whole organs

\section{CHAPTER 9}

Conclusions and future applications

Summary of results

Samenvatting

Acknowledgements

Curriculum Vitae 


\section{Introduction - The major obstacles facing clinical transplantation}

The field of organ transplantation has evolved to become the routine clinical reality for patients with end-stage organ failure it is today because of two major technical advancements: organ preservation and immunosuppression. Both of these disciplines were mandatory, and needed to be developed in tandem in order to achieve the greater than $90 \%$ 1-year graft survival that is commonplace today among the developed countries. Ironically, these two disciplines likewise represent the two major obstacles facing the transplantation fièlá today; namèly the persistent shortage of organs availabile for transplantation and chronic rejection.

The pool of organ donors providing allografts for transplantation has remained essentially stagnant over the past ten years. This donor pool has largely consisted of heartbeating donors, those patients on life-support in intensive care units. The heartbeating donor population represents a small fraction of the patients that expire each year from a traumatic injury, approximately $4 \%$ (1). Further complicating the situation is the fact that in the United States, the majority of the time the next-of-kin refuse consent for organ donation $(2,3)$. Several studies have demonstrated that the public does not have a problem with the concept of organ donation, per se, but rather has difficulty with the decision of terminating life support. This interpretation is supported by the disparity in the consent rates observed between cornea, bone and skin donation where there are no issues concerning the termination of life-support when compared to organ donation $(4,5)$. The vast majority of patients who die from traumatic injury never make it to an intensive care unit, but rather expire at the site of the injury, in the ambulance or in the emergency department. These patients are never considered as organ donors because the period of warm ischemia experienced has represented an insurmountable obstacle to transplantation. The organ shortage necessitates facing the reality that with the development of modern trauma care, if a patient survives an accident and is transitioned to an intensive care unit, he has an excellent chance of surviving. While living-related donation has been a solution for the long waiting 
times for kidney allografts in some families, the reality is that the organ shortage remains the major obstacle facing clinical transplantation today. The result is a paradigm where there is a huge discrepancy between the growing demand for kidneys by a pool of patients being maintained on hemodialysis that doubles in number every ten years and the pool of allografts demonstrating little growth over the past decade (6). Barring the development of a more physiologic dialysis, transplantation will remain the treatment of choice for end-stage renal failure, and the only opportunity for survival for patients with heart and liver and lung failure. Clearly there is an urgent need for substantially increased numbers of transplantable organs.

Complicating this clinical picture is the fact that while 1-year graft survival is excellent, approximately $45 \%$ of the cadaveric kidney recipients have rejected their grafts by 5 -years posttransplant (7). Despite the arsenal of potent immunosuppressive agents in use today, it is clear that the immune response that is initiated upon allorecognition in many cases eventually prevails. When immunocompetent cells in circulation interface with the donor endothelium lining the blood vessels within an allograft, a complex pathophysiologic inflammatory response develops. Whether the rejection is hyperacute, accelerated, acute, acute cellular or chronic, mediated by humoral or cellular mechanisms, the vascular endothelium is always the interface of the immunologic response (8). The immunologically mediated damage leads to structural and functional alterations, resulting in reduced blood flow due to luminal narrowing, endoarteritis, platelet adhesion and thrombosis.

Histocompatibility testing identifies preexisting sensitization in potential recipients avoiding hyperacute rejection by eliminating incompatible transplants and helps to minimize the frequency of accelerated rejection. Although the immunosuppressive regimens have been quite effective in recent years in preventing the early-phase immunologically mediated rejection, they do not adequately address the development of the chronic phase of the immune response. The second major obstacle facing transplantation today is the absence of effective treatment for chronic rejection (9). Chronic rejection is a slow progressive process that causes declining renal function. Treatment is essentially symptomatic focusing on controlling hypertension and correcting for acidosis. Chronic rejection ultimately returns the patient to dialysis or back on the waiting list for retransplantation which puts further pressure on an already overburdened system where there are clearly never enough organs to meet the demand. 


\section{A NEW APPROACH IS NEEDED}

Clearly, the techniques used presently to preserve organs will not provide for an expanded indication for organ donation. In the case of the heartbeating donor, the organ preservation technology in use today, developed over the past 30 years and culminating with the development of ViaSpan ${ }^{\mathrm{TM}}$ represents the optimal way to preserve non-damaged organs. It is not anticipated that new hypothermic preservation technology will markedly improve upon the results achieved with ViaSpan. However, in the case of warm ischemically damaged organs from the non-heartbeating donor, hypothermia represents a compounding damage resulting in substantially increased rates of ATN $(10,11)$. For there to be any significant expansion in the number of organs available for transplantation, alternative technology will need to be developed that will provide the basis for expanding the donor pool into the population of organs with substantial warm ischemic exposure.

It is unlikely that new immunosuppressive agents developed from the traditional $\mathrm{T}$ cell receptor perspective will have a higher degree of effectiveness in ameliorating chronic rejection. Given the redundancy of the immune system, it is likewise doubtful that therapies designed to modify specific cytokine pathways will be sufficient to avoid the ferocious nature of immunity sufficiently to prevent chronic rejection. Since the time when Medawar first proposed the concept that because antigenicity was under genetic control it represented an immutable obstacle, focus has been placed upon modifying the effector arm of the recipient's immune response (12). Efforts towards reducing the alloimmune response were subsequently focused upon minimizing antigenic differences by matching for the major histocompatibility complex antigens. However, it is well known that all HLA identical transplants, except those from identical twins, will reject their grafts without immunosuppression and even with immunosuppression, rejection eventually occurs in about $10 \%$ of recipients of HLA identical renal allografts $(13,14)$. Alternative approaches to reducing alloresponsiveness have included procedures such as those focused on reducing the mass of passenger leukocytes by pretreating cadaver donors with large doses of steroid and cytotoxic drugs, antibody removal by plasmaphoresis, $\mathrm{T}$ cell depletion by monoclonal and polyclonal antibodies, splenectomy, irradiation, drug therapy and lymphatic duct drainage (15-17). However, the cell surface of the vascular endothelium is rich in alloantigens including the $\mathrm{ABH}$ blood group, Major and Minor Histocompatibility antigens, antigens systems shared with platelets, granulocytes and peripheral blood monocytes, as well as endothelial specific antigens (18). Given the immunogenicity of the vascular endothelium and its anatomical location, it is 
logical to assume that matching for the HLA antigens in unrelated recipient-donor combinations, removal of passenger leukocytes and the temporary depletion of immunocompetant cells will not prevent the eventual development of chronic rejection. It is therefore rather simplistic to assume that if the initial allorecognition could be interrupted, the sequelae leading to chronic rejection could be ameliorated. Furthermore, the consequence of chronic immunosuppression is not benign. Transplant recipients experience increased rates of life-threatening infections, higher incidences of malignancies and side effects of steroids such as cataracts and bone disease $(19,20)$.

It is more logical to assume that a more permanent modification of either the host's immune system or the graft would be necessary to prevent the eventual development of chronic rejection. Unfortunately with current organ preservation technology based upon severe hypothermia, it is impossible to immunomodify allografts. Hypothermic preservation is predicated upon inhibiting oxidative metabolism by more than $95 \%(21)$. Without substantial basal metabolism, the ability to modify an organ is severely limited. Furthermore, the relatively limited preservation times of approximately 24 hours for kidneys, 18 hours for livers and only 6 hours for hearts, are not adequate to modify an allograft in terms any requirement for de novo synthesis.

\section{POTENTIAL OF WARM PERFUSION}

The development of a more physiologic organ preservation technology could provide the foundation to address the two major obstacles facing clinical transplantation today. A potential benefit of a more physiologic preservation technology would be that cell membranes would remain in their normal fluid state rather than undergoing the phase-change that occurs at temperatures below $18^{\circ} \mathrm{C}(22)$. Similarly, a warm perfusion would lead to increased membrane potential with maintenance of the distinct differences in the luminal-abluminal surface polarity.

A requisite component of a warm temperature perfusion technology would be that oxidative metabolism would be ongoing, and therefore, continually supported. If the level of metabolism was of sufficient magnitude during the ex vivo perfusion then organ function would continue, i.e. urine would be produced in kidneys, bile in livers and hearts would have continued mechanical and electrical work. Technical hurdles that would need to be addressed include the risk of microbial contamination, adequate support of ex vivo metabolism and the need to replace or regenerate the circulating perfusate, something not needed today with hypothermic technology. If these technical 
hurdles can be addressed than the potential benefits of a warm perfusion technology could be substantial, and potentially could help to solve the major problems facing transplantation field today.

\section{THESIS STATEMENT}

The following thesis is based upon experimental data obtained during the development of a new near-normothermic perfusion technology called Exsanguineous Metabolic Support (EMS) Technology. EMS has been developed and optimized over the past nine years. Previous to the studies described in this thesis, short periods of ex vivo EMS perfusion were achieved where kidney metabolism could be supported sufficiently to render the organs immediately functional when reimplanted, providing for normal serum chemistries and urinalysis 24 hours posttransplant.

The experimental studies described in this thesis include new work that demonstrates: 1) the identification of the limiting factor in efforts to expand the organ donor pool with warm ischemically damaged kidneys, 2 ) the potential of warm perfusion to ameliorate reperfusion injury, 3) the possibility of repairing damaged organs during ex vivo perfusion and 4) the ability to maintain whole organs in tissue culture-like conditions for extended periods with the potential for gene transfection, nuclear trafficking and de novo synthesis of the reporter gene product during warm perfusion. The experimental work was performed using three models: 1) a bovine calf kidney, 2) a canine autotransplantation model and 3) human kidneys deemed to be nontransplantable.

\section{REFERENCES}

1. Vernick JJ. Surgery, Jarrell BE, Carabasi RA (eds), Harwal Co., Media, PA 1986: 53

2. Beaulieu D. J Neurosci Nurs 1999: 31(1):37

3. UNOS Semi Annual Report July 1990

4. Howard W. Aust Nurs J 1999: 6(9):1

5. Nathan HM. Three Year Report of an Organ Procurement Organization Grant Program, Bethesda,MD HRSA 1989

6. Garrison RN, Bentley FR, Lucas BA. Surg Gynecol Obstet 1991: 173(5):391

7. Annual Report of the U.S. Scientific Request for Organ Transplant and Organ Procurement and Transfer Network, U.S. Department of Health and Human Services 1990 
8. McCluskey RT. Transpl Proc 1980: 12(3):22

9. Paul LC. Kidney Int 1999: 56:783

10. Wijnen R, Booster M, Stubenitsky B et al. Lancet 1995: 345:1067

11. Maessen JG, Van Der GJ, Vork M et al. Transpl Proc 1987: 19:4159

12. Medawar PB. J Anat 1944: 8:176

13. Brasile L, Clark J, Cerilli J. Transpl Proc 1987: 19:894

14. Cerilli J, Bay W, Brasile L. Human Immunol 1987: 7:45

15. Guttmann RD, Beaudoin JG, Morehouse DD. Transpl Proc 1973: 5:663

16. Woodruff MFA, Anderson NF. Nature 1963: 200:702

17. Cosimi AB, Colvin RB, Burton RC et al. N Engl J Med 1981: 305:308

18. Brasile L, Cerilli J. Organ Transplant and Replacement, Cerilli J (ed), Lippencott Philadelphia 1988: 208

19. Cantrell DA, Smith KA. Science 1984: 224:132

20. Richards JM, Vogelzang NJ, Bluestone JA. N Engl J Med 1990: 323:487

21. Fuhrman FA. Nat Acad Sci, Nat Res Council Washington 1956: 50

22. Pegg DE, Jacobsen IA, Halasz NA. Organ Preservation 1982: 17 
CHAPTER 2

\section{The cadaveric kidney and the organ shortage - A perspective review}

Brasile L, Stubenitsky BM, Booster MH, Kootstra G

Clinical Transplantation 2001; 15(6):369 
For patients awaiting kidney transplantation, a compatible living donor is not always available, nor preferable. The obvious result of this situation is that transplantation is dependant upon most allografts being procured from dead bodies. Complicating the situation is the need to remove the donated organs from the dead patient as soon as possible, once the designation has been made from that of patient to that of organ donor. It is the necessity of positioning the two so closely that leads to the ethical issues in organ donation. One of the most significant issues, determining the moment of death without possibility of resuscitation, has been a concern since the earliest days of transplantation in order to minimize warm ischemic damage to the organs. The need to subsequently hypothermically preserve the retrieved organ compounds the damage of warm and cold ischemia and may actually represent the major barrier to expanding the organ donor pool. The following discussion provides an overview of the historical experience during the early years of transplantation where retrieval of kidneys from non-heartbeating donors necessitated a prolonged period of warm ischemic exposure, with a corresponding minimal ex vivo period since organ preservation was in its infancy. The historical experience is discussed in light of today's situation where longer preservation times are due to the need to transport organs mandated by sharing algorithms. The mandated sharing of organs is the direct result of the severe shortage of organs. The following attempts to discuss the relative impact of warm ischemia on subsequent allograft function. While it is difficult to isolate the specific impact of warm ischemia given other contributing factors, it is nonetheless an important question that must be addressed if we are to design solutions to the organ shortage. In evaluating the clinical experience, it is important to keep the perspective that there is a continuum in the progression from clinical death to biologic cessation of function to cellular death.

\section{THE EARLY YEARS USING NON-HEARTBEATING DONORS}

Following the first successful kidney transplantations in the 1950's involving identical twins, human cadaveric kidney transplantations were attempted $(1,2)$. In the context of today's outcomes in clinical transplantation, these early efforts can be categorized as failures. However, the first cadaveric transplants demonstrated the proof- of -concept that organ transplantation was technically feasible. By 1976, 25,000 patients worldwide had been transplanted and approximately 10,000 of those patients still maintained functioning kidneys (3). At that time, expected one year graft survival for cadaveric kidneys was approximately $50 \%$. Despite the high rate of graft loss and its 
associated mortality rates, instances of successful long-term renal allograft function were achieved. Accepted practice throughout the 1960's and early 1970 's utilized the non-heartbeating donor. A feature of using the non-heartbeating donor was the need to remove the organs quickly upon cardiac arrest in order to minimize warm ischemia. The donor was heparinized and both kidneys were removed en bloc by clamping the aorta and vena cava above the renal arteries and veins and then transecting the aorta and vena cava below the renal vessels. The procedure was performed quickly, removing the organs in approximately 10 minutes and then quickly cooling the kidneys by flushing and storing them hypothermically (4). It is difficult to assess the impact of the non-heartbeating donor organ on the transplant outcomes during the early days of transplantation. Factors contributing to the outcomes such as inadequate immunosuppression, the fact that organ preservation was in its infancy and histocompatibility testing was not well standardized nor had Class II testing yet been developed, makes it almost impossible to dissect the effect of the non-heartbeating donor. However, in reviewing the data from the early years, it is clear that most of the grafts did provide life-sustaining function for a time and that most of the graft failure could be attributed to immunologic rejection and not primary non-function (4). During this early era of transplant, it was generally recognized that the use of warm ischemically damaged organs was largely problematic in not being able to differentiate reversible from non-reversible injury. While the outcomes in terms of 1-year and 2-year graft and patient survival was similar in patients with delayed graft function in comparison to those not requiring supportive dialysis for a time, the problem was primary nonfunction. At some transplant centers the primary nonfunction rate was reported to be as high as $30 \%(5)$. The incidence of delayed graft function severe enough to warrant hemodialysis during the period of 1968 through 1970 was reported to be 25 to $30 \%$, in contrast to $12 \%$ in recipients of living-related kidneys donors $(6,7)$. Long-term outcomes were not adversely affected, since there was no difference in patient survival nor in graft function in patients with delayed function in comparison to those that did not need dialysis. Oliguria was reported to last as long as one and a half months, although the average period of delayed function was 10 days. Even in the kidneys with prolonged delayed graft function full recovery of renal function was possible (8).

In another report from 1966 comprised of 40 cadaveric kidneys, warm ischemic damage of as much as 310 minutes resulted in ATN with oliguria of 12 days duration (9). The clinical outcomes from this group during the years of 1963 to 1966 are summarized in Table 1 below. 
TABLE 1. Outcomes of non-heartbeating donor cadavar kidney transplants, 1963-1966

\begin{tabular}{lccc}
\hline Warm Ischemic time & IF & ATN & PNF \\
$\leq 120 \mathrm{~min}(\mathrm{n}=7)$ mean=109min(range 93-120) & $3 / 7(43 \%)$ & $3 / 7(43 \%)$ & $1 / 7(14 \%)$ \\
$>120 \mathrm{~min}(\mathrm{n}=33)$ mean=186min (range 121-321) & $8 / 33(24 \%)$ & $19 / 33(58 \%)$ & $6 / 33(18 \%)$ \\
\hline
\end{tabular}

$\mathrm{IF}=$ immediate function, $\mathrm{ATN}=$ acute tubular necrosis, $\mathrm{PNF}=$ primary non-function. Data taken from (9).

It is apparent from Table 1 data that $6 / 7(86 \%)$ kidneys provided life-sustaining function from within a window of warm ischemia of as much as 2 hours postmortem. The shortest duration of ischemia reported was $93 \mathrm{~min}-$ utes. In paired kidneys cases of disparate results were observed even though the warm ischemic time and the time until reimplantation were quite similar. With warm ischemic times of greater than 2 hours postmortem the rate of immediate function was reduced by half, resulting in an increased number of cases of ATN. However, the PNF rate increased by only $4 \%$, despite as much as 5 hours of warm ischemic insult.

It was generally thought that the age of the donor was not significant and that kidneys could recover from extended periods of shock and anuria. Kidneys were also recovered from donors exhibiting hepatorenal failure (10). A startling concept, in light of today's reluctance to use warm ischemically damaged organs, was the idea that 2 hours of warm ischemia represented the upper limit of tolerable damage (11).

The interrelationship between the warm ischemic insult prior to harvest and the cold ischemia during ex vivo preservation was well recognized. Kidneys without warm ischemic insult withstood cold ischemia with superior outcomes. Although a limited warm ischemic insult did not preclude hypothermic preservation periods of as much as 24 hours $(12,13)$. It was thought that if a warm ischemically damaged kidney perfused well ex vivo, then good outcomes would be achieved even if a period of hemodialysis was necessary. Belzer reported reestablished renal function in 120 consecutive cadaver kidneys procured from non-heartbeating donors following warm ischemia ranging from 20 to 60 minutes with subsequent hypothermic preservation (13).

During the 1970's a 2-prong approach was developed to improve the quality of the cadaver organs. The first focused on improving the quality of the organ before preservation even started by limiting warm ischemic times and the second pertained to developing better preservation technology to prevent cell swelling during storage. Warm ischemic damage was viewed from the perspective that anoxic damage is readily repaired in vivo. However, the problem was that it was recognized that "repair" could not be achieved ex vivo by even 
the best hypothermic perfusion. Therefore, it was the combination of the total ischemic time between cardiac arrest (warm ischemia) and the establishment and duration of the artificial ex vivo storage (cold ischemia) that compromised allograft quality (14). The introduction of brain death legislation was in part derived from the need to allocate the scarce number of available organs and to develop a potential source of extrarenal organs. Nonetheless, the non-heartbeating donor essentially ceased to be used with the introduction of brain death criteria and the heartbeating donor.

\section{TRANSITION TO THE HEARTBEATING DONORS}

Formal discussions were begun in 1968 addressing the concept of brain death with the eventual goal of developing and implementing guidelines that would help to, not only standardize methodology but also, improve the quality of allografts (15). By the 1970's a definition of irreversible coma leading to brain death criteria was proposed by a committee at Harvard and by mid-decade these criteria were widely accepted $(16,17)$. According to the 1996 UNOS registry, in the United States approximately $99 \%$ of the organs retrieved from cadaveric donors were declared dead by brain-death criteria. A beneficial feature of using heartbeating donors was that the urgency to retrieve the organs upon death was eliminated. Circulatory support of the cadaver before and during the harvest procedure allowed for a more relaxed time frame for dissection that more conveniently fit into operating room schedules.

Similar to the difficulty in identifying the impact of non-heartbeating kidneys on outcomes during the early years of transplantation, it is likewise difficult to clearly assess the impact of introducing the clinical use of the heartbeating donor kidneys. This is in large part attributable to the introduction of cyclosporine in 1979, improvements in organ preservation and histocompatibility testing, the development of fine needle aspiration to assess rejection episodes earlier and the introduction of other immunosuppressive drugs (18). However there is evidence suggestive that any beneficial effect of eliminating substantial warm ischemic insult was actually offset by the introduction of prolonged hypothermic perfusion preservation technology. In 1976 despite the same group's (5) transition to using heartbeating donor kidneys, the introduction of hypothermic perfusion lead to a two-fold increase in the incidence of delayed graft function (10). Since the overall prognosis for patients with delayed graft function was not seen as being significantly different than for patients with immediate function, this increased rate in dysfunction was not considered to be problematic. There were also additional 
incentives to accepting the increased rate of immediate nonfunction secondary to the introduction of longer preservation periods. Cold preservation provided the time needed to perform organ harvests at external hospitals, thereby providing an expanded procurement base leading to increased numbers of organs. There was also more time for histocompatibility testing and increased preservation times provided the opportunity for clinical evaluation of the recipient prior to transplantation. For transplant programs demonstrating rapid growth in the number of procedures performed, more ex vivo preservation time meant more effective use of the operating rooms and support staff. Therefore, the delayed graft function caused by warm ischemic damage in using non-heartbeating donors may have been traded for the delayed graft function caused by extended hypothermic preservation in using heartbeating donors.

Overall, the incidence of delayed graft function in kidneys procured from the heartbeating donor is now $25 \%$ in the United States with mandated organ sharing (19). The requirement of having to ship organs across regions, has lead to longer cold ischemic times. The duration of the cold preservation period is known to contribute to this incidence of delayed graft function (20). As the period of cold ischemia is prolonged not only is the short-term graft function affected, long-term outcomes are likewise adversely affected when comparing 1-year and 5-year outcomes. This is particularly significant since approximately $40 \%$ of cadaveric primary kidney transplants were performed after more than 24 hours of cold ischemia (21). There was no statistically significant difference between static storage and perfusion preserved kidneys (22). Interestingly, in this multivariate analysis, the effects of variation in warm ischemic times during harvest did not adversely affect 1-year nor 5-year graft survival.

Hypothermic inhibition of metabolism can lead to altered tissue integrity that predisposes the development of reperfusion injury. The alterations in cellular integrity can include loss of the adenine compound pool, an accumulation of by-products such as free fatty acids, inhibition of the ion pumps, edema and time dependant structural changes in the vasculature. As the duration of cold ischemia becomes prolonged there is a direct correlation with the severity of the inflammatory processes generally categorized as reperfusion injury. Since the earliest days of transplantation it has been recognized that prolonged cold ischemia leads to poor reperfusion upon reimplantation. The inflammatory response is initiated by the up-regulation of adhesion molecules such as ICAM-1 and E and P-selectin on the surface of the vascular endothelium, the generation of oxygen radical species as well as modulation of a range of injury proteins such as ZO-1 and KIM-1. These cumulative inflammatory mediators 
trigger activation of leukocytes, platelets and can include the activation of the coagulation and complement cascades (23-26).

The introduction of the heartbeating donor provided the foundation to expand transplantation services. The heartbeating donor facilitated extrarenal transplantation and allowed for the expansion of transplant programs by providing time for adequate scheduling, allocation of resources and procurement from outlying hospitals. The introduction of the heartbeating donor during the same transitional era as the introduction of effective hypothermic preservation technology, facilitated the effective utilization of prospective histocompatibility testing and the potential for pretreating recipients. All of these benefits helped to make transplantation become a rather routine procedure in developed countries and also provided the foundation for the rapid growth of transplant centers. While the benefits of the introductions of the heartbeating donor and 24-hour cold preservation are clearly evident, it is not correspondingly clearly evident that these benefits translated into better long-term outcomes in comparison to kidneys from non-heartbeating donors.

\section{THE RETURN OF THE NON-HEARTBEATING DONOR}

The proliferation of programs offering transplantation services in conjunction with the improved outcomes for the procedures, provided compounding pressure on a healthcare system already struggling with the increasing demand for organs. The persistent organ shortage juxtapositioned with an increasing population of patients with end-stage renal failure awaiting transplantation, lead certain key centers to readdress the issue of the non-heartbeating donor and establish expanded donor-indication programs.

A major concern, particularly in the United States with its current emphasis on healthcare cost containment, is the impact of delayed graft function on the overall cost of transplantation. Increased costs associated with using organs from non-heartbeating donors include longer hospital stays and re-hospitalizations, the need for supportive hemodialysis during the period of delayed graft function and the reported increased rates of graft rejection (21). Another contributing factor leading to reluctance in using kidneys from non-heartbeating donor is rarely openly discussed. The individual transplant center outcomes are now widely distributed and reviewed, and the center-specific data are used to categorize the "centers of excellence" (22). With such high visibility, only the surgeons with true "pioneering" spirit have taken the initiative to attempt an expansion of the organ donor pool by readdressing the non-heartbeating donor. 
The institution of a non-heartbeating donor program necessitates that a definition of when death is irreversible be made. There is no clear agreement when that occurs. For example, the controversial University of Pittsburgh Protocol suggested organ retrieval could commence after two minutes of cardiac arrest (27). The particular perspective of the Pittsburgh Protocol was focused on the use of patients with planned removal of life-support as a source for multi-organ procurement. The situation of consented planned removal of life-support posed distinctly different ethical questions than cases of unsuccessful resuscitation following cardiac arrest where consent has not been obtained. In the later cases, a two-minute rule is not feasible. The Institute of Medicine responded to the controversy caused by the Pittsburgh Protocol by examining the relevant issues and issuing a report in 1997. In this report it was suggested that the period following cessation of circulation be increased to 5 minutes postmortem prior to death being pronounced and any organ removal being initiated (17). Since approximately 7 minutes of asystole are required for brain death to occur, perhaps the most ethically acceptable time frame for declaring death for the purpose of organ procurement is the definition used in the Maastricht Protocol (28). In this protocol, 10 minutos of asystole must occur after termination of all attempted resuscitation before recovery of organs is attempted. The 10-minute waiting period assures that brain death has occurred.

With the return of the non-heartbeating donor, medical classifications have been developed to identify increased numbers of potential organ donors (28). These categories include the "dead-dead" donor or the dead on arrival patient that is currently never considered for organ donation. Category 2 patients consist of unsuccessful resuscitation donors, usually residing in intensive care units. Alternatively, category 2 patients consist of those in emergency rooms when cardiopulmonary resuscitation is discontinued. The category 3 patients are similar to the focus of the Pittsburgh Protocol in consisting of instances of consented discontinuance of life-support. It is obvious from reviewing this data that the intent of developing these categories is to identify prospective donors and to be able categorize the expected warm ischemia that will be encountered (29).

The major concern of procuring organs with substantial warm ischemic insult is the fear of primary nonfunction. Since the earliest days of transplantation it has been recognized that delayed graft function would not adversely affect the long-term outcomes. However, primary nonfunction is distinct in that the condition describes kidneys that never function. The major barrier in attempting to expand the organ donor pool with kidneys from non-heartbeating donors is the occurrence of primary nonfunction. Further 
complicating the situation is that with current hypothermic preservation technology, metabolism is inhibited, making it difficult to develop prognostic testing. One approach has been to test for the release of intracellular enzymes such as glutathione-s-transferase to estimate the extent of cell damage (30). While the levels of leaked intracellular enzymes may indicate the extent of cell damage it does not provide a high degree of sensitivity in assessing the reversible nature of the injury. Therefore, the major obstacle is being able to distinguish which organs will eventually function from those that will never function, prospectively. A recent report using a combined index of indicators may provide a sensitive means to assess the overall viability status of a warm ischemically damaged organ (31). The lack of a validable testing method for prognostic evaluation of warm ischemically damaged organs has severely hampered the wide utilization of non-heartbeating donors. The result of not being able to prospectively evaluate an organ's functional status has been a restricted basis for procurement in cases of category 2 and 3 non-heartbeating donors. Presently, approximately 30 minutes of initial warm ischemia represents the upper limit of acceptable procurement (32-35). Therefore, category 1 patients that represent the vast majority of patients dying from a traumatic injury are not routinely considered for organ donation.

The returned focus on the non-heartbeating donor is important to the future of transplantation. Since the number of organs being procured from the heartbeating donors has remained constant over the past decade demonstrating little expansion, it is extremely important that means to identify new sources of transplantable organs be achieved. While only $1 \%$ of the organs procured in the United States are currently being retrieved from non-heartbeating donors, the results obtained from the new pioneers in this field are excellent and warrant being attempted by other transplant groups (36).

\section{CONCLUSIONS}

The incidence of delayed graft function in the early days when transplantation was dependant upon the non-heartbeating donor has not changed remarkably in comparison to recent results using organs procured from heartbeating donors. One obvious explanation for this startling observation is that the relative degree of damage between warm and cold ischemia are in fact additive. In the early days of transplantation, while kidneys were subjected to a substantial warm ischemic insult during the period from the moment of death until the organs could be retrieved, hypothermic preservation times were quite limited. 
There was likewise a sense of urgency to reimplant the kidneys in order to limit the preservation times. Today we have the inverse situation where warm ischemic times are quite limited and hypothermic preservation times average 24 hours while organs are shipped to remote centers due to the organ shortage. The recent experience with the reintroduction of non-heartbeating donors has necessitated combining the worst aspects from both eras: substantial warm ischemia with prolonged hypothermic preservation. The effect of combining these two injuries is a much higher rate of delayed function, reported to range from $68-80 \%(37-40)$. This increased incidence of delayed function in kidneys from today's non-heartbeating donors is much higher than those reported for the early years of non-hearting beating donors where the warm ischemic insults were substantially greater than today. Despite the technical and logistical hurdles that must be overcome with the reintroduction of the non-heartbeating donor, the results of the Maastricht group poignantly highlight the potential of this approach in expanding the organ donor pool.

\section{REFERENCES}

1. Hume DM, Merrill JP, Miller BF et al. J Clin Invest 1955: 34:327

2. Hume DM. Am J Surg 1979: 137:152

3. American College of Surgeons and the National Institutes of Health, Report of Kidney Transplantation 1976

4. Skinner DB, Newman MH, Squire RA. J Surg Res 1970: 10:287

5. Pegg DE. In Organ preservation Pegg DE (eds), Churchill Livingstone, Edinburgh 1973

6. Simmons RL, Tallent MB, Kjellstrand CM et al. Surgery 1971: 69: 201

7. Kjellstrand CM, Simmons RL, Buselmeier TJ et al. Minnesota Medicine 1974: 886

8. Kjellstrand CM, Simmons RL, Buselmeier TJ et al. In Transplantation, Lea and Febiger, Philadelphia 1972: 438

9. Khastagir B, Shibagaki M, Wilbrandt R et al. Trans Amer Soc Artif Int Organs 1966: $12: 239$

10. Koppel MH, Coburn JW, Mims MM et al. New Engl J Med 1960: 280:1367

11. Calne RY. Brit Med J 1969: 2:565

12. Kjellstrand CM, Casali RE, Simmons RL et al. Amer J Med 1976: 61:190

13. Simmons RL, Kjellstrand CM, Najarian JS. Transplantion, Najarian JS and Simmons RL (eds), Lea and Febiger, Philadelphia 1972: 449

14. Sell KW. In Transplantation, Najarian JS and Simmons RL (eds), Lea and Febiger, Philadelphia 1972: 404

15. Scarce Medical Resources. Columbia Law Review 1969: 69:620 
16. A Definition of Irreversible Coma. Report of the Ad Hoc Committee of the Harvard Medical School to examine the definition of brain death. JAMA 1968: 205:337

17. Institute of Medicine, National Academy of Sciences. Washington, DC, National Academy 1997

18. Calne RY, White DJG, Thiru S et al. Lancet 1978: (ii):1323

19. Cecka JM, Terasaki PI. Clinical Transplants, Terasaki PI and Cecka JM (eds), UCLA Tissue Typing Laboratory, Los Angeles, California 1993: 1

20. UNOS, Annual Report, Richmond, VA. United Network for Organ Sharing and the U.S. Department of Health and Human Services 1998

21. Whiting JF, Golconda M, Smith R et al. Economic Costs of Expanded Criteria Donors in Renal Transplantation Transpl 1998: 65:204

22. UNOS, Center Specific Graft and Patient Survival Rates. Richmond, VA: United Network for Organ Sharing and the U.S. Department of Health and Human Services 1994

23. Gibbons GH, Dzau VJ. Science 1996: 272:689

24. Molitoris BA, Kinne R. J Clin Invest 1987: 80:647

25. Boveris A. Adv Exp Med Biol 1977: 78:67

26. Ouellette AJ, Malt RA, Sukhatme VP et al. J Clin Invest 1990: 85:766

27. Kennedy Institute of Ethics 1993: 3:A-I

28. Kootstra G, Daemen JHC, Oomen APA. Transpl Proc 1995: 27:2929

29. Wijnen R, Booster M, Stubenitsky B et al. Lancet 1995: 345:1067

30. Daemen J, Oomen A, Janssen M et al. Transpl 1997: 63:89

31. Stubenitsky B, Booster M, Brasile L et al. Transpl 2000: 70(8): 1254

32. Orloff MS, Reed AI, Erturk E et al. Annals of Surg 1994: 220:578

33. Shirakura R, Kamiike W, Matsumura A et al. Transp Proc 1993: 25:3093

34. Booster MH, Wijnen RMH, Vroemen JPAM et al. Transpl 1993: 56:613

35. Gomez J, Alvarez J, Arias J et al. Transpl Proc 1993: 25:1501

36. Kootstra G. Transpl 1997: 63:917

37. Yokoyama I, Uchida K, Tominaga Y et al. Clin Transpl 1993: 7:258

38. Matsuno N, Kozaki M, Sakurai E et al. Transpl Proc 1993: 25(1):1516

39. Orloff MS, Reed AI, Erturk E et al. Annals of Surg 1994: 220:578

40. Wynen RMH, Booster M, Speatgens M et al. Transpl Proc 1993: 25:1522 
CHAPTER 3

\section{Solving the organ shortage - Potential strategies and the likelihood of success}

Brasile L, Stubenitsky BM, Kootstra G ASAIO 2002; accepted 
The discrepancy between the demand and supply of kidneys for clinical transplantation remains a major problem facing society today. Attempts over the past decade to expand the organ donor pool with programs aimed at increasing public awareness have had only marginal effect. The end-stage renal disease patient population being maintained with hemodialysis continues to grow, with the numbers of newly diagnosed patients each year exceeding healthcare group projections (1-3). Further enlarging the demand for transplantation is the number of patients that lose their grafts to chronic rejection. At the current incidence of end-stage renal disease, this patient population continues to double every decade. In contrast, there has been no substantial in roads made in developing a comparable increase in the number of available allografts. Society may soon be faced with the public healthcare issue of sustaining the costs associated with transplantation when relatively few patients will ever have the opportunity to be transplanted. If the discrepancy between the demand for and the supply of transplantable kidneys continues to grow, it is not so farfetched to consider the possibility of one day having politicians touting- 'a kidney for everyone, or a kidney for no one'.

It is very important to the future of transplantation that a source of more kidneys be developed. There are three possible avenues to providing significantly increased numbers of kidneys. Perhaps the most obtainable in the short term will be the development of technology that can access the much larger pool of warm ischemically damaged kidneys. To support such a substantial expansion it will be necessary for a technology to access not just the ICU-based non-heartbeating donor already successfully used in some transplant centers (4-6), but from the much larger pool of what is considered today to be the non-retrievable donor; the donor with greater than 30 minutes of circulatory arrest. To achieve this ambitious goal it will be necessary to develop the technology that mimics the physiologic processes involved in wound repair.

Alternatively, it has been proposed that an increased supply of organs can be developed based upon xenografts. In order to make xenotransplantation a clinical reality, it will be necessary to overcome the substantial barriers that exist in nature between the species. If these immunologic issues can be addressed, than xenotransplantation would present the opportunity to meet the needs of clinical transplantation.

Recent work in the area of stem cell research has provided tantalizing evidence supporting the potential of one day generating bioengineered organs. A major undertaking of this emerging field will be to develop the ability to define and control the cell differentiation processes involved in 
organ specificity. The limited regenerative capacity of adult tissues may represent major obstacles in being able to duplicate the intricate cell-to-cell and cell-to-extracellular matrices involved in the normal function of differentiated cells. The following is an overview of the issues involved with these three potential approaches to solving the organ shortage.

\section{POTENTIAL OF USING WARM ISCHEMICALLY DAMAGED RENAL ALLOGRAFTS}

Most kidneys, and all hearts and livers, are currently procured come from heartbeating $(\mathrm{HB})$ donors. These are donors who succumb to cerebral injury and are maintained on life-support systems prior to organ procurement. Therefore, the organs retrieved from $\mathrm{HB}$ donors experience virtually no warm ischemic exposure. However, HB donors represent only a small fraction of all deceased patients, and thus represent a limited donor pool (7).

The persistent organ shortage has lead to an expanded indication for donor selection criteria at some transplant centers by procuring kidneys from the ICU based non-heartbeating (NHB) donor population. A common clinical feature in these donors is that they have sustained less than 30 minutes irreversible circulatory arrest, excluding the period of attempted resuscitation, before the kidneys are procured that results in pre-procurement warm ischemic damage (8). The use of NHB kidneys has lead to as much as a $40 \%$ increase in the number of transplantation procedures performed at the centers using expanded donor criteria (6).

However, procurement of hearts and livers from NHB donors is currently not feasible because of the prerequisite for immediate graft function. In the case of kidneys from NHB donors, approximately $80 \%$ of these warm ischemically damaged kidneys demonstrated delayed graft function necessitating support by dialysis (9). The recovery period during which the kidneys regained function ranged from 7 days to 6 weeks, with a mean period of approximately 3 weeks. A concern is the increased incidence of primary non-function where the damage is irreversible and can be as high as $12.5 \%$, compared to a $6.7 \%$ incidence in the kidneys from $\mathrm{HB}$ donors (10). Although, long-term follow up of these recipients in comparison to the patients who received kidneys from $\mathrm{HB}$ donors indicated comparable outcomes, with no difference in 1-year or 5-year graft survival nor any difference in patient survival (11). These clinical results highlight the potential significance of using NHB donors as a source of kidneys to effectively expand the number of transplantation procedures performed. Wider use of NHB donor kidneys could help to mitigate the growing disparity in the demand for organs (5). 
Yet even the effective procurement of kidneys from NHB donors will not provide enough organs to meet the growing needs of clinical transplantation. In order to meet this demand a substantial expansion in procurement beyond even that of the ICU-based NHB donors will be required. The much larger pool of what is considered today to be the non-retrievable donor, the donor with greater than 30 minutes of circulatory arrest, represents a potential solution to the chronic organ shortage.

The common perspective in transplantation maintains that substantial postmortem warm ischemic injury ( $>30$ minutes) represents an insurmountable barrier to transplantation. Therefore, current thinking holds that warm ischemic injury after a certain threshold leads to irreversible damage, and yet wound repair is a common continuous physiologic process in vivo, and circumstantial evidence indicates repair from some forms of warm ischemic injury is feasible (12-17).

Upon cessation of blood flow, a cascade of events occurs starting with altered metabolism leading to cell injury and ultimately cell death. This cascade of events can be separated into 2 general phases, a prelethal and subsequent lethal phase. By definition, the injury to cells caused by prelethal warm ischemia is reversible. Effects of inadequate metabolism such as loss of the adenine compound pool, cell swelling and ion alterations are rapidly reversed when oxidative metabolism is restored. Cellular junction integrity, cell-to-cell attachment and surface polarity are likewise restored. Repolarization of surface membranes occurs concurrently with restoration of transport ability. The rate of recovery is dependant upon the severity of the warm ischemic injury.

The ability to repair kidneys following a substantial warm ischemic insult, albeit from within a prelethal phase of insult, will ultimately entail two interdependent and integral components to make available substantially increased numbers of organs for transplantation. The required components include the ability to perform long-term ex vivo perfusion at temperatures warm enough to sustain metabolism and adequate support of cellular repair processes during the ex vivo perfusion, including appropriate growth factor signaling to recover function. Both components will be required because if ex vivo perfusion cannot be accomplished for extended periods, there would not be adequate time to support repair of the ischemic damage. The result would be a compromised organ with insufficient renal function. Likewise, if long-term perfusion is successfully accomplished but inadequate repair occurs, then the result would also be compromised renal function. Therefore, the challenge will be to integrate both functions and provide substantially increased numbers of much needed organs. 
Such an approach to expanding the organ donor pools will mandate that rather than focusing merely on the duration of warm ischemia, as has been the traditional approach, it will be important to evaluate an organ on an individual basis and consist of two components (18). The first would entail the ability to assess the impact of warm ischemic injury on cellular integrity, thereby evaluating the extent of the damage. The second would assess the efficiency of inherent recovery functions (19). Therefore, the ability to perform prognostic testing would form the basis for distinguishing reversible injury (delayed graft function) from irreversible injury (primary non-function). The ability to distinguish which ischemically damaged organs are capable of providing life-sustaining function prospectively would support a near-term solution to the chronic organ shortage.

\section{CURRENT STATUS OF XENOTRANSPLANTATION}

While experimental xenotransplantation has existed since the early part of the last century, the potential use of xenografts has remained highly controversial (20). The first human xenotransplantations were performed during the 1960's and 1970 's. For example, in 1963 a baboon kidney was transplanted into a woman with end-stage renal failure. The baboon kidney functioned for three days when the woman developed severe gastrointestinal hemorrhage, hypotension and xenograft failure (21). The xenograft was nephrectomized, although the woman continued to bleed and died on the $15^{\text {th }}$ day. In the same year another group attempted rhesus kidney to human transplants and then chimpanzee to human transplants. All of the xenografts were rejected and all of the patients died (22-27). Similarly, another group with equivalent results attempted baboon to human kidney transplants with all the xenografts failing and most of the patients ultimately dying from sepsis $(28,29)$. Later attempts also using non-human primates xenografts have all been graft failures with high associated mortality rates in the recipients (30).

Recently, the transplant community has revisited the potential of xenotransplantation as a potential solution to the current organ shortage. To be assured of an easier path in gaining the public's acceptance of xenotransplantation, emphasis has been placed upon using "purpose-bred" animals that have already become well-established species for human consumption such as porcine and ovine (31). This renewed interest is attributable in part to the emerging new fields of gene therapy and bioengineering. Recent results have demonstrated progress in developing transgenic animals such as the pig model "humanized" by expressing DAF and immunologic 
manipulations attempting to induce tolerance (32). Studies involving xenotransplantation of porcine kidneys into primates suggested that instead of rejection occurring in minutes, $2-3$ week xenograft survival can be achieved $(33,34)$. It is clear that new approaches to immunosuppression will be required, since conventional immunosuppressive regimens have been inadequate to prevent xenograft rejection.

Therefore, a universal feature of xenotransplantation remains the short graft survival times $(30,32,35-37)$. Although efforts in xenotransplantation have been ongoing for almost 40 years, the fact that there are no reports of 1-year xenograft survival, speaks for the fact that there are no near-term prospects of introducing xenotransplantation clinically.

If the immunologic hurdles can be overcome, there are additional issues pertaining to the safety of xenotransplantation. The Institute of Medicine previously convened a committee to consider the ethical and public policy issues applicable to clinical trials of xenotransplantation. A report of the committee's findings was published in 1996 (38). The report contained 5 recommendations with special reference to the potential transmission of infectious agents from animals to humans. The recommendations acknowledged the ample risk of transmission of diseases and addressed approaches to be taken to reduce those risks. The committee concluded that the potential disease transmission risks associated with xenotransplantation were found to be significant enough to warrant funding by federal agencies. The U.S. Department of Health and Human Services has formed a national xenotransplantation advisory committee to include scientists, physicians, ethicists, lawyers and members of the lay public to enhance the safety and public awareness of xenotransplantation while allowing clinical trials to advance (39). A goal of the federal oversight is to insure that review of each proposed protocol includes the evaluation of human subjects for known infectious agents potentially associated with xenotransplantation. Nonetheless, a legitimate call was made for a moratorium on clinical xenotransplantation by well-known researchers in the field $(40)$.

\section{FUTURE OF BIOHYBRID ORGANS}

Tissue engineering represents an interdisciplinary field that necessitates combining the principles of engineering with those of the biologic sciences to develop biologic composites that would substitute for physiologic tissues and organs. Several different approaches are being used for the development of 
biohybrids. A simple approach consists of encapsulating purified cell populations isolated from complex tissues or from established cell lines.

Another, more complex approach, entails the actual attempt to develop a complex 3-dimensional composite tissue. Isolated cells are adhered to polymer scaffolds that are shape constructed to mimic the desired organ. In the case of composite scaffolded tissues, the ultimate goal is to develop constructs that contain all of the heterogeneous cell types required for adequate organ function. It would be preferable to derive autologous sources of the requisite cells in order to avoid immunologic rejection that is concomitant when using allogeneic or xenogenic sources. Deriving an adequate supply of autologous cells represents a major hurdle for bioengineering since in most cases only a small number of cells could be easily procured. Therefore, the population of isolated autologous cells in all probability would need to be expanded ex vivo in cell culture. Highly differentiated cell types such as those required for organ specificity are notoriously difficult to stimulate through the mitotic cycle and are known to turnover very rarely in vivo. An example of this is the fact that islets cells can be easily isolated from the intact pancreas, although adult islet cells do not replicate in cell culture, making the major obstacle to developing an artificial pancreas is the inability to derive enough insulin secreting cells (41).

The expertise involved in the development of biohybrids can be categorized in two general arenas. The first consists of the material sciences. It is obviously important that any synthetic materials used be biocompatible. Other concerns that need to be addressed include biodegradability, permeability and functional aspects such as elasticity, compressibility or tensile strength $(42,43)$. Likewise, there are many issues pertaining to any specialized application, such as the requirement of nonthrombogenicity in the case of any vascularized surface.

Cell biology represents the second general specialty in tissue engineering. Expertise is required for the isolation of relatively small populations within complex tissue architecture such as the in case in the isolation of islets of Langerhans from intact pancreas, where these insulin producing cells constitute approximately $2 \%$ the pancreas mass. Once the desired cell populations are isolated, a major goal is developing technology to expand the cell populations in vitro without losing the differentiating organ specificity. A growing area involves isolating stem cells that can be stimulated to differentiate (44). Also an important focus is being placed on immunomodifying cell surface proteins to avoid the concomitant requirement for immunosuppression in cases requiring the use of allogeneic cells (45). Specific issues must be solved, such as the need to support angiogenesis to adequately maintain complex 
3-dimensional constructs. Physical requirements could include the need to maintain the developing constructs with pulsatile perfusion in order to develop "normal" endothelial integrity and blood vessel wall strength (46).

The reality of attempting to develop bioengineered organs is the inherent complexity of tissues and organs. The development of biohybrids must take into consideration the functional complexity of organs in terms of the requisite cell-to-cell, cell-to-extracellular matrices and cell-to-physiologic system communication. More importantly, it may be naïve to view the possibility of a biohybrid being able to replace the physiologic role of an organ by simply incorporating a single cell type isolated from the original organ; such as fibroblasts replacing the many functions attributed to skin or islets replacing all the functions of the pancreas. A more realistic view may need to take into consideration the construction of biohybrids containing all the heterogeneous cell types necessary to provide equivalent function.

\section{CONCLUSIONS}

The enthusiasm generated from the proponents of both xenotransplantation and biohybrid organs has provided some very optimistic projections throughout the history of transplantation. For example, it was purported in 1972 that artificial hearts would be a clinical reality within a decade (47). This projection waited for Abiomed's recent first success with their implantable artificial heart for almost 30 years. Equally optimistic projections have been made for the development of xenotransplantation. However, xenotransplantation techniques have major technical hurdles to overcome that would make their introduction into the clinical arena difficult to imagine in the foreseeable future.

Despite more than 40 years of work in the field of xenotransplantation, performed by some of transplantation's largest figures, the clinical reality of xenografting is not much closer today than when the field was first started. There has never been a case reported of 1-year xenograft function between concordant or discordant species. Likewise, there have not been substantial improvements made in decreasing the risks to patients in terms of reducing the potential risk of transmission of infectious trans-species agents or even in survival following xenografting. Given the substantial investment that has been placed in xenotransplantation in terms of both efforts and money, there has been little progress made in ameliorating the associated aggressive immunologic rejection. The lack of results can be attributable to man's inability to 
overcome the biologic barriers that exist in nature. At the very least, it can be said that clinical xenografting is not "around the corner".

While the goals of bioengineering ventures have been straight forward, they have also been simplistic. This simplistic perspective can be seen in the early attempts at making artificial organs. Early attempts concentrated on mimicking the mechanical functions of an organ. The concentration on mechanical function lead to viewing the kidney as a filter and the heart as a pump. This simple mechanical perspective lead to the development of hemodialysis and the implantation of the artificial heart, the Jarvik 7 in the early 1980's (48). While hundreds of thousand's of end-stage renal disease patients are alive today thanks to dialysis, a case cannot be made that the dialysis is really replacing the functions of the kidney. The compromised quality of life experienced and communicated by dialysis patients attests to this fact. Taking a similar view from a cellular perspective, biohybrids consisting of artificial "skin equivalents" do not demonstrate function equivalent to normal skin. Similar to the situation in the case of xenotransplantation, the development of biohybrid organs is not "around the corner". Given that we are just now beginning to understand the underlying regulatory mechanisms involved in maintaining differentiated tissue specificity and control of remodeling, the complexity of organized tissues represents a major obstacle to developing biohybrids capable of replacing organs.

If xenotransplantation and the development of biohybrid organs are not the near-term solution to the organ shortage, perhaps the repair of warm ischemically damaged organs can be. At the very least, the potential to repair organs is technically a more realistic goal. First, there is a biologic precedent in that in vivo repair of cell damage is a commonplace and ongoing process. Renal repair from warm ischemic insult is also known to occur following as much as 45-60 minutes in cases of surgical repair of abdominal aneurisms. Given the highly regulated nature of metabolism, the initial up-regulation in function of the anaerobic enzymatic systems during hypoxia and ischemia may actually be protective; stimulating altered states of metabolic flux. Therefore, if the consequences of warm ischemia represent a continuum resulting in adapted metabolism and cell damage that is reversible in its early phase, followed by a lethal phase of damage representing irreversible damage, then intervention to restore oxidative metabolism and repair damage may be feasible.

Successful intervention to restore oxidative metabolism and initiate repair processes will entail the development of acellular ex vivo perfusion technology that is near normothermic $(18,19)$. This would be the inverse approach to that used today in organ preservation technology were the intent is to effectively 
inhibit metabolism. It must be acellular and ex vivo in order to prevent the reperfusion injury known to occur with blood reflow following warm ischemic insult. Restoring metabolism and cell volume regulation prior to actual reperfusion with blood would eliminate much of this reperfusion injury (8). If warm perfusion technology can be developed, then it may be feasible to resuscitate metabolism and repair warm ischemic damage and represent a near-term solution to the organ shortage.

\section{REFERENCES}

1. Davis CK: Data from the U.S. Healthcare Finance Administration, Washington, DC, April 1985

2. Annual Association of Organ Procurement Organizations Survey Results, 1992

3. UNOS, Annual Report of the U.S. Scientific Registry of Transplant Recipients and the Organ Procurement and Transplantation Network. Dept. HHS, 1996

4. Maessen JG, Van Der Vusse GJ, Vork M et al. Transpl Proc 1987: 19:4159

5. Kootstra G, Wijnen R, Van Hooff JP et al. Transpl Proc 1991: 23:910

6. Daemen JW, Oomen AP, Kelders WP et al. Clin Transplant 1997: 11:149

7. Daemen JH, de Wit RJ, Bronkhorst MW et al. Transplant Proc 1996: 28:105

8. Brasile L, Stubenitsky BM, Booster MHet al. Amer J Transpl 2001: 1:316-320

9. Booster MH, Wijnen RMH, Vroemen JPAM et al. Transpl 1993: 56:613

10. Kootstra G. Transpl 1997: 63:917

11. Kootstra G, Kievit JK, Heineman E. Br Med Bull 1997: 53:844

12. Clark R, Mortensen D, Rabkin R. Clin Sci 1994: 86:709

13. Mandal AK, Taylor CA, Bell RD et al. Lab Invest 1991: $65: 566$

14. Harkem JM, Chaudry IH. Crit Care Med 1992: 20:263

15. Adrendshorst W, Finn WF, Gootschalk GW. Circ Res 1975: 37:558

16. Harris KA, Wallace AC, Wall WJ. J Surg Res 1982: 33:524

17. Huguet C, Nordlinger B, Bloch P et al. Arch Surg 1978: 113:1448

18. Stubenitsky BM, Booster MH, Brasile L et al. Transpl 2001: 27:716

19. Brasile L, Stubenitsky BM, Booster MH et al. Transpl 2002: 73:6:897

20. Chapman LE, Folks TM, Salomon DR et al. N Engl J Med 1995: 333:1498

21. Hitchcock CR, Kiser JC, Telander RL et al. JAMA 1964: 189:934

22. Reemtsma K: In Transplantation Von Organen und Geweben, Seiffert KE and Geissendorfer R (eds), Stuttgart: Gerog Thieme Verlag 1967: 141

23. Reemtsma K: Heterotransplantation. In Human Transplantation, Rapaport FT and Dausset J (eds), Grune and Stratton 1968: 357

24. Reemtsma K, McCracken BH, Schlegel J et al. JAMA 1964: 187:691

25. Reemtsma K: Transpl Proc 1969: 1:251

26. Reemtsma K, McCracken BH, Schlegel JU, et al. Science 1964: 143:700

27. Reemtsma K, McCracken BH, Schlegel JU et al. Ann Surg 1964: 160:384 
28. Starzl TE: In Experience in Renal Transplantation, WB Saunders, Philadelphia, 1964

29. Starzl TE, Marchioro TL, Peters GN et al. Transpl 1970: 2:752

30. Oglesy TJ, Allen CJ, Lizsewski MK et al. J Exp Med 1992: 175:1547

31. Geller RI, Turman MA, Dalmasso AP et al. J Am Soc Nephrol 1992: 2(3):1189

32. Lublin DM, Coyne KE. J Exp Med 1991: 174:35

33. Nuffield Council on Bioethics. The ethics of Xenotransplantation, London, April, 1996

34. McKenzie IFC, Loveland BE, Fishman JA et al. Transpl, Ginns LC, Cosimi AB and Morris PJ (eds), Blackwell Science, Malden, Massachusetts 1999: 828

35. Starzl TE, Lerner RA, Dixon FJ et al. New Engl J Med 1968: 278:642

36. Williams GM, Hume DM, Hudson RP et al. New Engl J Med 1968: 279:611

37. Boyse EA, Old LJ, Thomas G. Transpl Bull 1968: 29:435

38. Sablinski T, Latinne D, Gianello P et al. Xenotranspl 1995: 2:264

39. Institute of Medicine Xenotransplantation Science, Ethics and Public Policy, National Academy Press, Washington, DC 1996

40. Developing U.S. Public Health Policy in Xenotransplantation, U.S. Department Of Health and Human Services, Bethesda, Maryland 1998

41. Hering BJ, Browatzki CC, Schulz A et al. Cell Transplant 1993: 2:283

42. Langer R, Vunjak G, Freed L et al. Tissue Eng 1995: 1:151

43. Barrera DA, Zylstra E, Lansbury P'T et al. J Am Chem Soc 1993: 115:11010

44. Griffith LG, Wu B, Cima MJ et al. Ann NY Acad Sci 1997: 831:383

45. Thomson JA, Itskovitz-Eldor J, Shapiro SS et al. Science 1998: 282:1145

46. Faustman D, Coe C. Science 1991: 252:1700

47. Niklason LE, Gao J, Abbott WM et al. Science 1999: 284:389

48. Westaby S, Banning AP, Jarvik R et al. Lancet 2000: 356:900 

CHAPTER 4

Exsanguineous Metabolic Support technology 


\section{INTRODUCTION}

Exsanguinous Metabolic Support (EMS) technology is a warm perfusion technology developed by Breonics, Inc. (301 Nott Street, Schenectady, NY 12305 ) that can maintain an organ in a metabolically active condition while isolated from the rest of the physiologic system. EMS functions by supporting two major ongoing and critical processes: the support of continued cellular metabolism and the maintenance of the integrity of the vasculature in order to provide continued barrier functions. The technology consists of a solution and a perfusion system.

\section{Cellular metabolism}

By definition, one must substitute for the systemic functions during the time that an organ is isolated from the physiologic system. Therefore the warm perfusion technology must provide the required nutrients necessary to maintain metabolic functions for all of the cellular components within an organ. Similarly, for continued metabolism in an isolated organ, a near physiologic temperature must be maintained. The failure to provide the necessary nutrients to sustain an adequate basal metabolism leads to compromised cellular functions and ultimately cell damage. Nutrient delivery includes: (a) all the needed raw materials for synthesis, substrates for energy and ongoing metabolism, vitamins and trace elements primarily for catalytic functions and bulk inorganic ions for both catalytic and physiologic functions; (b) physiologic parameters such as temperature, $\mathrm{pH}$, oxygen tension, oncotic pressure and perfusion pressures must be kept within a defined range; (c) supplements that are either labile or needed as macromolecular factors are also needed and interact with other nutrients.

\section{Vascular integrity}

Blood vessels are lined with endothelium as a monolayer throughout the entire circulatory system. Distinct differences in the luminal versus the abluminal polarity exist and this difference is attributable to their different protein specificities. The surfaces of endothelial cells are a mosaic of differentiated microdomains with different anionic site concentrations. The luminal membrane has a net negative charge that helps to account for its nonthrombogenic surface, with sulfated proteoglycans being the major contributor to this net negative charge. The luminal side is also rich in heparin sulfate secreted by the endothelial cells that is absent from the abluminal side. 
The endothelial surface consists of ectodomains of membrane proteins, glycoproteins, glycolipids and proteoglycans that function to sense, transport, transmit and participate in homeostasis.

Endothelial cell transport is done by plasmalemmal vesicles and transendothelial channels. Studies focused on the surface chemistry of the endothelium suggests that the endothelium is regionally modulated. The concentration of plasma proteins, particularly albumin, regulate endothelial permeability. This is especially so in the capillary beds. Water and small lipid soluble molecules diffuse readily through the entire endothelial surface, with the bulk of these molecules going through intercellular channels. However, there is no general agreement on specific transport pathways nor mechanisms for the exchange of large molecules. Therefore, it is feasible that more than one pathway may be involved in the transport of any given substance. The variations in modulation and biochemical heterogeneity that occurs support the concept that vascular endothelium functions as a refined charge barrier. Anionic plasma proteins are normally repelled by the net negative surface charge of the endothelium and this repulsion makes for concentration gradients at vesicles and channels. It is essential for the preservation of its barrier functions that endothelium maintain cell surface polarity.

During EMS perfusion, the vascular endothelial integrity is maintained in order to preserve its normal barrier functions to macromolecules and for continued electrostatic repulsion. It is thought that the concentration of specific proteins in the solution contributes to the preservation of the endothelial cells surface specificity. The warm perfusion technology is unique in that is maintains an isolated organ in a metabolically active condition and maintains vascular integrity sufficiently so that an organ will function normally when reimplanted and reperfused. An appropriate perspective for understanding the EMS technology is that it is a combination of the knowledge accumulated in the fields of cell biology, tissue culture and biochemistry and represents the maintenance of an intact organ in tissue culture-like conditions.

\section{UNDERLYING CONCEPTS AND PRINCIPLES}

The original concept underlying the development of warm perfusion technology was compromised of the two key points discussed in the introduction. Simply, if the cellular requirements for nutrients to support ongoing metabolism were met, and therefore, an adequate level of metabolism could be sustained; and if the barrier functions of the vascular endothelium could be preserved, why couldn't an organ be preserved at a near physiologic tempera- 
ture in conditions that mirrored cells in tissue culture. An important concern was the realization that continued cellular metabolism ex vivo would only occur of when all cellular requirements were satisfied.

A variety of normal mammalian cells can be maintained in tissue culture for extended periods of time. Tissue culture is the growth and maintenance of isolated cells in artificial nutrient media. Traditional tissue culture procedures all entail a rather traumatic dissociative procedure usually involving dissection, mincing, digestion with proteolytic enzymes and mechanical disruption. Following isolation, the cells follow a characteristic pattern. The cells when placed into tissue culture undergo an acquiescent phase, or lag phase, during which there is no cell division. The duration of the lag phase, or more accurately the recovery phase, is dependant upon the cell type, conditions and previous handling of the cells. Following recovery, the cells enter a log phase of growth where there can be an exponential increase in the number of cells. It is in the log phase that cells in tissue culture experience a peak metabolic rate. A stationary phase is then encountered at confluence, secondary to contact inhibition. The term confluent represents the situation where all adjacent cell surfaces are tightly interfaced. It is not until a confluent phase is reached that the cells in tissue culture mimic a physiologic setting where cell-to-cell and cell-to-extracellular matrix contact is restored.

In vivo, normal cells do not replicate once the cells within an organ reach stationary density. Any proliferation that occurs in vivo represents normal cell turnover or replacement. Therefore, the cell migration and proliferation observed in tissue culture can be considered to be the direct result of the dissociative procedures used in tissue culture techniques. The dissociative procedures are used because traditional tissue culture procedures cannot adequately provide nutrient and metabolic support for large sections of complex three dimensional tissues.

There are five tissue culture techniques commonly used to maintain isolated cells in vitro. These tissue culture techniques vary in the cell density that can be successfully achieved (Table 1). Clonal cultures represent the growth achieved from a single starting cell and is performed with cells attached to a solid substrate under a liquid medium, or cells suspended in a semi-solid medium such as soft agar. Monolayer cultures involve attached cells grown in tissue culture where the technique is limited by the surface available for the cells to grow upon. Cell growth can be increased by increasing the surface area available such as microaniea beads. Suspension cultures are performed without the cells being attached to a substrate. Generally, suspension cultures are supported by providing continuous shaking or stirring. The use of explant culture techniques is less common than other forms of standard 
TABLE 1. Tissue culture technology

\begin{tabular}{l|l}
\hline Technique & \\
Clonal & Increasing cellular population density \\
Monolayer & \\
Explant & \\
Bioreactor \\
EMS
\end{tabular}

TABLE 2. Relative cellular density

\begin{tabular}{ll}
\hline Method & Maximum density \\
Standard tissue culture & $6 \times 10^{6}$ cells $/ \mathrm{ml}$ \\
Bioreactor culture & $50 \times 10^{6}$ cells $/ \mathrm{ml}$ \\
EMS technology & $6,000 \times 10^{6} \mathrm{cells} / \mathrm{ml}$ \\
\hline
\end{tabular}

"relative cell density after confluence is obtained

tissue culture involving dispersed cells isolated from tissues and organs. Explant tissue culture consists of dissecting and culturing very small pieces of tissues, where the fragments must be $<1 \mathrm{~cm}$ for adequate gas and nutrient diffusion to occur. Bioreactor culture typically is made up of a system with a plurality of trays inside a closed housing. A rotation of the trays allows for the cultivation of cells on all sides. Features such as raised edges maintain predetermined volumes of culture media allowing for the cells to adhere.

The major difference between traditional tissue culture technology and the EMS is that EMS is designed to maintain cells at the stationary phase of metabolism and not the metabolic rate occurring during the log phase of population expansion. The respective differences in the resulting maximal cellular density that can be supported by different cell culture techniques are listed in Table 2. EMS technology can maintain 1,000 times the cellular density per $\mathrm{ml}$ at the stationary phase of metabolism. EMS is also different than traditional forms of tissue culture in that the solution is distributed via perfusion of the vascular bed, thereby using the natural distribution pathway that occurs in tissues. A direct result of applying the solution via the normal circulatory path is that a higher oxygen tension is required compared to that achieved with other forms of tissue culture. 


\section{History of tissue culture media}

In the 1950 's, cell lines such as the HeLa line were used to study growth responses while the cells were maintained in tissue culture. During this period media such as Eagle's basal and Minimum Essential media were developed for use with serum supplementation. More recent tissue culture techniques focused on using normal cells (nontransformed) to measure nutrient requirements and are more representative of physiologic function. These media include: M-199, F10, F12, Waymouth's, Yamane, DMEM, RPMI-1640 and MCDB 202.

Despite great efforts at eliminating non-defined proteins components, most normal cells in tissue culture still do better when a source of plasma protein is added to the culture medium. Cells in tissue culture require ions to maintain membrane potential and osmotic balance. These univalent ion requirements include sodium, potassium, calcium, magnesium, cloride, phosphate and bicarbonate. Most cells in tissue also display some requirements for trace elements, including iron, zinc, manganese and selenium. Almost all tissue culture media supply cells with a 6-carbon sugar. Glucose is the most common sugar employed in tissue culture media. Likewise, most tissue culture provides the essential amino acids, those that cannot be made by the cells themselves. There are 13 essential amino acids: arginine, cysteine, glutamine, histidine, isoleucine, leucine, lysine, methionine, phenylalanine, threonine, tryptophan, tyrosine and valine. Since tissue culture technology is not equivalent to physiologic conditions, many nonessential amino acids are also required for successful tissue culture. Some of the nonessential amino acids which are frequently required include: asparagine, proline, glycine, glutamic acid, aspartic acid and alanine. As a result, all the amino acids that are involved in cell protein synthesis are frequently included in tissue culture media formulations. Vitamins and coenzymes are also common ingredients in tissue culture media.

Therefore, a typical tissue culture medium has a formula consisting minimally of glucose, 13 amino acids, 7 or 8 vitamins, choline, meso-inositol, cholesterol, at least 2 purines, bulk ions and sera. It is important to remember that while tissue culture techniques have been in use for 50 years, the growth requirements of normal cells are still not fully understood.

\section{How EMS is different}

EMS is distinct from traditional tissue culture techniques not only in its ability to maintain cells at a stationary phase of metabolism, but also in its ability to 
preserve intact complex tissue without any form of dispersion. The warm perfusion technology allows for an organ to metabolize and function as if it were part of an intact physiologic system. While the tenants and principles of traditional tissue culture technology have been applied to the development of the warm perfusion technology, EMS goes beyond traditional tissue culture by supplying the physical parameters and processes necessary to maintain an intact organ.

\section{THE EMS SOLUTION}

The basal solution contains a mixture of defined low-molecular weight nutrients dissolved in a buffered physiologic saline solution (Table 3). The term nutrient describes substances that enter cells as substrates for biosynthesis or metabolism, or as catalyst in cellular processes. The term metabolism describes the sum of all physical and chemical changes that take place within an organism. In other words, metabolism is all energy and material transformations that occur within cells. Metabolism entails the transformation of chemical energy of foodstuffs to mechanical energy or heat. It involves two processes: anabolic, the assimilation or building up process and catabolic, disintegration or tearing down processes. Anabolism converts ingested substances into constituents of protoplasm. Catabolism breaks down substances into simple substances.

\section{Bulk ions}

The bulk ions are required for their physiologic roles in maintaining membrane potentials and osmotic balance in the cells of the nephron. The ions also provide co-factor roles for many enzymatic reactions. All the cells within the nephron require sodium, potassium, calcium, magnesium, chloride and phosphate for normal cell functions. Bicarbonate is also needed for biosynthetic reactions as well as in combination with $\mathrm{CO}_{2}$ for the buffering of the perfusate.

\section{Sugars}

Cells require a six-carbon sugar as a source of metabolic energy and reduced carbon for biosynthesis. Pyruvate and ribose supplement the glucose functions. 
TABLE 3. Composition of the EMS solution

\begin{tabular}{|c|c|c|c|}
\hline DL-Alanine & $.12 \mathrm{~g} / \mathrm{L}$ & Menadione (Na Bisulfate) & $.00003 \mathrm{~g} / \mathrm{L}$ \\
\hline L-Arginine $\mathrm{HCl}$ & $.14 \mathrm{~g} / \mathrm{L}$ & Myo-Inositol & $.0001 \mathrm{~g} / \mathrm{L}$ \\
\hline DL-Aspartic Acid & $.12 \mathrm{~g} / \mathrm{L}$ & Niacinamide & $.00005 \mathrm{~g} / \mathrm{L}$ \\
\hline L-Cysteine $\mathrm{HCl} \mathrm{H}_{2} \mathrm{O}$ & $.00022 \mathrm{~g} / \mathrm{L}$ & Nicotinic Acid & $.00005 \mathrm{~g} / \mathrm{L}$ \\
\hline L-Cystine $2 \mathrm{HCl}$ & $.52 \mathrm{~g} / \mathrm{L}$ & Para-Aminobenzoic Acid & $.0001 \mathrm{~g} / \mathrm{L}$ \\
\hline DL-Glutamic Acid & $.2672 \mathrm{~g} / \mathrm{L}$ & D-Pantothenic Acid Ca & $.00002 \mathrm{~g} / \mathrm{L}$ \\
\hline alphal-Glutamine & $.20 \mathrm{~g} / \mathrm{L}$ & Polyoxyethylenesorbitan Monoolate & $.04 \mathrm{~g} / \mathrm{L}$ \\
\hline Glycine & $.10 \mathrm{~g} / \mathrm{L}$ & Pyridoxal $\mathrm{HCl}$ & $.00005 \mathrm{~g} / \mathrm{L}$ \\
\hline L-Histidine $\mathrm{HCl} \mathrm{H}_{2} \mathrm{O}$ & $.04376 \mathrm{~g} / \mathrm{L}$ & Pyridoxine $\mathrm{HCl}$ & $.00005 \mathrm{~g} / \mathrm{L}$ \\
\hline L-Hydroxyproline & $.02 \mathrm{~g} / \mathrm{L}$ & Retinol Acetate & $.00028 \mathrm{~g} / \mathrm{L}$ \\
\hline DL-Isoleucine & $.08 \mathrm{~g} / \mathrm{L}$ & Riboflavin & $.00002 \mathrm{~g} / \mathrm{L}$ \\
\hline DL-Leucine & $.24 \mathrm{~g} / \mathrm{L}$ & Ribose & $.001 \mathrm{~g} / \mathrm{L}$ \\
\hline L-Lysine HCl & $.14 \mathrm{~g} / \mathrm{L}$ & Thiamine $\mathrm{HCl}$ & $.00002 \mathrm{~g} / \mathrm{L}$ \\
\hline DL-Methionine & $.06 \mathrm{~g} / \mathrm{L}$ & Thymine & $.0006 \mathrm{~g} / \mathrm{L}$ \\
\hline DL.Phenylalanine & $.10 \mathrm{~g} / \mathrm{L}$ & Uracil & $.0006 \mathrm{~g} / \mathrm{L}$ \\
\hline L-Proline & $.08 \mathrm{~g} / \mathrm{L}$ & Xanthine $\mathrm{HCl}$ & $.00069 \mathrm{~g} / \mathrm{L}$ \\
\hline DL-Serine & $.10 \mathrm{~g} / \mathrm{L}$ & Calcium Chloride $2 \mathrm{H}_{2} \mathrm{O}$ & $.265 \mathrm{~g} / \mathrm{L}$ \\
\hline DL-Theonine & $.12 \mathrm{~g} / \mathrm{L}$ & Ferric Nitrate $9 \mathrm{H}_{2} \mathrm{O}$ & $.00144 \mathrm{~g} / \mathrm{L}$ \\
\hline DL-Tryptophan & $.04 \mathrm{~g} / \mathrm{L}$ & Magnesium Sulfate (anhydrous) & $1.2 \mathrm{~g} / \mathrm{L}$ \\
\hline L-Tyrosine $2 \mathrm{Na}$ & $.11532 \mathrm{~g} / \mathrm{L}$ & Potasium Chloride & $.40 \mathrm{~g} / \mathrm{L}$ \\
\hline DL-Valine & $.10 \mathrm{~g} / \mathrm{L}$ & Sodium Acetate (anhydrous) & $.10 \mathrm{~g} / \mathrm{L}$ \\
\hline Adenine Hemisulfate & $.02 \mathrm{~g} / \mathrm{L}$ & Sodium Chloride & $6.8 \mathrm{~g} / \mathrm{L}$ \\
\hline Adenosine Triphosphate $2 \mathrm{Na} 2 \mathrm{Na}$ & $.002 \mathrm{~g} / \mathrm{L}$ & Sodium Phosphate Monobasic (anh) & $.224 \mathrm{~g} / \mathrm{L}$ \\
\hline Adenylic Acid & $.0004 \mathrm{~g} / \mathrm{L}$ & D-Glucose & $2.0 \mathrm{~g} / \mathrm{L}$ \\
\hline Alpha Tocopherol Phosphate $2 \mathrm{Na}$ & $.00002 \mathrm{~g} / \mathrm{L}$ & Insulin & $.01 \mathrm{~g} / \mathrm{L}$ \\
\hline Ascorbic Acid & $.001 \mathrm{~g} / \mathrm{L}$ & Bovine Serum Albumin & $30 \mathrm{~g} / \mathrm{L}$ \\
\hline D-Biotin & $.00002 \mathrm{~g} / \mathrm{L}$ & Sodium Bicarbonate & $4.4 \mathrm{~g} / \mathrm{L}$ \\
\hline faautoCalciferol & $.0002 \mathrm{~g} / \mathrm{L}$ & Pyruvate & $.22 \mathrm{~g} / \mathrm{L}$ \\
\hline Cholesterol & $.0024 \mathrm{~g} / \mathrm{L}$ & Transferin & $.10 \mathrm{~g} / \mathrm{L}$ \\
\hline Choline Chloride & $.001 \mathrm{~g} / \mathrm{h}$ & Serum & $10 \mathrm{ml}$ \\
\hline Deoxyribose & $.001 \mathrm{~g} / \mathrm{L}$ & B-cyclodextrin & $.50 \mathrm{~g} / \mathrm{L}$ \\
\hline Folic Acid & $.00002 \mathrm{~g} / \mathrm{l}$ & Chordroitin sulfate B & $.004 \mathrm{~g} / \mathrm{L}$ \\
\hline Glutathione (reduced) & $.0001 \mathrm{~g} / \mathrm{h}$ & Acidic fibroblast growth factor & $.02 \mathrm{~g} / \mathrm{L}$ \\
\hline Guanine $\mathrm{HCl}$ & $.0006 \mathrm{~g} / \mathrm{L}$ & heparin & $.18 \mathrm{~g} / \mathrm{L}$ \\
\hline Hypoxanthine & $.0006 \mathrm{~g} / \mathrm{L}$ & & \\
\hline
\end{tabular}




\section{Amino acids}

Thirteen amino acids: arginine, cysteine, glutamine, histidine, isoleucine, leucine, lysine, methionine, phenylalanine, threonine, tryptophan, tyrosine and valine are essential for normal function of the cells within the nephron. The non-essential amino acids are also required because of the cellular density encountered in preserving an intact organ and to also reduce the cellular biosynthetic loads during the warm perfusion. By also supplying the non-essential amino acids, any potential need to provide additional nitrogen sources for synthesis of the non-essential amino acids can be eliminated. Both D- and L-isomers are incorporated into the solution, even though current thought maintains that only the $\mathrm{L}$-isomers are biologically active. The differentiated tubule cell contains the enzymes, D-amino acid oxidase, carbonic anhydrase, high levels of alkaline phosphatase and a renal specific pattern of lactate dehydrogenase. The uptake carrier in the tubule system has a very low stereospecificity. In areas of the tubule system where there is colocalization of reabsorption and metabolic functions, there is recycling of the carbon structure of D-isomers of the amino acids. D-amino acids are reabsorbed more slowly in the proximal tubule than the L-isomers. Studies have shown that D-isomers have a measurable affinity for the reabsorption mechanisms in renal tubule cells. The D- and L-isomers share common transport systems along the tubule systems and reabsorption is not stereospecific. Some of the amino acids move directly from the vasa recta into the tubules. Autoradiographic studies of labeled D-amino acids have demonstrated that $\mathrm{D}$-isomers concentrate in the pancreas and the kidney. Therefore exogenous $\mathrm{D}$-amino acids of dietary origin contribute to the presence of these isomers in tissues, particularly the kidney and pancreas. We believe the inclusion of D-amino acids was an important development in optimizing the solution and lead to better preservation of the tubule system.

\section{Vitamins}

Cells within the nephron generally require vitamin B: biotin, folic acid, niacinamide, pantothenic acid, pyridoxine, riboflavin, thiamin, and Para-Aminobenzoic Acid. Ascorbic acid is important for metabolism in the cells that synthesize the various collagens. Choline and inositol serve as metabolic substrates and complement the catalytic roles of the vitamins. 


\section{Other organic nutrients}

Purine sources of adenine and hypoxanthine in combination with thymidine are important to cellular efficiency and are synergistic with folic acid. Cholesterol provides the lipid requirements of cells within the nephron. A variety of other organic compounds listed in Table 3 have also been included in the formulation during the optimization of the solution. The additional organic compounds have been included on the basis that they are beneficial to the continued metabolism during ex vivo warm perfusion and because they also appear to do no harm. The EMS solution does not represent an equilibrium system because for cellular metabolism to continue outside of the intact physiologic system, the cells within the nephrons must continue to catalyze energy-yielding reactions among the various components of the EMS system. For the sake of space, components of the solution that are distinct from traditional tissue culture media formulations and provide unique functions during the warm perfusion, are described in detail in the following sections.

\section{FUNCTIONS OF THE EMS SOLUTION}

\section{Carrier functions}

An adequate supply of oxygen cannot be dissolved by an aqueous solution. A major reason why previous studies attempting a warm temperature preservation failed because of the inability to supply enough oxygen. The use of red blood cells has been problematic because of the mechanical damage that occurs to the circulating red cells over time. EMS uses either a perfluorochemical emulsion or a chemically modified hemoglobin as the source of an oxygen carrier (Table 4). Microbubble technology provides preparations that can supply adequate oxygen delivery. The major limitation to using microbubbles as the oxygen carrier, is the tendancy of the bubbles to sublimate, necessitating continual replenishment. Perfluorochemicals are not specific oxygen carriers, but rather function as a sponge for any gas. Although they can provide an adequate supply of oxygen to the renals cells during EMS perfusion, perfluorochemicals preferentially take up $\mathrm{CO}_{2}$ at a rate that is eight times that of oxygen.

Chemically modified hemoglobins that do not cause nephrotoxcity can be successfully used to deliver an adequate supply of oxygen to an intact organ. Therefore, an oxygen carrier is an integral component of the solution. 
TABLE 4. Oxygen cariers

Conjugated hemoglobins

Crosslinked hemoglobins

Perfluorochemical emulsions

Microbubble technology

TABLE S. Role of serum albumin

Inhibits interfacial reactions

Detoxifies

Antioxidant

Colloid osmotic pressure

Carrier functions

Serum albumin has several functions in the solution (Table 5). By far the most important function of albumin is its carrier functions. In the same manner that an oxygen carrier delivers oxygen and removes carbon dioxide, albumin delivers nutrients to the cells within the nephron and removes the by-products of the ongoing metabolism. Albumin is a heart-shaped, $65 \mathrm{kd}$ molecule consisting of 6-sub-domains each with three alpha helices connected to pliable hinge regions. Because of its unique structure, albumin accommodates a large number of different molecules making it the universal carrier. Studies with albumin have demonstrated simple binding equilibrium, where the higher the albumin concentration, the more binding sites there are available. The delivery capacity of the albumin is dependant upon the quality in terms of whether the albumin is already ligandized. Delivery of nutrients to the cells within an organ during warm perfusion correlates more closely with the total amount bound than with the unbound ligand concentration. Therefore, too low of a concentration of albumin results in competition for shared transport mechanisms among the various ingredients. This makes albumin an integral component of the EMS solution.

\section{Growth factor}

The term growth factor can be confusing. For this discussion, the growth factor can be describes a stimulating substance that is not a nutrient, in that it is not an intracellular metabolic substrate or cofactor. The definition we have employed for the incorporation of growth factor is that it is a small protein that induces increased cell synthesis of nucleic acids and proteins, or case of 
TABLE 6. Biologic significance of growth factors

Metabolic effect

Mitogenic effect

Control normal development

Regulate wound healing and regeneration

Contribute to homeostasis

Modulate function of endothelium

cell damage or death, leads to recovered cellular mass. Table 6 lists the biologic significance of growth factors. Two of the most important biologic roles in terms of the EMS solution are the contribution to homeostasis and modulation of endothelial functions. Growth factor evaluation was pursued with the EMS technology because it is recognized that growth factors stimulate the transport of small molecules causing an increased rate of transport through the plasma membrane. By far the most beneficial effect is the prevention of the development of interstitial edema. The growth factor used is of the heparin-binding class of acidic-FGF. The FGF receptor is a tyrosine kinase expressed on the cells in the nephron. Acidic-FGF too is an integral component of the EMS solution.

\section{INTERACTIONS AND COMPLEXITY}

The EMS solution is complex and not in an equilibrium state. Rather during warm perfusion, the cells within the nephron must be able to catalyze energy-yielding reactions among the various components of the intact organ culture system. While the tendency in dealing with such a complex solution is to group the individual ingredients into the generic categories, this represents a serious oversimplification. Unlike the situation with hypothermic solutions, where cellular metabolism is largely inhibited and transport mechanisms are shut down, and therefore, the components remain mostly unaltered; warm perfusion is dynamic. A better approach to understanding the interactions is to group the ingredients into function rather than chemical classes. A review of Table 7 highlights the multifactoral role of some EMS ingredients in that these components serve multiple functions. 
TABLE 7. Functional categories

\begin{tabular}{|c|c|c|c|}
\hline Metabolic factors & Trophic factors & Antioxidants & Buffer system \\
\hline Glucose & Glucose & Amino Acids & Bicarbonate \\
\hline Pyruvate & Pyruvate & Serum albumin & $\mathrm{CO}_{2}$ \\
\hline ATP & Insulin & Cyclodextrin & \\
\hline Cholesterol & Growth factor & vitamins & \\
\hline Amino acids & Amino acids & & \\
\hline Bicarbonate & Mucopolysaccaride & & \\
\hline Inostol & Magnesium & & \\
\hline \multicolumn{4}{|l|}{ Ions } \\
\hline Carrier function & Vasodilators & Large vessel specific & Microvessel specific \\
\hline Oxygen carrier & Arginine & Cyclodextin & Mucopolysaccaride \\
\hline \multirow[t]{2}{*}{ Serum albumin } & $\mathrm{CO}_{2}$ & Heparin & Magnesium \\
\hline & Growth factor & Growth factor & Growth factor \\
\hline
\end{tabular}

THE EMS PERFUSION SYSTEM

\section{Temperature}

Metabolism is directly correlated to the temperature that tissue is maintained ex vivo. In determining the optimal perfusion temperature, considerations focused on several key factors. At temperatures below $22^{\circ} \mathrm{C}$ a cessation of glomerular filtration occurs and below $18^{\circ} \mathrm{C}$ tubular activity is inhibited. Most enzyme systems functioning at normothermia experience an approximately two-fold decrease for every ten-degree decrease in temperature. Likewise, the demand for oxygen is decreased as the temperature is declined. These considerations highlighted the need for a minimal threshold perfusion temperature of $25^{\circ} \mathrm{C}$. At the upper end of the temperature scale, $37^{\circ} \mathrm{C}$ is the usual temperature at which cells in tissue culture are maintained. However, maintaining an intact organ containing approximately three trillion cells at $37^{\circ} \mathrm{C}$ represented huge obstacles in terms of supporting the metabolic rate and eliminating the accumulation of metabolic by-products.

After evaluating canine kidneys perfused ex vivo at varying temperatures with subsequent reimplantation, it was determined that warm perfusion could adequately support organ metabolism at temperatures ranging from $25-34^{\circ} \mathrm{C}$. This temperature range supported oxidative metabolism, as deter- 
mined by the oxygen consumed by the kidney, at rates ranging from approximately $50 \%$ to approximately $75 \%$ of physiologic levels. In current studies warm perfusion is conducted at a temperature range of $30-32^{\circ} \mathrm{C}$. A temperature controller is used in-line in conjunction with a heat exchanger to maintain the perfusion temperature in this targeted range.

\section{Perfusion: pressure, pulse rate and vascular flow rate}

The perfusion parameters required to maintain the vascular integrity have been carefully elucidated for the canine transplant model. A systolic perfusion pressure of $>70 \mathrm{mmHg}$ was found to result in substantial mechanically induced endothelial cell damage. Likewise vascular flow rates of $>150 \mathrm{cc} / \mathrm{min}$ have also been found to result in blood vessel damage, while flow rates of $<70$ $\mathrm{cc} / \mathrm{min}$ were found to provide for inadequate support of oxidative metabolism. Careful evaluations have optimized the perfusion characteristics to target a mean arterial pressure of $35-40 \mathrm{mmHg}$, providing for a vascular flow of approximately $80-120 \mathrm{cc} / \mathrm{min}$ with a pulse rate of 60 beats $/ \mathrm{min}$. An in-line manometer controls for the systolic perfusion pressures. An ultrasonic flowmeter is used to monitor the flow rate resulting from the controlled perfusion pressures.

The temperature controlled and oxygenated EMS solution is introduced through the cannulated renal artery. The perfusate leaves the organ as venous effluent and drains by gravity directly into an effluent reservoir situated beneath the compartment of the organ chamber holding the organ. The venous effluent is collected, reheated, reoxygenated and then recirculated, minimizing perfusion contamination due to contact with air.

\section{Oxygen tension and $\mathrm{pH}$}

The perfusate, containing a titrated concentration of oxygen carrier, is oxygenated prior to contact with the organ via an in-line membrane oxygenator. The solution is oxygenated by gassing with oxygen to maintain a targeted partial pressure of oxygen in the range of $150-200 \mathrm{mmHg}$. The $\mathrm{pH}$ is controlled in the range of 7.30 to 7.40 by gassing the perfusate with $\mathrm{CO}_{2}$, providing a partial pressure of $\mathrm{CO}_{2}$ in the range of $27-60 \mathrm{mmHg}$.

\section{CONCLUSION}

The exsanguinous metabolic support system can be used to maintain an organ in a metabolically active state while isolated from the circulatory system of the body. 
CHAPTER 5

Hypothermia - A limiting factor in using warm ischemically damaged kidneys

Brasile L, Stubenitsky BM, Booster MH, Araneda D, Haisch CE, Kootstra G

AJT 2001; 1(4): 316 


\begin{abstract}
A study was performed to determine the limiting factors to expanding the donor pool with warm ischemically (WI) damaged kidneys.

Canine kidneys were damaged by 30 minutes of $\mathrm{WI}$, and then either cold stored (CS) in ViaSpan $\left(4^{\circ} \mathrm{C}\right)$ for 18 hours, or warm perfused with Exsanguineous Metabolic Support (EMS) technology $\left(32^{\circ} \mathrm{C}\right)$ for 18 hours, or subjected to combinations of both techniques. The kidneys were autotransplanted with contralateral nephrectomy.

In kidneys with $\mathrm{WI}$ and $\mathrm{CS}$ alone, the mean peak serum creatinine value was $6.3 \mathrm{mg} / \mathrm{dL}$ and took 14 days to normalize. In contrast, kidneys where renal metabolism was resuscitated ex vivo during 18 hours of warm perfusion demonstrated mild elevations in the serum chemistries $(2.6 \mathrm{mg} / \mathrm{dL})$. The damage in kidneys CS for 18 hours was ameliorated with 3 hours of subsequent warm perfusion and eliminated by 18 hours of warm perfusion. In contrast, reversing the order with CS following WI and 18 hours of warm perfusion resulted in a time-dependant increase in damage.

These results identify hypothermia as a major limiting factor to expanding indications for kidney donation. While hypothermia represents the foundation of preservation in the heartbeating donor, its use in WI damaged organs appears to represent a limiting factor.
\end{abstract}




\section{INTRODUCTION}

Society may soon be faced with the public healthcare issue of sustaining the costs associated with transplantation when relatively few patients will ever have the opportunity to be transplanted. The persistent organ shortage remains one of the major obstacles facing the field of clinical transplantation today. The end-stage renal disease patient population being maintained with dialysis continues to grow, with the numbers of newly diagnosed patients each year exceeding healthcare group projections and doubling every decade (1-3). In contrast, there has been no comparable increase in the number of available allografts.

The disparity between the availability of kidney allografts and the number of patients in need of renal transplantation has led several groups to readdress the use of kidneys from non-heartbeating (NHB) donors. These efforts have largely focused on procurement in an ICU setting from patients who cannot be resuscitated and has led to an increase in donors in the centers where this approach is practiced $(4,5)$. The result has been the procurement of kidneys from NHB donors with relatively limited warm ischemic exposure, usually no more than 30 minutes prior to any form of intervention. The major barrier to more widespread use of these NHB donor kidneys is the high rates of delayed graft function and primary non-function.

In sharp contrast to this small ICU patient population, the largest number of potential NHB donors expire at the site of injury or in the ambulance and are almost never considered as organ donors. The warm ischemic insult encountered in this population has represented an insurmountable barrier to organ procurement. Despite the technical hurdles that must be addressed in using kidneys from NHB donors, the effective utilization of organs from NHB donors represents the best option for a near-term solution to the organ shortage.

A study was undertaken with the intent of defining the factors affecting the ability to recover function in kidneys with warm ischemic damage. Using a warm perfusion technology, that can reestablish cellular metabolism ex vivo, in varying combinations with traditional hypothermic preservation, we studied the impact of subsequent preservation on warm ischemically damaged kidneys. 


\section{Animals and surgical protocol}

Autotransplantation experiments were performed on two year old foxhounds weighing 20-30 kilograms. The animals received standard kennel food, routine lighting cycle and room temperature, and demonstrated normal renal function prior to the start of the study. All experiments were performed following the principles of laboratory animal care according to the NIH standards. Kidneys were exposed through a midline incision and the left renal artery, vein, and ureter were mobilized. If two renal arteries were present, the right kidney was used. Ten minutes prior to excision, $200 \mathrm{mg} / \mathrm{kg}$ of mannitol was administered intravenously. The excised kidneys were exposed to 30 minutes of warm ischemia (WI) while remaining in the abdominal cavity $\left(37^{\circ} \mathrm{C}\right)$. Subsequent to the warm ischemic insult, the kidneys were divided into six groups each with an $\mathrm{n}=4$.

Group $130 \mathrm{~min}$. WI followed by 18 hours cold storage (CS) in Viaspan ${ }^{\mathrm{TM}}\left(4^{\circ} \mathrm{C}\right)$ Group $230 \mathrm{~min}$. WI followed by 18 hours warm perfusion $\left(32^{\circ} \mathrm{C}\right)$

Group $330 \mathrm{~min}$. WI followed by 18 hours CS and then 3 hours warm perfusion Group $430 \mathrm{~min}$. WI followed by 18 hours CS and then 18 hours warm perfusion Group $530 \mathrm{~min}$. WI followed by 18 hours warm perfusion and then 12 hours CS Group $630 \mathrm{~min}$. WI followed by 18 hours warm perfusion and then 24 hours CS

The kidneys requiring cold storage according to the experimental protocol, were flushed with $120 \mathrm{ml}$ of $\operatorname{Viaspan}^{\mathrm{TM}}\left(4^{\circ} \mathrm{C}\right)$ at $50 \mathrm{mmHg}$. Reimplantation time varied between 20 and 30 minutes, with a mean reanastomosis time of 27 minutes. Fifteen minutes before to reperfusion, mannitol $(200 \mathrm{mg} / \mathrm{kg})$ and verapamil $(0.1 \mathrm{mg} / \mathrm{kg})$ were administered. Contralateral nephrectomy was performed prior to reperfusion of the preserved kidney.

\section{Posttransplant graft function}

Blood samples for BUN and serum creatinine were taken each morning and analyzed using an ACE analyzer (Schiapparelli Biosystems, Inc., Fairfield, NJ, USA). For the purpose of grading the severity of the renal impairment the area under the curve (AUC) was calculated for the posttransplant serum creatinine curves above the normal range $(<2.0 \mathrm{mg} / \mathrm{dL})(6)$. In addition to the AUC, the peak serum creatinine (Peak-Scr) and the day serum creatinine normalized 
TABLE 1. Compostion of basal EMS medium

\begin{tabular}{|c|c|c|c|}
\hline DL-Alanine & $.12 \mathrm{~g} / \mathrm{L}$ & Menadione (Na Bisulfate) & $.00003 \mathrm{~g} / \mathrm{L}$ \\
\hline L-Arginine $\mathrm{HCl}$ & $.14 \mathrm{~g} / \mathrm{L}$ & Myo-Inositol & $.0001 \mathrm{~g} / \mathrm{L}$ \\
\hline DL-Aspartic Acid & $.12 \mathrm{~g} / \mathrm{L}$ & Niacinamide & $.00005 \mathrm{~g} / \mathrm{L}$ \\
\hline L-Cysteine $\mathrm{HCI} \mathrm{H}_{2} \mathrm{O}$ & $.00022 \mathrm{~g} / \mathrm{L}$ & Nicotinic Acid & $.00005 \mathrm{~g} / \mathrm{L}$ \\
\hline L-Cystine $2 \mathrm{HCl}$ & $.52 \mathrm{~g} / \mathrm{L}$ & Para-Aminobenzoic Acid & $.0001 \mathrm{~g} / \mathrm{L}$ \\
\hline DL-Glutamic Acid & $.2672 \mathrm{~g} / \mathrm{L}$ & D-Pantothenic Acid Ca & $.00002 \mathrm{~g} / \mathrm{L}$ \\
\hline L-Glutamine & $.20 \mathrm{~g} / \mathrm{L}$ & Polyoxyethylenesorbitan Monoolate & $.04 \mathrm{~g} / \mathrm{L}$ \\
\hline Glycine & $.10 \mathrm{~g} / \mathrm{L}$ & Pyridoxal $\mathrm{HCl}$ & $.00005 \mathrm{~g} / \mathrm{L}$ \\
\hline L-Histidine $\mathrm{HCl} \mathrm{H}_{2} \mathrm{O}$ & $.04376 \mathrm{~g} / \mathrm{L}$ & Pyridoxine $\mathrm{HCl}$ & $.00005 \mathrm{~g} / \mathrm{L}$ \\
\hline L-Hydroxyproline & $.02 \mathrm{~g} / \mathrm{L}$ & Retinol Acetate & $.00028 \mathrm{~g} / \mathrm{L}$ \\
\hline DL-Isoleucine & $.08 \mathrm{~g} / \mathrm{L}$ & Riboflavin & $.00002 \mathrm{~g} / \mathrm{L}$ \\
\hline DL-Leucine & $.24 \mathrm{~g} / \mathrm{L}$ & Ribose & $.001 \mathrm{~g} / \mathrm{L}$ \\
\hline $\mathrm{L}-\mathrm{Ly}$ sine $\mathrm{HCl}$ & $.14 \mathrm{~g} / \mathrm{L}$ & Thiamine $\mathrm{HCl}$ & $.00002 \mathrm{~g} / \mathrm{L}$ \\
\hline DL-Methionine & $.06 \mathrm{~g} / \mathrm{L}$ & Thymine & $.0006 \mathrm{~g} / \mathrm{L}$ \\
\hline DL.Phenylalanine & $.10 \mathrm{~g} / \mathrm{L}$ & Uracil & $.0006 \mathrm{~g} / \mathrm{L}$ \\
\hline L-Proline & $.08 \mathrm{~g} / \mathrm{L}$ & Xanthine $\mathrm{HCl}$ & $.00069 \mathrm{~g} / \mathrm{L}$ \\
\hline DL-Serine & $.10 \mathrm{~g} / \mathrm{L}$ & Calcium Chloride $2 \mathrm{H}_{2} \mathrm{O}$ & $.265 \mathrm{~g} / \mathrm{L}$ \\
\hline DL-Theonine & $.12 \mathrm{~g} / \mathrm{L}$ & Ferric Nitrate $9 \mathrm{H}_{2} \mathrm{O}$ & $.00144 \mathrm{~g} / \mathrm{L}$ \\
\hline DL-Tryptophan & $.04 \mathrm{~g} / \mathrm{L}$ & Magnesium Sulfate (anhydrous) & $1.2 \mathrm{~g} / \mathrm{L}$ \\
\hline L-Tyrosine $2 \mathrm{Na}$ & $.11532 \mathrm{~g} / \mathrm{L}$ & Potasium Chloride & $.40 \mathrm{~g} / \mathrm{L}$ \\
\hline DL-Valine & $.10 \mathrm{~g} / \mathrm{L}$ & Sodium Acetate (anhydrous) & $.10 \mathrm{~g} / \mathrm{L}$ \\
\hline Adenine Hemisulfate & $.02 \mathrm{~g} / \mathrm{L}$ & Sodium Chloride & $6.8 \mathrm{~g} / \mathrm{L}$ \\
\hline Adenosine Triphosphate $2 \mathrm{Na} 2 \mathrm{Na}$ & $.002 \mathrm{~g} / \mathrm{L}$ & Sodium Phosphate Monobasic (anh) & $.224 \mathrm{~g} / \mathrm{L}$ \\
\hline Adenylic Acid & $.0004 \mathrm{~g} / \mathrm{L}$ & D-Glucose & $2.0 \mathrm{~g} / \mathrm{L}$ \\
\hline Alpha Tocopherol Phosphate $2 \mathrm{Na}$ & $.00002 \mathrm{~g} / \mathrm{L}$ & Insulin & $.01 \mathrm{~g} / \mathrm{L}$ \\
\hline Ascorbic Acid & $.001 \mathrm{~g} / \mathrm{L}$ & Bovine Serum Albumin & $30 \mathrm{~g} / \mathrm{L}$ \\
\hline D-Biotin & $.00002 \mathrm{~g} / \mathrm{L}$ & Sodium Bicarbonate & $4.4 \mathrm{~g} / \mathrm{L}$ \\
\hline Calciferol & $.0002 \mathrm{~g} / \mathrm{L}$ & Pyruvate & $.22 \mathrm{~g} / \mathrm{L}$ \\
\hline Cholesterol & $.0024 \mathrm{~g} / \mathrm{L}$ & Transferin & $.10 \mathrm{~g} / \mathrm{L}$ \\
\hline Choline Chloride & $.001 \mathrm{~g} / \mathrm{L}$ & Serum & $10 \mathrm{ml}$ \\
\hline Deoxyribose & $.001 \mathrm{~g} / \mathrm{L}$ & B-cyclodextrin & $.50 \mathrm{~g} / \mathrm{L}$ \\
\hline Folic Acid & $.00002 \mathrm{~g} / \mathrm{L}$ & Chondroitin sulfate B & $.004 \mathrm{~g} / \mathrm{L}$ \\
\hline Glutathione (reduced) & $.0001 \mathrm{~g} / \mathrm{L}$ & Fibroblast growth factor & $.02 \mathrm{~g} / \mathrm{L}$ \\
\hline Guanine $\mathrm{HCL}$ & $.0006 \mathrm{~g} / \mathrm{L}$ & heparin & $.18 \mathrm{~g} / \mathrm{L}$ \\
\hline Hypoxanthine & $.0006 \mathrm{~g} / \mathrm{L}$ & & \\
\hline
\end{tabular}


(D-norm) were determined. Serum creatinine was considered normal once the curve fell below $2.0 \mathrm{mg} / \mathrm{dL}$. All values are reported as the mean along with the calculated standard error. For statistical analysis of differences in obtained data between the experimental groups the Student T-test was used.

\section{Ex vivo warm perfusion}

Exsanguineous Metabolic Support (EMS) technology (Breonics, Inc., Schenectady, NY, USA), was used for ex vivo warm perfusion $\left(32^{\circ} \mathrm{C}\right)$. Following treatment as listed above for each group, the kidneys requiring warm perfusion according to the experimental protocol, were flushed (120 $\mathrm{ml}$ ) at $50 \mathrm{mmHg}$ and then placed on a pressure controlled perfusion system. The perfusion system included an oxygenator and a pulsatile pump, retrofitted with controllers to maintain $\mathrm{PaO}_{2}, \mathrm{PaCO}_{2}, \mathrm{pH}$ and temperature. The renal artery was cannulated and connected to the perfusion circuit. The pulsatile perfusion pressure was targeted to $50 / 30 \mathrm{mmHg}$ and the circulating perfusate volume was $500 \mathrm{~mL}$. Both flush solution and perfusate consisted of a highly enriched tissue culture-like medium that contained amino acids, carbohydrates, metabolites, inorganic ions, serum proteins, lipids, hormones, vitamins, reducing agents, a buffering system, trophic factors, radical scavengers, and adenine compound substrates adjusted to a $\mathrm{pH}$ of 7.4 (Table 1). The warm flush/perfusion solution is a proprietary technology of Breonics, Inc. (Schenectady, NY, USA). The acellular perfusate was supplemented with pyridoxylated bovine hemoglobin ( $6 \mathrm{~g} \%)$ (Ezon, Inc., Piscataway, NJ, USA) to provide adequate oxygen $\left(\mathrm{PaO}_{2}\right.$ of $\left.200 \mathrm{mmHg}\right)$ to support ongoing renal metabolism.

\section{Histology}

Biopsies of Group 1 and 2 kidneys were taken at 1-hour post-reperfusion using a 15-gauge biopsy punch. The biopsies were fixed in $4 \%$ neutral-buffered formalin for histologic evaluation. Sections were made from each biopsy and stained with hematoxylin and eosin for light macroscopic evaluation. The morphologic characteristics of each kidney were determined by blinded histological evaluation. 
TABLE 2. Posttransplant graft function

\begin{tabular}{lccc}
\hline & AUC & Peak- Scr $(\mathbf{m g} / \mathbf{d L})$ & D-norm (days) \\
Group 1 & 35 & 6.3 & $>14$ \\
Group 2 & $2^{*}$ & $2.6^{*}$ & $5^{*}$ \\
Group 3 & 18 & 4.9 & 13 \\
Group 4 & $2^{*}$ & $2.8^{*}$ & $6^{*}$ \\
Group 5 & 16 & 5 & 11 \\
Group 6 & $43^{\circ}$ & $7.5^{\circ}$ & $>14^{\circ}$
\end{tabular}

All values expressed as means; $\mathrm{AUC}=$ area under the curve; Peak- $\mathrm{Scr}=$ peak serum creatinine; D-norm $=$ day serum creatinine normalized $(<2.0 \mathrm{mg} / \mathrm{dL}) ;^{*}=p<0.05$ as compared to Group 1; ${ }^{0}=\mathrm{p}<0.05$ as compared to Group 2.

\section{RESULTS}

The AUC, a marker for the severity of the renal impairment; together with the Peak-Scr and the D-norm for each group are listed in Table 2.

\section{Cold storage versus warm perfusion}

Figure 1. When kidneys were subjected to 30 minutes of WI followed by CS (Group 1) the mean peak serum creatinine was higher and the time to normalization of the serum chemistries longer than in kidneys that were instead warm perfused for 18 hours (Group 2). Group 1 dogs, demonstrated a mean peak serum creatinine value of $6.3 \mathrm{mg} / \mathrm{dL}$ and took on average 14 days to normalize the serum chemistries. In contrast, Group 2 dogs demonstrated a mean peak serum creatinine value of $2.6 \mathrm{mg} / \mathrm{dL}$ and the mean time to normalization of the serum chemistries was 5 days.

\section{Amelioration of damage with warm perfusion}

Figure 2. The damage observed following 30 minutes of WI with 18 hours of subsequent CS was ameliorated with 3 hours of subsequent warm perfusion (Group 3) and eliminated by 18 hours of warm perfusion (Group 4). The time-dependant benefit of EMS following combined warm and cold ischemia, lead to a reduced mean peak serum creatinine and reduced the time to normalization of the serum chemistries by more than $50 \%$ (Table 2 ). 


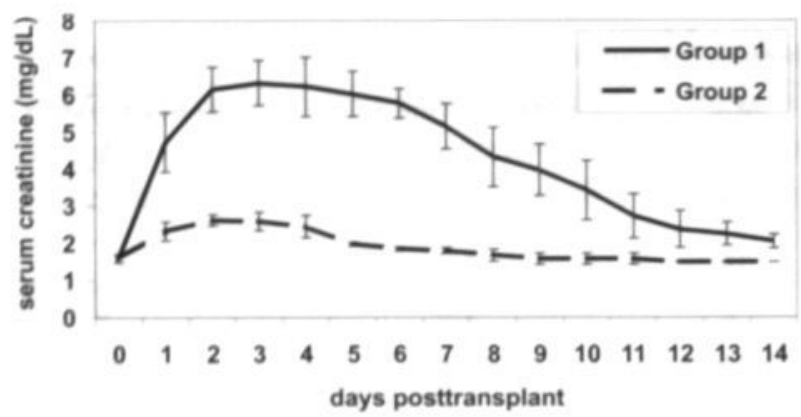

FIGURE 1. Mean serum creatinine concentration following renal transplantation of kidneys subjected to 30 minutes of WI followed by either 18 hours of cold storage (Group 1) or 18 hours of warm perfusion (Group 2).

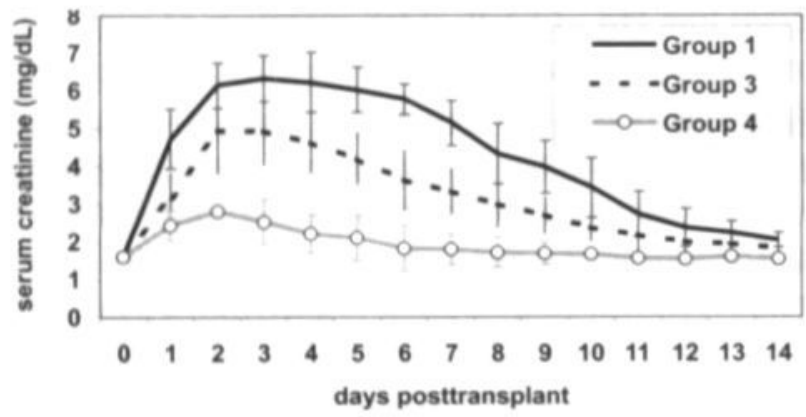

FIGURE 2. Mean serum creatinine concentration following renal transplantation of kidneys subjected to 30 minutes of WI followed by either 18 hours of cold storage (Group 1); 18 hours of cold storage and subsequent 3 hours of warm perfusion (Group 3); or 18 hours of cold storage and subsequent 18 hours of warm perfusion (Group 4).

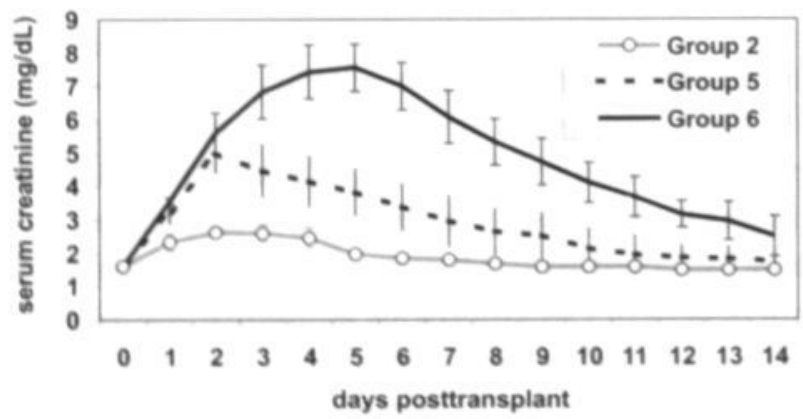

FIGURE 3. Mean serum creatinine concentration following renal transplantation of kidneys subjected to 30 minutes of WI followed by either 18 hours of warm perfusion (Group 2); 18 hours of warm perfusion and subsequent 12 hours of cold storage (Group S); or 18 hours of warm perfusion and subsequent 24 hours of cold storage (Group 6). 


\section{Detrimental effect of hypothermia}

Figure 3. In contrast to the results above, CS following WI and 18 hours of warm perfusion resulted in a time-dependant increase in damage (Groups 5 and 6). The time-dependant damage that was associated with cold storage was demonstrated by both an increased mean peak serum creatinine and an increase in the number of days needed to normalize the serum chemistries (Table 2).

\section{Histology}

Biopsies taken at 1-hour post-reperfusion from Group 1 and 2 kidneys highlighted a marked difference between kidneys reperfused from the cold and those reperfused following warm perfusion. Reperfusion directly from 18 hours of cold storage resulted in more tubular degeneration, with acute tubular epithelial damage observed in approximately $70 \%$ of the renal tubules. Renal tubules contained numerous intra-epithelial neutrophils. Interstitial edema was pronounced with moderate numbers of neutrophil infiltrates. Likewise, neutrophil aggregates were evident within the glomerular tufts.

Reperfusion directly from 18 hours of warm perfusion resulted in approximately $50 \%$ of the renal tubules having swollen epithelial cells. A small number of neutrophils were observed in the interstitium but were absent in the glomerular tufts. The results of the blinded histologic evaluations indicated that reperfusion of warm perfused kidneys resulted in less inflammatory cell components and the absence neutrophil aggregates in the glomerular tufts.

\section{CONCLUSION}

The results of this study identify cold ischemia as the major obstacle to expanding indications for organ donation with warm ischemically damaged kidneys. Although only static storage with Viaspan was used for this study, previous work using this animal model has demonstrated the lack of significant differences in outcome when hypothermic machine perfusion with Belzer solution was used instead of static storage in Viaspan $(7,8)$. While hypothermic technique represents the foundation of organ preservation in the heartbeating donor, its use in warm ischemically damaged organs appears to represent a major limiting factor. 
One obvious explanation for this startling observation is that the relative degree of damage between warm and cold ischemia is in fact additive. In the early days of transplantation, using kidneys procured from NHB donors there was substantial warm ischemic insult during the period from the moment of death until the organs could be retrieved. The hypothermic preservation times were quite limited and there was a sense of urgency to reimplant the kidneys in order to limit the preservation times, since preservation technology was in its infancy (9). Today in using kidneys from heartbeating donors we have the inverse situation. Warm ischemic times are now minimal and there is prolonged hypothermic preservation times averaging 24 hours while organs are shipped to remote centers due to the organ shortage. The recent experience with the reintroduction of the NHB donor has necessitated combining the prolonging aspects from each era, substantial warm ischemia with prolonged hypothermic preservation. The effect of combining these two injuries is a much higher rate of delayed function, reported to range from $68-80 \%$; a rate much higher than those reported for either the early years of transplantation using NHBD or currently with heartbeating donors (10-14). As the period of cold ischemia becomes prolonged, there is a correlation with increased severity of the reperfusion injury and at some point the hypothermic inhibition of metabolism becomes irreversible. Prolonged cold ischemia has been shown to lead to a lag-phase in the restoration of renal metabolism, with low initial rates of oxygen consumption (15).

A benefit of warm perfusion is that it ameliorates the reperfusion injury known to occur when a warm ischemically damaged and hypothermically stored organ is reperfused with blood (16). The acellular nature of EMS warm perfusion presents the opportunity to restore cellular integrity ex vivo, prior to contact with inflammatory components. It would likewise be expected that microvessel circulation would be superior with less red cell sludging in warm kidneys than in kidneys undergoing the requisite lipid phase-change that occurs in cell membranes when a hypothermically stored kidney is reperfused (17). The results of 1-hour biopsies support the amelioration of reperfusion injury in the EMS perfused kidneys.

An additional benefit of warm perfusion beyond simply ameliorating reperfusion injury, is the potential to substantially recover metabolism and function during ex vivo perfusion at temperatures approaching normothermia $\left(32^{\circ} \mathrm{C}\right)$. It is logical to expect that a kidney with continued metabolic function, retention of normal barrier functions and restoration of cell volume regulatory functions, maintained at near-normothermic temperature would sustain less damage. The results of this study support this interpretation since longer periods of warm perfusion ( 3 hours versus 18 hours of EMS 
perfusion) provided for enhanced recovery of renal function from both the warm and cold ischemic insults. Therefore, warm perfusion holds the potential to ameliorate reperfusion injury and recover function ex vivo, both functions being necessary to allow for effective prospective evaluation of damaged kidneys $(18,19)$. These combined functions could support a more effective utilization of kidneys from NHBD and could have a positive effect on cost containment issues by helping to reduce the period of delayed graft function.

The goal of this study was to address the obstacles to recovering renal function in warm ischemically damaged kidneys. Following warm ischemic insult, further inhibition of cellular metabolism mediated by severe hypothermia appears to have a time-dependant, detrimental effect on subsequent graft function. In conclusion, the NHBD represents the only near-term solution for making substantially increased numbers of kidney allografts available for transplantation. The results of this study suggest that hypothermia may be the major limiting factor to the effective utilization of NHBD kidneys.

\section{REFERENCES}

1. US Department of Health and Human Sevices, Health Care Financing Administration, Bureau of Data Management and Strategy (eds): United States Renal Data System, 1999 Annual data report.

2. Annual Association of Organ Procurement Organizations Survey Results. 1992

3. UNOS: Annual Report of the U.S. Scientific Registry of Transplant Recipients and the Organ Procurement and Transplantation Network. Dept. HHS. 1996

4. Daemen JW, Oomen AP, Kelders WP et al. Clin Transplant 1997: 11:149

5. Daemen JH, de Wit RJ, Bronkhorst MW et al. Transplant Proc 1996: 28:105

6. Matthews JN, Altman DG, Campbell MJ et al. BMJ 1990: 300(6719):230

7. Booster MH, van der Vusse GJ, Wijnen RM et al. Transpl 1994: 58:979

8. Booster MH, Wijnen RM, Yin M et al. Transplant Proc 1993: 25:3006

9. Morris PJ. Kidney Transplantation Principles and Practice. Morris PJ (eds). Saunders Philadelphia 1994: 504.

10. Matsuno N, Sakurai E, Uchiyama M et al. Transplant Proc 1993: 25:3095

11. Paprocki S, Kruk R, Erturk E et al. Transpl 1992: 54:381

12. Matsuno N, Kozaki M, Sakurai E et al. Transplant Proc 1993: 25:1516

13. Hernandez A, Light JA, Barhyte DY et al. Transpl 1999: 67:200

14. Daemen JH, de Vries B, Oomen AP et al. Transpl Int 1997: 10:317

15. Stubenitsky BM, Booster MH, Brasile L et al. ASAIO J 2000: 46:60

16. Koo DD, Welsh KI, Roake JA et al. Am J Pathol 1998: 153:557

17. Urbaniak JR, Seaber AV, Chen LE. Clin Orthop 1997: 334:30

18. Stubenitsky BM, Booster MH, Brasile L et al. Transpl 2000: 70:1254

19. Stubenitsky BM, Booster MH, Brasile L et al. Transpl 2001: 71:716 

CHAPTER 6

\section{Amelioration of reperfusion injury by ex vivo warm perfusion}

Brasile L, Stubenitsky BM, Booster MH, Salleng K, Surprenant R, Haisch CE, Kootstra G

Submitted 


\section{ABSTRACT}

Objective and background data. Traditional hypothermic preservation is predicated upon the concept of inhibiting oxidative metabolism. Kidneys with prior warm ischemic exposure experience a more severe secondary injury when reperfused following hypothermic storage, than if the kidneys are immediately reimplanted. The present study was designed to examine if restoration of metabolism during ex vivo warm perfusion could ameliorate reperfusion injury.

Methods. Using a canine autotransplantation model, kidneys were subjected to 30-minutes of warm ischemia. Subsequent to the warm ischemic insult, the kidneys were flushed of blood and either cold stored (CS) in ViaSpan ${ }^{\mathrm{TM}}$ at $4^{\circ} \mathrm{C}$ for 18 hours (control kidneys), or alternatively warm perfused with EMS (test kidneys). Following the 18- hour period, the kidneys were reimplanted with contralateral nephrectomy.

Results. 1-hour biopsy results demonstrated that reperfusion from the cold resulted in more tubular damage, inflammatory cell components and neutrophil aggregates in comparison to kidneys reperfused from the acellular warm EMS. Similarly, kidneys reperfused directly from profound hypothermia generated more free radicals as assessed by measurement of malondialdehyde and increased LDH leakage. Clinical outcomes mirrored these findings in that kidneys reperfused directly from the cold storage were oliguric with proteinuria and had mean peak sera creatinine values of 7.1 $\mathrm{mg} / \mathrm{dL}$ and did not normalize until day 13. Kidneys reperfused from warm perfusion were polyuric, did not develop proteinuria and had a mean serum creatinine values of $2.7 \mathrm{mg} / \mathrm{dL}$ that normalized on day 4 .

Conclusions. The results of this study provide evidence for the amelioration of reperfusion injury in warm ischemically damaged kidneys reimplanted directly from 18 hours of warm perfusion, where metabolism had been supported during the ex vivo period rather than inhibited via standard hypothermic preservation. 
The opportunity to effectively expand the organ donor pool with warm ischemically damaged kidneys from non-heartbeating (NHB) donors has not been widely embraced, with utilization of these kidneys being limited to a few transplant centers world-wide. A major concern is the current inability to distinguish reversible damage, called delayed graft function, from irreversible damage referred to as primary nonfunction with a high degree of confidence. This is an important issue in clinical transplantation because kidneys from the non-heartbeating donor represent the only near term solution to the persistent organ shortage(1-3).

A complicating factor is that warm ischemic insult followed by hypothermic preservation results in a secondary reperfusion injury when blood flow is restored upon reimplantation $(4,5)$. The reperfusion injury can be mediated by an array of mechanisms cumulatively referred to as a generalized inflammatory response. The various mechanisms of reperfusion injury can include the generation of reactive oxygen species, cellular derangement, up-regulation of adhesion molecules such as P-selectin and I-CAM, leukocyte mediated damage and hypercoagulation (6-12). The inhibition of oxidative metabolism that occurs during hypothermic preservation combined with a prior warm ischemic insult frequently results in congestion and red cell trapping in the microvessel beds when the organ is reoxygenated upon reimplantation. This vascular effect can reduce renal blood flow by as much as $50 \%(13,14)$.

In previous studies using a new acellular warm temperature perfusion technology, called Exsanguineous Metabolic Support (EMS), we established that metabolism could be successfully resuscitated during the ex vivo period following warm ischemic insult (15-18). It was found that the restored metabolism may be of sufficient magnitude to form the basis for developing prognostic testing (19). The occurrence of reperfusion injury subsequent to any prospective organ evaluation, represents a major obstacle in using a validated prognostic testing that could distinguish primary nonfunction from delayed graft function. Therefore, prospective testing would be hindered by the inability to assess the severity of any reperfusion injury that has not yet occurred. We evaluated if the EMS could impact the secondary ischemic/reperfusion injury. 


\section{METHODS}

\section{Animals and surgical protocol}

An autotransplantation model was employed using 1-year old mixed foxhounds weighing 25-35 kilograms. The canines received standard kennel food, routine lighting cycle and room temperature. Health screens were performed prior to enrollment in the study and all animals demonstrated normal renal function prior to the start of the study. All experiments were performed following the principles of laboratory animal care according to the NIH standards for animal use. Kidneys were exposed via a midline incision and mobilized. Ten minutes prior to excision $200 \mathrm{mg} / \mathrm{kg}$ of mannitol were administered intravenously, no heparin was given. The excised kidneys were exposed to 30 minutes of warm ischemia, while remaining free in the abdominal cavity $\left(37^{\circ} \mathrm{C}\right)$.

Cold Storage Group-The control kidneys were subjected to 30 minutes of warm ischemia, followed by flushing with $150 \mathrm{cc}$ of cold ViaSpan ${ }^{\mathrm{TM}}$ and were subsequently stored statically in the ViaSpan for 18 hours at $4^{\circ} \mathrm{C}$.

EMS Group-The test kidneys were also subjected to 30 minutes of warm ischemia, followed by flushing with $150 \mathrm{cc}$ of EMS solution $\left(32^{\circ} \mathrm{C}\right)$ and were subsequently warm perfused for 18 hours at $32^{\circ} \mathrm{C}$.

Each group consisted of 4 canines. Following 18 hours of either cold storage or warm EMS perfusion, the kidneys were reimplanted. Prior to reperfusion the contralateral kidneys were excised. Fifteen minutes prior to reperfusion, mannitol $(200 \mathrm{mg} / \mathrm{kg})$ and verapamil $(0.1 \mathrm{mg} / \mathrm{kg})$ were given intravenously.

\section{Ex vivo EMS perfusion}

Exsanguineous Metabolic Support (EMS) technology (Breonics, Inc., Schenectady, NY) was used for the ex vivo warm perfusions. Following 30 minutes of warm ischemia, the kidneys were temperature transitioned to $32^{\circ} \mathrm{C}$ by flushing and were then placed on a pressure controlled perfusion system including an oxygenator and a pulsatile pump, retrofitted with controllers to maintain the partial pressures of oxygen and carbon dioxide, $\mathrm{pH}$ and temperature. The renal artery was cannulated and connected to the perfusion circuit. Both the flush solution and perfusate consisted of a highly enriched tissue culture-like solution containing amino acids, carbohydrates, inorganic ions, vitamins, reducing agents, radical scavengers and adenine compound substrates adjusted to a $\mathrm{pH}$ of 7.4. The EMS formulation listed in Table 1 is a 
TABLE 1. Composition of the EMS solution

\begin{tabular}{|c|c|c|c|}
\hline DL-Alanine & $.12 \mathrm{~g} / \mathrm{L}$ & Menadione (Na Bisulfate) & $.00003 \mathrm{~g} / \mathrm{L}$ \\
\hline L-Arginine $\mathrm{HCl}$ & $.14 \mathrm{~g} / \mathrm{L}$ & Myo-Inositol & $.0001 \mathrm{~g} / \mathrm{L}$ \\
\hline DL-Aspartic Acid & $.12 \mathrm{~g} / \mathrm{L}$ & Niacinamide & $.00005 \mathrm{~g} / \mathrm{L}$ \\
\hline L-Cysteine $\mathrm{HCl} \mathrm{H}_{2} \mathrm{O}$ & $.00022 \mathrm{~g} / \mathrm{L}$ & Nicotinic Acid & $.00005 \mathrm{~g} / \mathrm{L}$ \\
\hline L-Cystine $2 \mathrm{HCl}$ & $.52 \mathrm{~g} / \mathrm{L}$ & Para-Aminobenzoic Acid & $.0001 \mathrm{~g} / \mathrm{L}$ \\
\hline DL-Glutamic Acid & $.2672 \mathrm{~g} / \mathrm{L}$ & D-Pantothenic Acid Ca & $.00002 \mathrm{~g} / \mathrm{L}$ \\
\hline L-Glutamine & $.20 \mathrm{~g} / \mathrm{L}$ & Polyoxyethylenesorbitan Monoolate & $.04 \mathrm{~g} / \mathrm{L}$ \\
\hline Glycine & $.10 \mathrm{~g} / \mathrm{L}$ & Pyridoxal HCl & $.00005 \mathrm{~g} / \mathrm{L}$ \\
\hline L-Histidine $\mathrm{HCl} \mathrm{H}_{2} \mathrm{O}$ & $.04376 \mathrm{~g} / \mathrm{L}$ & Pyridoxine $\mathrm{HCl}$ & $.00005 \mathrm{~g} / \mathrm{L}$ \\
\hline L-Hydroxyproline & $.02 \mathrm{~g} / \mathrm{L}$ & Retinol Acetate & $.00028 \mathrm{~g} / \mathrm{L}$ \\
\hline DL-Isoleucine & $.08 \mathrm{~g} / \mathrm{L}$ & Riboflavin & $.00002 \mathrm{~g} / \mathrm{L}$ \\
\hline DL-Leucine & $.24 \mathrm{~g} / \mathrm{L}$ & Ribose & $.001 \mathrm{~g} / \mathrm{L}$ \\
\hline L-Lysine $\mathrm{HCl}$ & $.14 \mathrm{~g} / \mathrm{L}$ & Thiamine $\mathrm{HCL}$ & $.00002 \mathrm{~g} / \mathrm{L}$ \\
\hline DL-Methionine & $.06 \mathrm{~g} / \mathrm{L}$ & Thymine & $.0006 \mathrm{~g} / \mathrm{L}$ \\
\hline DL-Phenylalanine & $.10 \mathrm{~g} / \mathrm{L}$ & Uracil & $.0006 \mathrm{~g} / \mathrm{L}$ \\
\hline L-Proline & $.08 \mathrm{~g} / \mathrm{L}$ & Xanthine $\mathrm{HCl}$ & $.00069 \mathrm{~g} / \mathrm{L}$ \\
\hline DL-Serine & $.10 \mathrm{~g} / \mathrm{L}$ & Calcium Chloride $2 \mathrm{H}_{2} \mathrm{O}$ & $.265 \mathrm{~g} / \mathrm{L}$ \\
\hline DL-Threonine & $.12 \mathrm{~g} / \mathrm{L}$ & Ferric Nitrate $9 \mathrm{H}_{2} \mathrm{O}$ & $.00144 \mathrm{~g} / \mathrm{L}$ \\
\hline DL-Tryptophan & $.04 \mathrm{~g} / \mathrm{L}$ & Magnesium Sulfate (anhydrous) & $1.2 \mathrm{~g} / \mathrm{L}$ \\
\hline L-Tyrosine $2 \mathrm{Na}$ & $.11532 \mathrm{~g} / \mathrm{L}$ & Potassium Chloride & $40 \mathrm{~g} / \mathrm{L}$ \\
\hline DL-Valine & $.10 \mathrm{~g} / \mathrm{L}$ & Sodium Acetate (anhydrous) & $.10 \mathrm{~g} / \mathrm{L}$ \\
\hline Adenine Hemisulfate & $.02 \mathrm{~g} / \mathrm{L}$ & Sodium Chloride & $6.8 \mathrm{~g} / \mathrm{L}$ \\
\hline Adenosine Triphosphate $2 \mathrm{Na} 2 \mathrm{Na}$ & $.002 \mathrm{~g} / \mathrm{L}$ & Sodium Phosphate Monobasic (anh) & $.224 \mathrm{~g} / \mathrm{L}$ \\
\hline htAdenylic Acid & $.0004 \mathrm{~g} / \mathrm{L}$ & D-Glucose & $2.0 \mathrm{~g} / \mathrm{L}$ \\
\hline Alpha Tocopherol Phosphate $2 \mathrm{Na}$ & $.00002 \mathrm{~g} / \mathrm{L}$ & Insulin & $.01 \mathrm{~g} / \mathrm{L}$ \\
\hline Ascorbic Acid & $.001 \mathrm{~g} / \mathrm{L}$ & Bovine Serum Albumin & $30 \mathrm{~g} / \mathrm{L}$ \\
\hline D-Biotin & $.00002 \mathrm{~g} / \mathrm{L}$ & Sodium Bicarbonate & $4.4 \mathrm{~g} / \mathrm{L}$ \\
\hline Calciferol & $.0002 \mathrm{~g} / \mathrm{L}$ & Pyruvate & $.22 \mathrm{~g} / \mathrm{L}$ \\
\hline Cholesterol & $.0024 \mathrm{~g} / \mathrm{L}$ & Transferin & $.10 \mathrm{~g} / \mathrm{L}$ \\
\hline Choline Chloride & $.001 \mathrm{~g} / \mathrm{L}$ & Serum & $10 \mathrm{ml}$ \\
\hline Deoxyribose & $.001 \mathrm{~g} / \mathrm{L}$ & B-cyclodextrin & $.50 \mathrm{~g} / \mathrm{L}$ \\
\hline Folic Acid & $.00002 \mathrm{~g} / \mathrm{L}$ & Chondroitin sulfate B & $.004 \mathrm{~g} / \mathrm{L}$ \\
\hline Glutathione (reduced) & $.0001 \mathrm{~g} / \mathrm{L}$ & Acidic fibroblast growth factor & $.02 \mathrm{~g} / \mathrm{L}$ \\
\hline Guanine $\mathrm{HCL}$ & $.0006 \mathrm{~g} / \mathrm{L}$ & heparin & $.18 \mathrm{~g} / \mathrm{L}$ \\
\hline Hypoxanthine & $.0006 \mathrm{~g} / \mathrm{L}$ & & \\
\hline
\end{tabular}


proprietary formulation of Breonics, Inc. The acellular perfusate was supplemented with pyridoxylated bovine hemoglobin $(6 \mathrm{~g} \%)$ (Enzon, Inc., Piscataway, $\mathrm{NJ}$ ) to provide adequate oxygen transport to support ongoing renal metabolism.

\section{Biopsies}

Biopsies were taken at 1-hour post-reperfusion using a 15-gauge biopsy punch. The biopsies were fixed in $4 \%$ neutral-buffered formalin for histologic evaluation. The biopsy material was fixed in $4 \%$ neutral-buffered formalin, dehydrated and paraffin embedded. Four-micron sections from each biopsy were made and stained with haematoxylin and eosin for light macroscopic evaluation. The morphologic characteristics of the kidneys were determined via blinded histologic evaluation by the collaborating pathologist.

\section{Measurement of reactive oxygen species and $L D H$ release}

Sera specimens were collected 15 minutes pre- and 15 minutes postreperfusion from each canine and snap frozen. Radical formation was measured by the degradation of 2-deoxyribose which when attacked by radicals yields malondialdehyde (MDA) that was detected by the thiobarbituric acid assay (20-22). The chromagen produced was measured by absorbance at $532 \mathrm{~nm}$ and the amount of MDA produced was calculated from a standard curve. The relevant MDA produced was determined by subtracting the baseline values at 15 minutes pre-reperfusion from the concentration of MDA found 15 minutes post-reperfusion. All testing was performed in duplicate and the samples were evaluated in a blinded fashion. The concentration of serum LDH was measured using an ACE analyzer (Schiapparelli Biosystems, Inc., Fairfield, $\mathrm{NJ}$ ) and were determined in sera samples collected at 15 minutes pre-, 15 minutes and 4 hours post-reperfusion.

\section{Posttransplant graft function}

Blood samples for BUN and serum creatinine were collected each morning and analyzed using an ACE analyzer (Schiapparelli Biosystems, Inc., Fairfield, $\mathrm{NJ})$. The early posttransplant function of each autotransplant was evaluated by the serum chemistries and urinalysis. The urine produced during the first 24 hours posttransplant was collected from each animal and tested for urinary concentrations of protein and creatinine. The severity of the subsequent period of dysfunction was evaluated on the basis of the peak serum creatinine and the time to normalization once the values fell below $2.0 \mathrm{mg} / \mathrm{dL}$. 


\section{RESULTS}

\section{1-Hour biopsy}

Biopsies taken at 1-hour post-reperfusion demonstrated a marked difference between kidneys reperfused from the cold and those reperfused directly from warm perfusion. Reperfusion from the cold resulted in more tubular degeneration, more inflammatory cell components and neutrophil aggregates in the glomerular tufts (Figure 1) in comparison to kidneys reperfused from the warm EMS perfusion (Figure 2).

\section{Measurement of reactive oxygen species and $\mathrm{LDH}$ release}

Thirty minutes of warm ischemia followed by cold storage resulted in an increased MDA content with a mean increase of $9 \mathrm{nM} / \mathrm{mL}$ at 15 minutes post-reperfusion (Figure 3). In the EMS kidneys the mean MDA content was 1 $\mathrm{nM} / \mathrm{mL} 15$ minutes post-reperfusion. These results are mirrored by the LDH released into the circulation 15 minutes and 4 hours post-reperfusion. Kidneys reperfused from the essentially frozen state of cold storage released considerably more LDH than kidneys that were warm at the time of reperfusion (mean values of $160 \mathrm{vs} 95 \mathrm{mg} / \mathrm{dL}$ )(Figure 4).

\section{Cold storage group outcomes}

The cold stored group kidneys with 30 minutes of warm ischemic damage followed by ex vivo cold storage at $4^{\circ} \mathrm{C}$ in ViaSpan reperfused slowly, with the cold kidneys having focal areas of discoloration. By 1-hour post-reperfusion the patchy appearance of the kidneys had largely dissipated. Urine was not produced during the early posttransplant period. The urine produced by the control dogs contained low concentrations of urinary creatinine and BUN and exhibited proteinuria $(1.5 \mathrm{~g} / \mathrm{dL}+/-0.7)$ (Table 2$)$. Kidneys reperfused directly from the cold storage demonstrated a mean peak serum creatinine value of 7.1 $\mathrm{mg} / \mathrm{dL}$ and took on average 13 days to normalize the serum chemistries (Figure 5).

\section{EMS group outcomes}

Following 30 minutes of warm ischemic injury the kidneys were initially vasoconstricted, but subsequently dilated well demonstrating good perfusion pressures of $38 \mathrm{mmHg}$ with flow rates in excess of $80 \mathrm{cc} / \mathrm{min}$ during ex vivo perfusion at $32^{\circ} \mathrm{C}$. In all cases urine flow was restored during the ex vivo 


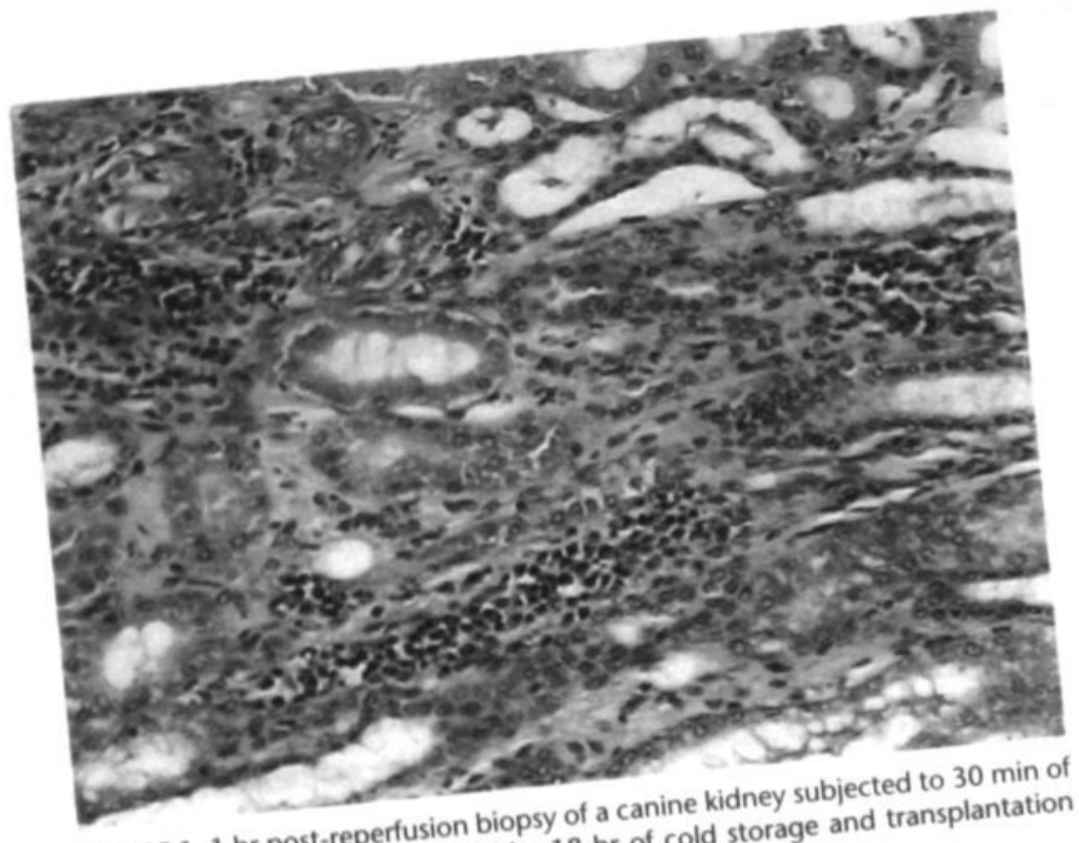

FIGURE $1.1 \mathrm{hr}$ post-reperfusion biopsy of a can cold storage and transplantation warm ischemic damage followed $\times 20$ ).

(Hematoxylin and eosin stai

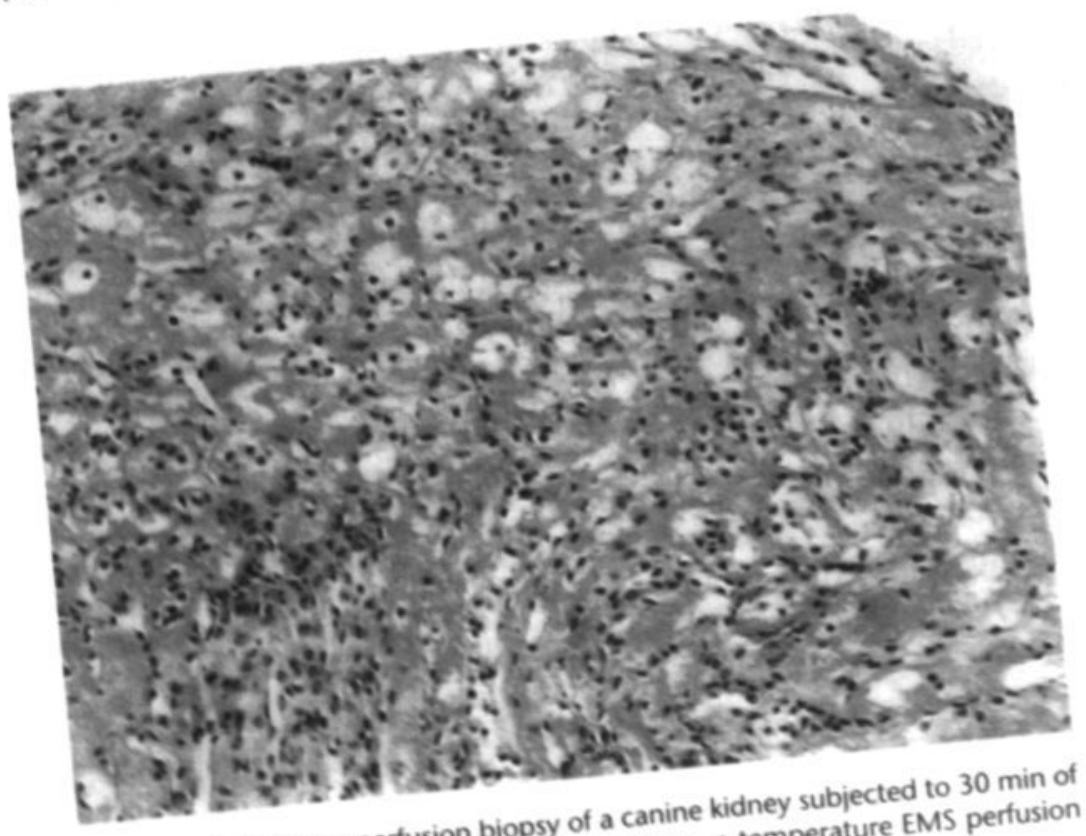

FIGURE $2.1 \mathrm{hr}$ post-reperfusion biops $18 \mathrm{hr}$ of warm temperat warm ischemic damage followed by 18 antation (Hematoxylin and eosin staining $\times 20$ ). 


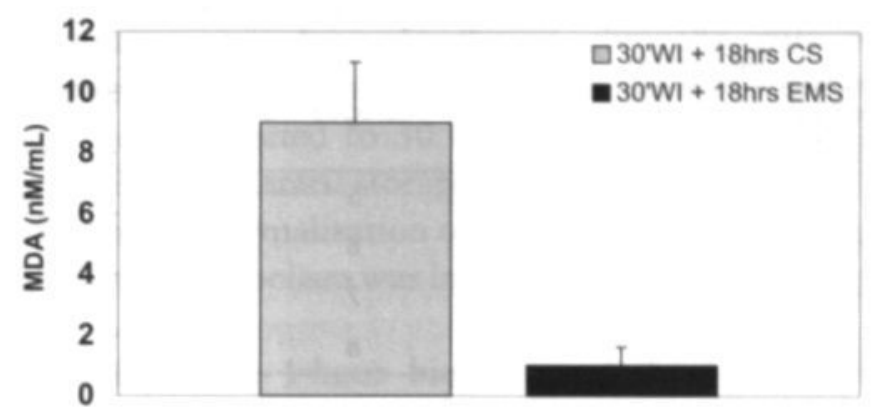

FIGURE 3. Malondialdehyde (MDA) concentration that was detected by the thiobarbituric acid assay following $15 \mathrm{~min}$ of reperfusion in kidneys subjected to either $30 \mathrm{~min}$ of warm ischemic damage followed by $18 \mathrm{hr}$ of cold storag or $18 \mathrm{hr}$ of warm temperature EMS perfusion and transplantation.

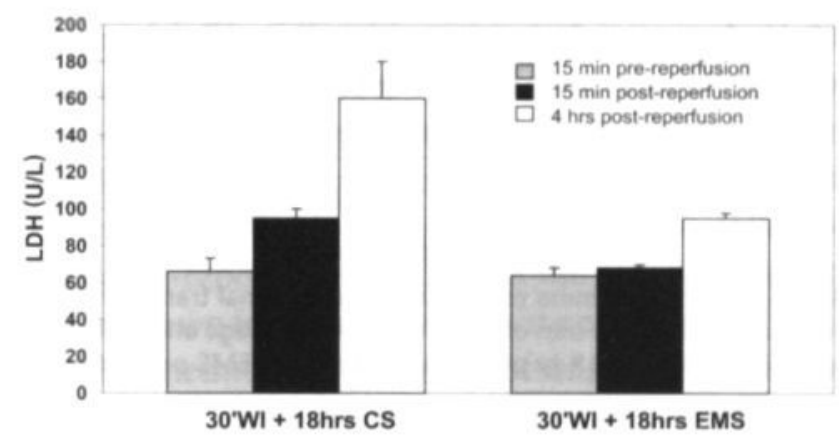

FIGURE 4. Lactatedehydrogenase (LDH) concentration that was detected by the thiobarbituric acid assay following $15 \mathrm{~min}$ of reperfusion in kidneys subjected to either $30 \mathrm{~min}$ of warm ischemic damage followed by $18 \mathrm{hr}$ of cold storag or $18 \mathrm{hr}$ of warm temperature EMS perfusion and transplantation.

perfusion, prior to reimplantation. Resumption of urine flow was considered to be significant since it is dependent upon reduction of ischemic swelling in the capillaries; particularly in the medulla that is susceptible to compression following ischemic tubular swelling.

The kidneys reperfused well when reimplanted, displaying good turgor without evidence of vasospasm and were evenly colored with no areas that appeared to be poorly perfused. All reimplanted kidneys produced urine within several minutes of reperfusion and continued to produce urine throughout the posttransplant period. Proteinuria did not develop in the kidneys perfused ex vivo at $32^{\circ} \mathrm{C}$ with EMS. The urines at 24 hours 
TABLE 2. 24 Hour Urinalysis of warm versus cold reperfused kidneys

\begin{tabular}{|c|c|c|c|c|c|c|c|}
\hline \multirow[b]{2}{*}{ Dog nr } & \multicolumn{3}{|c|}{ EMS group } & \multirow[b]{2}{*}{ Dog nr } & \multicolumn{3}{|c|}{ CS group } \\
\hline & $\begin{array}{c}\text { Creatinine } \\
\mathrm{mg} / \mathrm{dL}\end{array}$ & $\begin{array}{c}\text { Total protein } \\
\text { g/dL. }\end{array}$ & $\begin{array}{l}\text { BUN } \\
\mathrm{mg} / \mathrm{dL}\end{array}$ & & $\begin{array}{c}\text { Creatinine } \\
\text { mg/dL }\end{array}$ & $\begin{array}{c}\text { Total protein } \\
\text { g/dL }\end{array}$ & $\begin{array}{l}\text { BUN } \\
\mathrm{mg} / \mathrm{dL}\end{array}$ \\
\hline 1 & 24.7 & 0.1 & 310 & 5 & 10.7 & 1.5 & 162 \\
\hline 2 & 30.7 & 0.1 & 400 & 6 & 2.7 & 2.1 & 61 \\
\hline 3 & 29.6 & 0.2 & 145 & 7 & 3.0 & 2.0 & 49 \\
\hline 4 & 24.8 & 0.1 & 349 & 8 & 1.2 & 0.5 & 36 \\
\hline
\end{tabular}

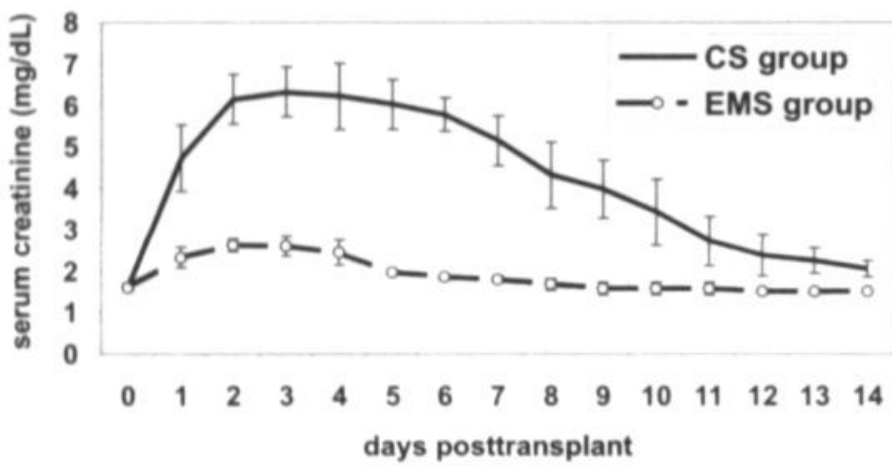

FIGURE S. Serum creatinine concentration after renal transplantation of kidneys subjected to $30 \mathrm{~min}$ of warm ischemic damage and $18 \mathrm{hr}$ of cold storage (CS group) or $18 \mathrm{hr}$ of warm temperature EMS perfusion.

posttransplant had a mean urinary creatinine concentration of $27.5 \mathrm{mg} / \mathrm{dL}$ $(+/-3.1)$ and mean BUN concentration of $301 \mathrm{mg} / \mathrm{dL}(+/-110)$ with urine total protein concentrations of $0.13 \mathrm{~g} / \mathrm{dL}(+/-0.05)$ (Table 2$)$. In contrast to hypothermically preserved kidneys, EMS kidneys at reperfusion demonstrated a reduced mean peak serum creatinine value of $2.7 \mathrm{mg} / \mathrm{dL}$ and the mean time to normalization of the serum chemistries was 4 days $(\mathrm{P}<0.05)$ (Figure 5).

\section{CONCLUSION}

Currently the upper limit of tolerable warm ischemia acceptable clinically in using kidneys from non-heartbeating donors is 30 minutes without intervention following cardiac arrest. While cold storage technique was used for the control group kidneys in this study, we have previously reported similar outcomes with this model using hypothermic machine perfusion. $(23,24)$ 
Since there was no difference in outcomes in this model and because static storage is the most commonly used technique clinically, static storage technique was selected for this study. The results of this study demonstrate that when kidneys were subjected to 30 minutes of warm ischemia and then preserved by hypothermic static storage, the mean peak serum creatinine was higher and the time to normalization of the serum chemistries longer than in kidneys where renal metabolism was instead resuscitated during warm perfusion.

The results from the 1-hour biopsies and the analysis of the urine produced during the first 24 hours posttransplant provide further evidence for the amelioration of reperfusion injury in the warm perfused organs. EMS perfused kidneys following reperfusion demonstrated less inflammatory cell components and neutrophil aggregates than kidneys reperfused directly from the cold. Likewise, warm kidneys following reperfusion did not develop proteinuria, while cold kidneys did. An elevated urinary protein concentration is a common feature following warm ischemic injury and is thought to result from damage to the capillary wall barrier caused by reperfusion injury. Proteinuria of $>1.0 \mathrm{~g} / \mathrm{dL}$ suggests direct damage to the glomerular filtration barrier. Three of the four control dogs had proteinuria $>1.0 \mathrm{mg} / \mathrm{dL}$

For consistency in collection, sera specimens were collected uniformly at fifteen minutes post-reperfusion, although the rate of production of oxygen radical species is known to frequently peak at approximately five minutes post reoxygenation,. Nonetheless, 30 minutes of warm ischemia coupled with subsequent hypothermic preservation resulted in the formation of radical species at reperfusion as assessed by the thiobarbituric acid release of the chromogen MDA. However, radical formation did not occur when kidneys were instead maintained with warm perfusion. This finding was mirrored by an increased concentration of $\mathrm{LDH}$ in the control kidneys reperfused from hypothermia at both 15 minutes and 4 hours post-reperfusion in comparison to the test kidneys. The evaluation of oxygen radical formation in this study provides indirect evidence for the formation of radical species following the combined effects of 30 minutes of warm ischemia and hypothermic preservation. This finding is consistent with other studies demonstrating the formation of MDA following ischemia/reperfusion (25).

These results suggest that controlled perfusion ex vivo at $32^{\circ} \mathrm{C}$ with an acellular perfusate ameliorated reperfusion injury following 30 minutes of warm ischemic insult. The ability to reperfuse constricted microvessels adequately during an ace 11 ular ex vivo perfusion at near physiologic temperature allows for the resuscitation of cellular metabolism and supported restoration of cell volume regulation. The ability to restore metabolism ex vivo, and 
acellularly, may have eliminated red cell trapping and prevented further injury following reperfusion. The relatively near physiologic temperature $\left(32^{\circ} \mathrm{C}\right)$ employed during EMS, in comparison to traditional hypothermia used in organ preservation $\left(4^{\circ} \mathrm{C}\right)$, supports the preservation of cell membranes in their normal fluid state, eliminating the rapid temperature phase-change transition involved when a hypothermically preserved kidney is reperfused with blood. The supported oxidative metabolism during the ex vivo EMS perfusion appears to have prevented the generation of oxygen radicals that occurred in the control kidneys that were reperfused directly from hypothermic storage conditions. The warm temperature used in the EMS also enhances the opportunity to initiate vasodilation on an endothelial cell-dependant basis restoring urine flow prior to reimplantation. It is postulated that: 1) the resuscitated metabolism and restored cell volume regulation prior to reperfusion contributed to the prevention of subsequent microvessel congestion and 2) continued oxidative metabolism ex vivo and the elimination of a severe temperature transition at reperfusion made possible by EMS technology prevented the generation of oxygen free radicals. The combined affect of these underlying mechanisms during EMS perfusion may have lead to the amelioration of the reperfusion injury observed in this study.

An impediment to developing effective prognostic testing that can differentiate ischemic damage resulting in delayed graft function from permanent damage leading to primary non-function has been the inhibition of metabolism that occurs during hypothermia (26). In a previous study by our group we demonstrated the feasibility of utilizing the ongoing metabolism during the warm temperature EMS perfusion to assess organs before they are transplanted (19). The ability to ameliorate any subsequent ischemia / reperfusion injury could positively impact clinically relevant prognostic testing and help to expand utilization of ischemically damaged kidneys.

\section{REFERENCES}

1. Orloff MS, Reed AI, Erturk E et al. Ann Surg 1994: 220(4):578

2. Shirakura R, Kamiike W, Matsumura A et al. Transpl Proc 1993: 25(6):3093

3. Gomez J, Alvarez J, Arias J et al. Transpl Proc 1993: 25:1501

4. Paller MS, Neuman TV. Kidney Int 1991: 40:1041

5. Rosen S, Epstein FH, Brezis M. Ren Fail 1992: 14:3211

6. Baker GL, Corry RJ, Autor AP. Ann Surg 1985: 202:628

7. Klausner JM, Paterson IS, Goldman G et al. Am J Physiol 1989: 256:F794

8. Takada M, Nadeau KC, Shaw GD et al. J Clin Invest 1997: 99:2682

9. Takada M, Chandraker A, Nadeau KC et al. J Clin Invest 1997: 100:1199 
10. Takada M, Nadeau KC, Shaw GD. Transpl Proc 1997: 29:1324

11. Linas SL, Whittenberg D, Repine JE. Am J Physiol 1990: 258:F711

12. Baker GL, Corry RJ, Autor AP. Ann Surg 1985: 202:628

13. Ames AD, Wright RL, Kowanda M et al. Am J Pathol 1968: 52:437

14. Urbaniak JR, Seaber AV, Chen L. Clin Orth Rel Res 1997: 334:30

15. Brasile L, Green E, Haisch C. ASAIO J 1997: 43:M427

16. Brasile L, Green E, Haisch C. Transpl Proc 1997: 32:40

17. Stubenitsky BM, Booster MH, Brasile L et al. ASAIO J 2000: 46:62

18. Stubenitsky BM, Booster MH, Brasile L et al. Transpl 2000: 70(8):1254

19. Stubenitsky BM, Booster MH, Brasile L et al. Transpl 2001: 71:716

20. Halliwell B, Grootveld M, Gutteride JMC. Meth Biochem Anal 1988: 33:59

21. Ohkawa H, Ohishi N, Yagi K. Anal Biochem 1979: 95:351

22. Yagi K. Biochem Med 1976: 15:212

23. Booster MH, van der Vusse GJ, Wijnen RM et al. Transpl 1994: 58:979

24. Booster MH, Wijnen RM, Yin M et al. Transpl Proc 1993: 25:3006

25. Paller MS, Hoidal JR, Ferris TF. J Clin Invest 1984: 74:1156

26. Kootstra G, Kievit JK, Heineman E. Brit Med Bull 1997: 53:844 

CHAPTER 7

Overcoming severe renal ischemia The role of ex vivo warm perfusion

Brasile L, Stubenitsky BM, Booster MH, Lindell S, Araneda D, Buck C, Bradfield J, Haisch CE, Kootstra G

Transplantation 2002; 73(6):897 


\begin{abstract}
Background. The ability to effectively utilize kidneys damaged by severe ( 2 hours) warm ischemia (WI) could provide increased numbers of kidneys for transplantation. The present study was designed to examine the effect of restoring renal metabolism following severe $\mathrm{WI}$ insult during ex vivo warm perfusion using an acellular technology. Following warm perfusion for 18 hours kidneys were reimplanted and evaluated for graft function.

Methods. Using a canine autotransplant model, kidneys were exposed to 120 minutes of WI. They were then either reimplanted immediately; hypothermically machine perfused $\left(4^{\circ} \mathrm{C}\right)$ for 18 hours with Belzer's solution; or transitioned to 18 hours of warm perfusion $\left(32^{\circ} \mathrm{C}\right)$ with an acellular perfusate prior to implantation.

Results. Warm perfused kidneys with 120 minutes of WI provided life-sustaining function following transplantation, while the control kidneys immediately reimplanted or with hypothermic machine perfusion did not. The mean peak serum creatinine in the warm perfused kidneys was 3.7 $\mathrm{mg} / \mathrm{dL}$, with the mean peak occurring on day 2 and normalizing on day 9 posttransplant.

Conclusions. These results indicate that 18 hours of ex vivo warm perfusion of kidneys is feasible. Furthermore, recovery of renal function during warm perfusion is demonstrated, resulting in immediate function following transplantation. The use of ex vivo warm perfusion to recover function in severe ischemically damaged kidneys could provide the basis for increasing the number of transplantable kidneys.
\end{abstract}


For the past decades the organ donor pool has consisted largely of the ICU-based heartbeating cadaver donor that represents a limited pool of potential donors. Despite concerted efforts, the number of organs available for transplantation has remained stagnant over the past 10 years $(1,2)$. Recent attempts to provide more kidneys have focused on using non-heartbeating (NHB) donors with limited warm ischemia ( $\leq 30$ minutes). Unfortunately the posttransplant outcomes with these kidneys are characterized by a high incidence of both delayed graft function and primary non-function, thereby hampering effective use of the NHB donor kidney. The major obstacle preventing any substantial expansion of the donor pool is warm ischemia (WI) combined with cold preservation (3). While it has been proposed that the kidney can tolerate as much as two hours of WI before the damage becomes irreversible, the added cold ischemia used to preserve the kidney during the period of tissue typing, matching and transportation, has made WI of greater than 30 minutes an insurmountable obstacle in transplantation today.

While the WI insult is unavoidable in using kidneys from the NHB donor, an alternative to traditional hypothermic inhibition of metabolism may be feasible. Our hypothesis was that an acellular warm perfusion following WI, could reestablish metabolism, restore vascular integrity and reinstitute cell volume regulation ex vivo sufficiently to render severely damaged kidneys capable of providing life-sustaining function when reimplanted.

To test this hypothesis a canine autotransplant model consisting of an initial WI insult of 120 minutes was employed. Exsanguinous Metabolic Support (EMS) technology was used for ex vivo warm perfusion $\left(32^{\circ} \mathrm{C}\right)$ for 18 hours.

\section{MATERIALS AND METHODS}

\section{Animals and surgical protocol}

The autotransplantation experiments were performed on foxhounds weighing 20-30 kilograms and approximately two years old. The animals received standard kennel food, routine lighting cycle and room temperature, and demonstrated normal renal function prior to the start of the study. All experiments were performed following the principles of laboratory animal care according to the NIH standards. Kidneys were exposed through a midline incision and the left renal artery, vein, and ureter were mobilized. If two renal arteries were present, the right kidney was used. Ten minutes prior to excision, 
$200 \mathrm{mg} / \mathrm{kg}$ of mannitol was administered intravenously. The excised kidney was exposed to 120 minutes of WI while remaining in the abdominal cavity $\left(37^{\circ} \mathrm{C}\right)$. Kidneys were then divided into three groups:

Group 1 ( $n=2$ ) Controls; $120 \mathrm{~min}$ WI followed by reimplantation

Group 2 ( $n=2$ ) Controls; $120 \mathrm{~min}$ WI followed by $18 \mathrm{hrs}$ hypothermic machine perfusion (MP) at $4^{\circ} \mathrm{C}$ and reimplantation

Group 3 ( $n=5$ ) Test, $120 \mathrm{~min}$ WI followed by $18 \mathrm{hrs}$ warm perfusion $\left(32^{\circ} \mathrm{C}\right)$ and reimplantation

The mean anastomosis time was 27 minutes and ranged from 20 to 30 minutes. Fifteen minutes before to reperfusion, mannitol $(200 \mathrm{mg} / \mathrm{kg})$ and verapamil $(0.1 \mathrm{mg} / \mathrm{kg})$ were administered. Contralateral nephrectomy was performed prior to reperfusion of the preserved kidney. Group 1 kidneys were flushed of blood prior to reimplantation with the same solution as was used to pump the test kidneys.

\section{Hypothermic machine perfusion}

Following the period of WI, the kidneys in Group 2 were flushed and placed into a MOX-100 perfusion machine (Waters instruments, MN, USA) with $500 \mathrm{ml}$ of Belzer's perfusate used as a circulating solution (4). After the kidney was connected to the perfusion system, perfusion was set to a systolic pressure of $50 \mathrm{mmHg}$. Following 1 hour of MP, if needed, the systolic pressure was readjusted to $50 \mathrm{mmHg}$. Flow and pressure were continuously monitored.

\section{Warm perfusion}

EMS technology (Breonics, Inc., Schenectady, NY, USA), was used for ex vivo warm perfusion $\left(32^{\circ} \mathrm{C}\right)$. Following the period of WI, the test kidneys in Group 3 were flushed and then placed on a pressure controlled perfusion system including a siliconized membrane oxygenator and a pulsatile pump, retrofitted with controllers to maintain $\mathrm{PaO}_{2}, \mathrm{PaCO}_{2}, \mathrm{pH}$ and temperature. The renal artery was cannulated and perfusion was initiated aiming for a pulsatile perfusion pressure of $50 / 30 \mathrm{mmHg}$. The volume of the circulating perfusate was $500 \mathrm{ml}$. Both flush solution and perfusate consisted of a highly enriched tissue culture-like solution that contained amino acids, carbohydrates, metabolites, inorganic ions, serum proteins, lipids, hormones, vitamins, reducing agents and a bicarbonate buffering system (Table 1). The warm flush/perfusion solution is a proprietary technology of Breonics, Inc. (Schenectady, NY, 
TABLE 1. Compostion of basal EMS medium

\begin{tabular}{|c|c|c|c|}
\hline DL-Alanine & $.12 \mathrm{~g} / \mathrm{L}$ & Menadione (Na Bisulfate) & $.00003 \mathrm{~g} / \mathrm{l}$ \\
\hline L-Arginine $\mathrm{HCl}$ & $.14 \mathrm{~g} / \mathrm{L}$ & Myo-Inositol & $.0001 \mathrm{~g} / \mathrm{L}$ \\
\hline DL-Aspartic Acid & $.12 \mathrm{~g} / \mathrm{L}$ & Niacinamide & $.00005 \mathrm{~g} / \mathrm{l}$ \\
\hline L-Cysteine $\mathrm{HCl} \mathrm{H}_{2} \mathrm{O}$ & $.00022 \mathrm{~g} / \mathrm{L}$ & Nicotinic Acid & $.00005 \mathrm{~g} / \mathrm{L}$ \\
\hline L-Cystine $2 \mathrm{HCl}$ & $.52 \mathrm{~g} / \mathrm{l}$ & Para-Aminobenzoic Acid & $.0001 \mathrm{~g} / \mathrm{L}$ \\
\hline DL-Glutamic Acid & $.2672 \mathrm{~g} / \mathrm{L}$ & D-Pantothenic Acid Ca & $.00002 \mathrm{~g} / \mathrm{h}$ \\
\hline L-Glutamine & $20 \mathrm{~g} / \mathrm{L}$ & Polyoxyethylenesorbitan Monoolate & $.04 \mathrm{~g} / \mathrm{L}$ \\
\hline Glycine & $.10 \mathrm{~g} / \mathrm{L}$ & Pyridoxal HCl & $.00005 \mathrm{~g} / \mathrm{L}$ \\
\hline L-Histidine $\mathrm{HCl} \mathrm{H}_{2} \mathrm{O}$ & $.04376 \mathrm{~g} / \mathrm{L}$ & Pyridoxine $\mathrm{HCl}$ & $.00005 \mathrm{~g} / \mathrm{l}$ \\
\hline L-Hydroxyproline & $.02 \mathrm{~g} / \mathrm{L}$ & Retinol Acetate & $.00028 \mathrm{~g} / \mathrm{L}$ \\
\hline DL-Isoleucine & $.08 \mathrm{~g} / \mathrm{L}$ & Riboflavin & $.00002 \mathrm{~g} / \mathrm{L}$ \\
\hline DL-Leucine & $.24 \mathrm{~g} / \mathrm{L}$ & Ribose & $.001 \mathrm{~g} / \mathrm{L}$ \\
\hline L-Lysine $\mathrm{HCl}$ & $.14 \mathrm{~g} / \mathrm{L}$ & Thiamine $\mathrm{HCL}$ & $.00002 \mathrm{~g} / \mathrm{t}$ \\
\hline DL-Methionine & $.06 \mathrm{~g} / \mathrm{L}$ & Thymine & $.0006 \mathrm{~g} / \mathrm{L}$ \\
\hline DL-Phenylalanine & $.10 \mathrm{~g} / \mathrm{L}$ & Uracil & $.0006 \mathrm{~g} / \mathrm{L}$ \\
\hline L.Proline & $.08 \mathrm{~g} / \mathrm{L}$ & Xanthine $\mathrm{HCl}$ & $.00069 \mathrm{~g} / \mathrm{L}$ \\
\hline DL-Serine & $.10 \mathrm{~g} / \mathrm{L}$ & Calcium Chloride $2 \mathrm{H}_{2} \mathrm{O}$ & $.265 \mathrm{~g} / \mathrm{L}$ \\
\hline DL-Theonine & $.12 \mathrm{~g} / \mathrm{L}$ & Ferric Nitrate $9 \mathrm{H}_{2} \mathrm{O}$ & $.00144 \mathrm{~g} / \mathrm{L}$ \\
\hline DL-Tryptophan & $.04 \mathrm{~g} / \mathrm{L}$ & Magnesium Sulfate (anhydrous) & $1.2 \mathrm{~g} / \mathrm{L}$ \\
\hline L-Tyrosine $2 \mathrm{Na}$ & $.11532 \mathrm{~g} / \mathrm{L}$ & Potasium Chloride & $.40 \mathrm{~g} / \mathrm{L}$ \\
\hline DL-Valine & $.10 \mathrm{~g} / \mathrm{L}$ & Sodium Acetate (anhydrous) & $.10 \mathrm{~g} / \mathrm{L}$ \\
\hline Adenine Hemisulfate & $.02 \mathrm{~g} / \mathrm{L}$ & Sodium Chloride & $6.8 \mathrm{~g} / \mathrm{L}$ \\
\hline Adenosine Triphosphate $2 \mathrm{Na} 2 \mathrm{Na}$ & $.002 \mathrm{~g} / \mathrm{L}$ & Sodium Phosphate Monobasic (anh) & $.224 \mathrm{~g} / \mathrm{L}$ \\
\hline Adenylic Acid & $.0004 \mathrm{~g} / \mathrm{L}$ & D-Glucose & $2.0 \mathrm{~g} / \mathrm{L}$ \\
\hline Alpha Tocopherol Phosphate $2 \mathrm{Na}$ & $.00002 \mathrm{~g} / \mathrm{L}$ & Insulin & $.01 \mathrm{~g} / \mathrm{L}$ \\
\hline Ascorbic Acid & $.001 \mathrm{~g} / \mathrm{L}$ & Bovine Serum Albumin & $30 \mathrm{~g} / \mathrm{L}$ \\
\hline D-Biotin & $.00002 \mathrm{~g} / \mathrm{L}$ & Sodium Bicarbonate & $4.4 \mathrm{~g} / \mathrm{L}$ \\
\hline Calciferol & $.0002 \mathrm{~g} / \mathrm{L}$ & Pyruvate & $.22 \mathrm{~g} / \mathrm{L}$ \\
\hline Cholesterol & $.0024 \mathrm{~g} / \mathrm{L}$ & Transferin & $.10 \mathrm{~g} / \mathrm{L}$ \\
\hline Choline Chloride & $.001 \mathrm{~g} / \mathrm{L}$ & Serum & $10 \mathrm{ml}$ \\
\hline Deoxyribose & $.001 \mathrm{~g} / \mathrm{L}$ & B-cyclodextrin & $.50 \mathrm{~g} / \mathrm{L}$ \\
\hline Folic Acid & $.00002 \mathrm{~g} / \mathrm{L}$ & Chondroitin sulfate B & $.004 \mathrm{~g} / \mathrm{L}$ \\
\hline Glutathione (reduced) & $.0001 \mathrm{~g} / \mathrm{L}$ & Fibroblast growth factor & $.02 \mathrm{~g} / \mathrm{L}$ \\
\hline Guanine $\mathrm{HCl}$ & $.0006 \mathrm{~g} / \mathrm{L}$ & heparin & $.18 \mathrm{~g} / \mathrm{L}$ \\
\hline Hypoxanthine & $.0006 \mathrm{~g} / \mathrm{L}$ & & \\
\hline
\end{tabular}


USA). The acellular perfusate was supplemented with pyridoxylated bovine hemoglobin $(6 \mathrm{~g} \%)$ (Ezon, Inc., Piscataway, NJ, USA) to provide adequate oxygen $\left(\mathrm{PaO}_{2}\right.$ of $200 \mathrm{mmHg}$ ) to support ongoing renal metabolism. Metabolism was assessed by measuring the renal oxygen consumption. $\mathrm{PaO}_{2}$ analysis of pre-renal and post-renal samples were performed using an ABL5 blood gas analyzer (Radiometer Medical A/S, Copenhagen, Denmark). Oxygen consumption $(\mathrm{ml} / \mathrm{min} / \mathrm{g})$ was calculated using the following formula: $\left[\left(\mathrm{PaO}_{2}\right.\right.$ art- $\mathrm{PaO}_{2}$ ven) $\mathrm{x}$ flow]/ weight.

\section{Posttransplant graft function}

Blood samples for BUN and serum creatinine were taken each morning and analyzed using an ACE analyzer (Schiapparelli Biosystems, Inc., Fairfield, NJ, USA). Animals deemed to be in poor condition, with unlikely chance of recovery from the delayed graft function were classified as primary non-function (PNF). Canines with PNF were euthanized. Serum creatinine was considered normal once the curve fell below $2.0 \mathrm{mg} / \mathrm{dL}$.

\section{Histologic evaluation}

The study protocol called for euthanizing surviving canines following the second posttransplant week if the serum creatinine values normalized to $<2.0$ $\mathrm{mg} / \mathrm{dL}$. Irreversibly damaged kidneys necessitated euthanizing the canines with clinical symptoms of renal failure and a serum creatinine $>8.0 \mathrm{mg} / \mathrm{dL}$ according to our standard institutional animal use protocol. At autopsy the implanted kidneys were bisected for gross macroscopic examination. Wedge-shaped biopsies were taken and fixed in $4 \%$ neutral-buffered formalin, dehydrated and paraffin embedded. Four micron sections from each kidney were made and stained using hematoxylin and eosin for light macroscopic evaluation. A minimum of five sections per kidney were studied. The morphological characteristics of the kidneys were determined by blinded histologic evaluation.

To address the extent of WI damage and the effect of 18 hours of subsequent warm or cold perfusion ex vivo, contralateral kidneys, subjected to the same protocol, were sectioned and fixed in $4 \%$ neutral-buffered formalin, dehydrated and paraffin embedded. 
RESULTS

\section{Testing during perfusion}

Group 2-In the kidneys that were hypothermically MP for 18 hours, the initial perfusion pressure that was set at $50 \mathrm{mmHg}$, resulted in a mean flow rate of 12 $\mathrm{ml} / \mathrm{min}$. After 60 minutes of MP the pressure was readjusted to $50 \mathrm{mmHg}$ resulting in a mean flow rate of $20 \mathrm{ml} / \mathrm{min}$ that remained virtually unchanged during the course of perfusion.

Group 3- Table 2. All the warm perfused kidneys of Group 3 demonstrated initially reduced flow rates that increased during the course of perfusion, together with a corresponding decrease in the vascular resistance. Oxygen consumption was lowest at the start of the ex vivo perfusion in comparison to the rates observed at subsequent time points.

\section{Posttransplant graft function}

Group 1 and 2-Following 120 minutes WI, control kidneys were either immediately reimplanted or hypothermically MP for 18 hours. All control dogs were anuric posttransplant with resulting uremia. Since our results in the controls were consistent with the literature and because of the distress to the dogs, ethically the number of control dogs was limited to two in each group to demonstrate reproducibility. All control dogs (Group 1 and 2) autotransplanted with kidneys damaged by 120 minutes WI demonstrated rising serum creatinine values that necessitated euthanasia (Figure 1).

Group 3-Test kidneys subjected to 120 minutes WI and 18 hours of warm perfusion reperfused well with evidence of restored and continual urine flow within minutes of reperfusion. The peak serum creatinine values ranged from 2.4 to $4.9 \mathrm{mg} / \mathrm{dL}$. All five dogs survived with normalization of the serum chemistries on day 3, 7, 8, 11 and 10 (Figure 1).

\section{Histology}

At autopsy the control kidneys that were immediately reimplanted following 2 hours of ischemic insult demonstrated moderate coagulative necrosis with marked interstitial and medullary hemorrhage. In control kidneys that were subsequently cold perfused, large lumenal thrombi were observed in the intralobular arteries. Many glomerular capillaries were observed to contain thrombi. All control kidneys had evidence of tubular necrosis, with intermit- 
TABLE 2. Warm perfusion characteristics

\begin{tabular}{lrcc}
\hline & \multicolumn{1}{c}{$\mathrm{FR}^{A}$} & \multicolumn{1}{c}{$\mathrm{VR}^{\mathrm{B}}$} & $\mathrm{O}_{2}$ cons $^{\mathrm{C}}$ \\
\hline Initial & $37 \pm 25$ & $1.53 \pm 1$ & $0.08 \pm 0.02$ \\
$90 \mathrm{~min}$. & $79 \pm 20$ & $0.64 \pm 0.1$ & $0.11 \pm 0.01$ \\
$12 \mathrm{hrs}$. & $96 \pm 19$ & $0.51 \pm 0.1$ & $0.14 \pm 0.01$ \\
18 hrs. & $101 \pm 16$ & $0.45 \pm 0.1$ & $0.14 \pm 0.01$ \\
\hline
\end{tabular}

All values expressed as mean with the standard deviation. $A=F R$, vascular flow rate $(\mathrm{ml} / \mathrm{min}) ; B=$ $V R$, vascular resistance (MAP/FR); $\mathrm{C}=\mathrm{O}_{2}$, oxygen consumption $\left(\mathrm{PaO}_{2}\right.$ artery- $\mathrm{PaO}_{2}$ vein) $\times \mathrm{FR}$ / weight

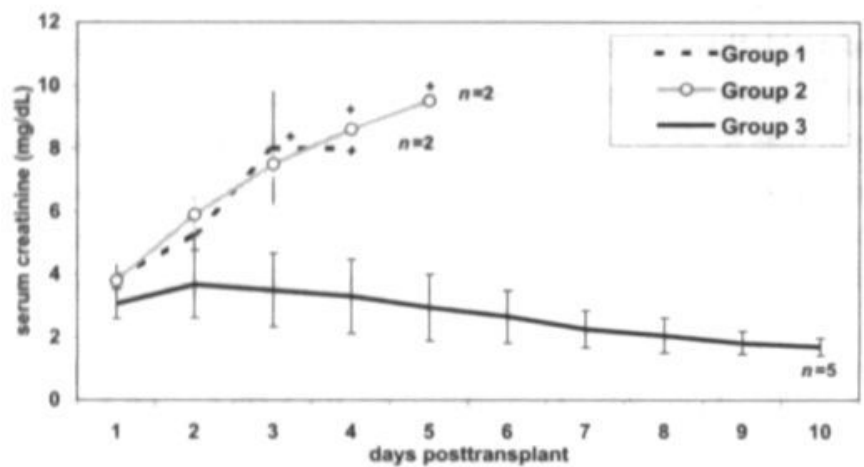

FIGURE 1. Serum creatinine concentration following renal transplantation of kidneys subjected to 120 minutes of WI. The two control groups consisted of transplantation immediately following 120 minutes of WI (Group 1) and 120 minutes of warm ischemia followed by 18 hours of hypothermic MP (Group 2). The test group (Group 3) consisted of 120 minutes of warm ischemia followed by 18 hours of warm perfusion. An increase in serum creatinine concentrations due to PNF was observed in Group 1 and 2. In Group 3 serum creatinine levels increased slightly posttransplant and returned to normal values by day 9 . Values are expressed as the mean with standard deviation for each experimental group. $+=$ euthanized due to primary non-function.

tent areas of active tubular necrosis. In contrast, the test kidneys that were warm perfused following 2 hours of warm ischemic insult demonstrated normal vessels and glomeruli. Tubule epithelium was essentially normal, although there were occasional, mild cystic dilation of tubules with mild multifocal peritubular mononuclear infiltrates.

The contralateral kidneys were subjected to 120 minutes of warm ischemia and then either MP $\left(4^{\circ} \mathrm{C}\right)$ or warm perfused for 18 hours. Warm ischemia and subsequent MP resulted in widespread damage to the tubule system by hematoxylin and eosin staining consisting of cell swelling, individual 


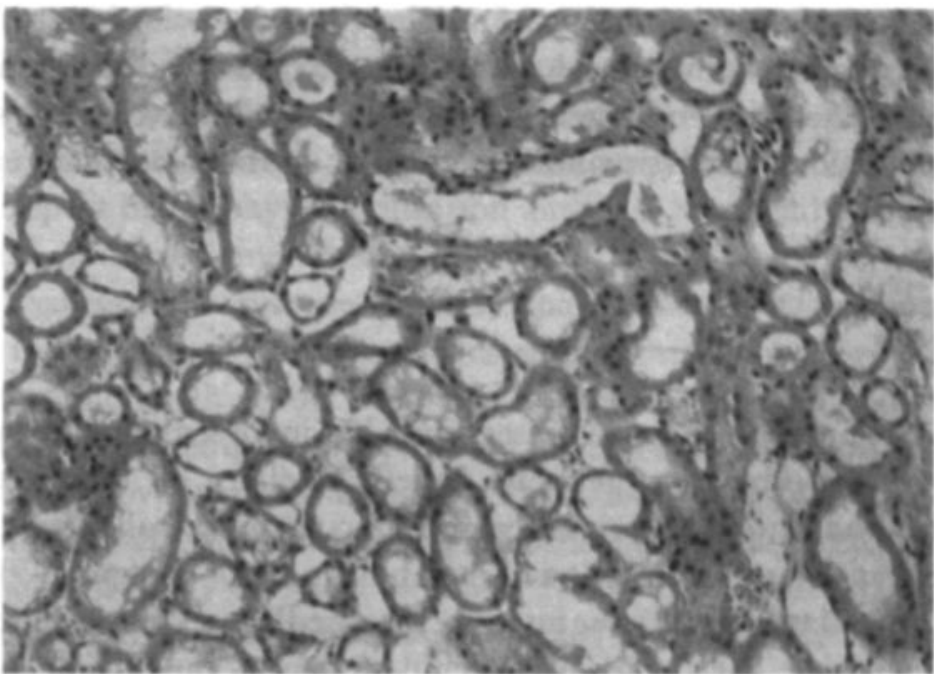

FIGURE 2. Hematoxylin and eosin staining 20x. Canine kidney with 120 minutes of warm ischemic damage followed by 18 hours of hypothermic MP resulting in widespread damage to the tubule system consisting of individual cell death and loss of apical cytoplasm.

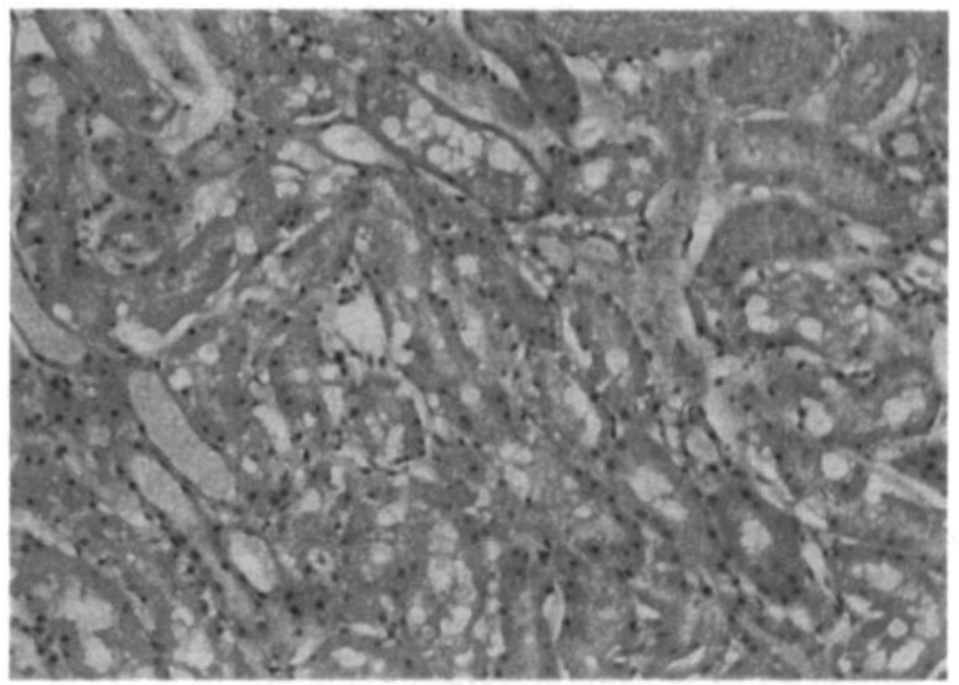

FIGURE 3. Hematoxylin and eosin staining 20x. Canine kidney with 120 minutes of warm ischemia and subsequent 18 hours of warm perfusion resulted in preserved cellular integrity. Focal tubular damage was present. 
cell death, loss of apical cytoplasm and plugging of tubular lumina systems (Figure 2). In contrast, warm perfusion resulted in preserved cellular integrity (Figure 3). Widespread tubular damage was present as expected, since 18 hours of perfusion would be an inadequate period to observe tubule epithelial regeneration.

\section{DISCUSSION}

The historic approach to organ preservation has involved using hypothermic techniques. Hypothermia exerts its beneficial effect by diminishing the oxygen demand of the organs and also by reducing the overall metabolic rate. However, hypothermic inhibition of metabolism is not benign (5-7). Hypothermia can lead to altered tissue integrity that predisposes the development of reperfusion injury. The alterations in cellular integrity can include loss of the adenine compound pool, an accumulation of by-products such as free fatty acids, inhibition of the ion pumps, edema and time dependant structural changes in the vasculature. As the duration of cold ischemia becomes prolonged there is a direct correlation with the severity of the inflammatory processes generally categorized as reperfusion injury. Most importantly, the inhibition of cellular metabolism that occurs during hypothermic preservations eliminates the possibility of substantial reparative processes occurring following warm ischemic injury.

The initial effects of ischemia, whether at warm or cold temperatures, are from the lack of molecular oxygen for oxidative phosphorylation; which leads to the depletion of cellular energy stores (8). Nucleotides are rapidly lost during ischemia and this loss is an important factor in the failure of tissue subjected to prolonged ischemia to regenerate after restored blood circulation (9). The principal difference between ischemia at warm and cold temperatures is the rate at which the cell injury and death occur. The hypothermic time dependant increase in the incidence of delayed function in kidneys is substantially increased with prior warm ischemic exposure, as is the case with kidneys procured from non-hearting beating donors. Therefore, the combination of warm and cold ischemic damage represents the major obstacle to substantially expanding the organ donor pool into the non-heartbeating cadaver population. Until the damaging effects of ischemia can be alleviated, the donor pool cannot be substantially expanded.

However, many of the ischemia related problems would be eliminated if organs could be perfused at warmer temperatures. Warm perfusion at temperatures greater than $25^{\circ} \mathrm{C}$, would support membrane lipids remaining in a nor- 
mal fluid state. Most enzyme systems functioning at $37^{\circ} \mathrm{C}$ also function at temperatures as low as $20^{\circ} \mathrm{C}$, but at a slower rate. Similarly, energy substrates can be readily resynthesized following ischemic insult once oxidative phosphorylation resumes at warm perfusion temperatures. Warm perfusion would support better oxygen utilization and raise the metabolic rate during the period an organ is maintained ex vivo.

The results of this study demonstrate that warm perfusion is feasible and presents the opportunity to reestablish metabolism ex vivo following a severe warm ischemic insult. Most importantly, warm perfusion following two hours of warm ischemic insult recovered metabolism sufficiently to support the eventual recovery of normal renal function. In contrast, primary non-function occurred in all control dogs. Hypothermic preservation did not alter this outcome.

Previous attempts at isolated organ perfusion at near normothermic temperatures using acellular solutions have resulted in deteriorating perfusion characteristics and metabolic function after relatively short periods (10). In reviewing the literature, it becomes apparent that the previous attempts at mimicking a physiologic preservation failed for two major reasons (11). First, the failure to maintain the integrity and normal barrier functions of the vasculature leads to a rapid deterioration in vascular flow and the concurrent development of edema. Second, the inability to support adequate delivery of nutrients and oxygen lead to a deteriorating metabolic state.

The perfusate we used consists of a highly enriched tissue culture-like media. Certain components are distinct from traditional tissue culture media formulations and provide unique functions:

Oxygen carrier. An adequate supply of oxygen cannot be dissolved by an aqueous solution. A major reason why previous studies attempting warm perfusion failed can be attributed to the inability to supply adequate oxygen tension. The use of red blood cells has been problematic because of the mechanical damage that occurs to the circulating red cells over time. We used chemically modified hemoglobin as the source of an oxygen carrier.

Albumin. Aside from providing colloid osmotic pressure, by far the most important function of albumin is its carrier functions. In the same manner that an oxygen carrier delivers oxygen and removes carbon dioxide, albumin delivers nutrients to the cells within the nephron and removes the by-products of the ongoing metabolism. 
Metabolism is directly correlated to the temperature at which tissue is maintained ex vivo. It was determined from previous studies that warm perfusion could adequately support organ metabolism at temperatures ranging from $30-34^{\circ} \mathrm{C}(12-15)$. In current studies warm perfusion is conducted at a temperature $32^{\circ} \mathrm{C}$.

The recovery processes during warm perfusion should not to be confused with the physiologic processes involved in normal wound repair since wound repair consists of the primary steps of coagulation and inflammation, along with a migratory/adhesion phase. Since EMS is acellular and ex vivo, the recovery is more analogous to the cellular recovery that occurs with restoration of metabolism during cell culture. Nonetheless, the ex vivo recovery entails these distinct features: reestablishment of oxidative metabolism, restoration of cell volume regulation, recovery of vascular functions including autoregulation, barrier functions, normalized vasculature resistance and resumed urine flow. Most importantly, it is sufficient to render an organ damaged by 120 minutes of warm ischemic damage capable of providing life-sustaining function with serum chemistries within a normal range, normal urine and essentially normal histologic evaluation following reimplantation.

Ex vivo recovery of organs could provide the foundation for changing the current time frame for procuring organs from within minutes of death to that of hours. These results provide the first experimental evidence to recover organs following an ischemic insult of as much as 120 minutes and represent a potential solution to the persistent organ shortage. 


\section{REFERENCES}

1. Cohen B. Introduction. Eurotransplant Newsletter 1998: 145:1

2. Meester de J. Kidney: donation, waiting lists and transplants. In: Cohen B, Persijn G, De Meester J (eds) Eurotransplant International Foundation. Annual Report 1996. Koninklijke Bibliotheek, The Hague 1996: 27

3. Wijnen RM, Booster MH, Stubenitsky BM et al. Lancet 1995: 345:1067

4. Moen J, Claesson K, Pienaar H et al. Transpl 1989: 47:940

5. Gao WS, Takei Y, Marzi I et al. Transpl 1991: 52:417

6. Shoskes DA, Cecka JM. Transpl 1998: 66:1697

7. Abendroth D. Transplant Proc 1998: 30:4288

8. Weinberg JM. Biochem Med Metab Biol 1988: 39:319

9. Mandel LJ, Takano T, Soltoff SP et al. J Clin Invest 1988: 81:1255

10. Southard, J.H. Cryobiology 1989: 26:239

11. Stubenitsky BM, Booster MH, Nederstigt AP et al. Transpl Int 1999: 12:83

12. Brasile L, Clarke J, Green EM et al. Transplant. Proc 1996: 28:349

13. Brasile L, Green EM, Haisch CE. Transplant Proc 1997: 29:3422

14. Stubenitsky BM, Booster MH, Brasile L et al. Transpl 2000: 70:1254

15. Stubenitsky BM, Booster MH, Brasile L et al. Transpl 2001: 71:716 
CHAPTER 8

The culture of whole organs

Brasile L, Stubenitsky BM, Booster MH, Haisch CE, Kootstra G submitted 


\begin{abstract}
Research involving metabolically active and functioning organs, maintained ex vivo in culture-like conditions, could provide new opportunities for medical innovations and research. We report successful perfusion of isolated canine and human kidneys ex vivo at near physiologic temperature for 48 hours. During the perfusions parameters of metabolism and function remained stable. Likewise, there was evidence of de novo protein synthesis during the period the organs were in culture. Nitric oxide synthase (NOS) was identified as the underlying mechanism preserving vascular integrity. Most importantly, when the canine kidneys were reimplanted there was immediate normal renal function. This report highlights the potential significance of whole organ culture using a warm temperature ex vivo perfusion and discusses medical applications that could be developed.
\end{abstract}




\section{INTRODUCTION}

"... It is obvious to everybody that a treatise on medicine is necessary for it is conjoined to the whole art of healing and because its scope may be enlarged both in the direction of methods of preparation and of experiments on diseases..." Pedanius Discorides, first century B.C.

As Dioscorides recognized 2,100 years ago, the cure for diseases is dependant upon experimentation eliciting underlying mechanisms and identifying treatments (1). Two experimental models have formed the basis of modern scientific endeavors for studying biologic processes. The first has been used since antiquity and consists of in vivo studies using live animal models. The second model utilized for the past 50 years is based upon isolated, and usually purified, cell populations expanded and maintained in cell culture. The balance between in vivo and in vitro experimentation is important to the advancement of scientific pursuits elucidating cellular mechanisms involved in the pathogenesis of disease.

\section{Animal models}

Animal models have been instrumental to our understanding of complex interactive physiologic processes. The ancient Greeks, Herophilus and Erasistratus, experimented on human prisoners until Celsus objected to the cruelty; after which animals were instead used for comparative experimentation to understand human structure and physiology $(2,3)$. By the second century A.D., experimentation with animals had progressed to performing controlled studies providing explanations for spinal cord injuries, an understanding of metabolism, identified organ specific function, described the origin of several diseases and introduced the use of surgical procedures (4). The use of animal models in scientific endeavors continued through the Renaissance period ushering in the modern era of anatomy $(5,6)$.

However, most animal models differ from human disease in terms of etiology and pathogenesis (7). Environmental factors, genetic drift, diet, infectious agents and housing conditions can impact the overall physiology and contribute to pathogenic mechanisms that affect the outcomes of experimental procedures (8-10). The traditional approach has been to employ large experimental populations to compensate for inherent variability. 


\section{Cell culture}

Tissue culture has represented a cornerstone of scientific investigation by providing populations of isolated cells for research. During the 1950's pioneers in this field painstakingly developed a variety of tissue culture media and techniques. Early formulations were optimized for fibroblastic cells and later focused on established cell lines employing media with defined chemical components.

A common feature of cell culture is the need to dissociate complex tissues and organs into isolated cell populations that are expanded during cell culture. The dissociative process involves mincing, proteolytic enzyme digestion, agitation, centrifugation, gradient purification and cell sorting procedures. All of these manipulations can be considered traumatic in that dissociating complex tissues into isolated cells, necessitates disrupting the normal cell-cell junctional integrity as well as the cell-extracellular matrix interfaces. A direct result of the cellular dissociation is a high metabolic rate associated with a log-phase of population expansion. The impact of the requisite up-regulation of gene expression in cells that have been artificially stimulated to proliferate can impact experimental protocols. This is particularly poignant when one considers that most highly differentiated cells replicate only rarely. The cells in culture proliferate and migrate until they are once again contact inhibited. However, the complex three-dimensional nature of tissues is never reestablished.

Studies using isolated cell populations do not reflect the complexity of the heterogeneous cells that collectively constitute an organ's function. The ability to maintain the functional complexity of organs in terms of cellular interactions and their requisite regulatory functions, requires that differentiated cells be maintained in complex 3-dimensional format and limits the usefulness of cells in culture.

\section{Isolated organ perfusion}

The ability to study isolated organs in metabolically active states, presents an alternative approach to experimental science. Moreover, experimenting with an isolated organ presents the opportunity to institute controls that are not feasible when using animal models. One of the first researchers to recognize the potential significance of maintaining intact organs was the Nobel Laureate, Alexis Carrel at the turn of the $20^{\text {th }}$ century. Using intermittent blood perfusion alternatively with saline, Carrel reported being able to maintain viability in organ blocks consisting of heart, lung, gut, pancreas and 
kidney (11). However, the organs within the block were never reimplanted to demonstrate subsequent life-sustaining function nor was there histologic or functional data supporting viability.

Attempts at isolated organ perfusion subsequent to the work of Carrel using either blood perfusion or cell-free perfusates results in loss of vascular barrier functions and edema. No one has reported maintaining an isolated organ at near physiologic temperature with corresponding continued metabolism ex vivo for greater than a few hours (12) and no one has demonstrated life-sustaining function following ex vivo periods of greater than 24 hours by reimplanting the organ (13-19). A common feature of isolated organ perfusion has been rising perfusion pressures and diminished vascular flow rates following several hours of ex vivo perfusion (12). This is attributable to the loss of cellular integrity with the onset of an injury cascade from the moment organs are separated from their physiologic system. Currently, the only reliable means of maintaining organ viability once an organ is removed from the body is to suppress the metabolic rate via profound hypothermia (19-22).

Dovolopment of whole urgun culture

Our hypothesis in developing organ culture was that if retention of normal barrier functions within the vasculature could be preserved and cellular metabolism could be adequately supported, then it would be possible to maintain organ integrity during an ex vivo near-normothermic and acellular perfusion. Rather than employing a standard electrolyte solution supplemented with a few ingredients that is used in traditional isolated perfusion of kidneys, we instead utilized a cell culture perspective. This approach represented the coupling of organ perfusion technology with cell culture techniques to maintain whole organs. The formulation comprised the needed raw materials for synthesis, substrates for energy and ongoing metabolism and bulk inorganic ions for both catalytic and physiologic functions. Physiologic parameters such as temperature, $\mathrm{pH}, \mathrm{O}_{2}$ - tension and perfusion pressures were kept within a defined range.

In previous experiments we have reported successfully maintaining canine kidneys in a metabolically active condition at near physiologic temperature $\left(32^{\circ} \mathrm{C}\right)$. When these canine kidneys were reimplanted following 18 hours of organ culture, they provided immediate normal renal function (23). Organ Culture has also demonstrated successful resuscitation of oxidative metabolism in kidneys damaged by two hours of warm ischemia and when transplanted, provided for immediate life sustaining function (24). 
We now report organ culture of human kidneys for up to 48 hours, with confirming life sustaining canine transplant studies. Furthermore we provide evidence of de novo synthesis of protein and present the initial evidence for the underlying mechanisms of vascular regulation during the period of organ culture.

\section{METHODS}

\section{Whole organ culture}

Exsanguineous Metabolic Support (EMS) Technology (Breonics, Inc., Schenectady, NY, USA), was used for ex vivo warm perfusion $\left(32^{\circ} \mathrm{C}\right)$. Kidneys were placed in the perfusion system consisting of an oxygenator and pulsatile pump, retrofitted with controllers to maintain $\mathrm{PaO}_{2}, \mathrm{PaCO}_{2}, \mathrm{pH}$ and temperature. Perfusion was initiated with pulsatile perfusion pressure of $50 / 30 \mathrm{mmHg}$ and a $500 \mathrm{~mL}$ circulating medium volume. The EMS medium is an enriched tissue culture-like solution (Table 1) supplemented with nvridoxvlated bovine hemoglobin ( $6 \mathrm{~g} \%$ ) (Ezon, Inc., Piscataway, NJ, USA).

The medium was exchanged $(10 \%)$ every 4 hours. $\mathrm{PaO}_{2}$ analysis of preand post-renal samples were performed using an ABL5 blood gas analyzer (Radiometer Medical A/S, Copenhagen, Denmark). $\mathrm{O}_{2}$-consumption $(\mathrm{ml} / \mathrm{min} / \mathrm{g})$ was calculated using the following formula:

$\left[\left(\mathrm{PaO}_{2}\right.\right.$ art $-\mathrm{PaO}_{2}$ ven $) \mathrm{x}$ flow $] /$ weight.

\section{Human kidneys}

Human kidneys determined to be nontransplantable by institutional criteria were stored in ViaSpan ${ }^{\mathrm{TM}}$ at $4^{\circ} \mathrm{C}$ (mean cold storage time of 38 hours) prior to their release for research use. The kidneys were weighed and flushed with approximately $250 \mathrm{cc}$ of organ culture medium warmed to $32^{\circ} \mathrm{C}$ to remove hypothermic solution. During organ culture at $32^{\circ} \mathrm{C}$, the kidneys were evaluated for oxidative metabolism, vascular dynamics and organ function. The organ parameters were tested hourly. Human kidneys were perfused for either 12 hours $(n=2) ; 24$ hours $(n=2)$; or 48 hours $(n=2)$.

\section{Animals and surgical protocol}

The autotransplantation experiments were performed on foxhounds weighing 20-30 kilograms. All experiments were performed following the 
TABLE 1. Composition of the basal organ culture medium

\begin{tabular}{|c|c|c|c|}
\hline DL-Alanine & $.12 \mathrm{~g} / \mathrm{L}$ & Menadione (Na Bisulfate) & $.00003 \mathrm{~g} / \mathrm{L}$ \\
\hline L-Arginine $\mathrm{HCl}$ & $.14 \mathrm{~g} / \mathrm{L}$ & Myo-Inositol & $.0001 \mathrm{~g} / \mathrm{L}$ \\
\hline DL-Aspartic Acid & $.12 \mathrm{~g} / \mathrm{L}$ & Niacinamide & $.00005 \mathrm{~g} / \mathrm{t}$ \\
\hline L-Cysteine $\mathrm{HCl} \mathrm{H}_{2} \mathrm{O}$ & $.00022 \mathrm{~g} / \mathrm{L}$ & Nicotinic Acid & $.00005 \mathrm{~g} / \mathrm{l}$ \\
\hline L-Cystine $2 \mathrm{HCl}$ & $.52 \mathrm{~g} / \mathrm{L}$ & Para-Aminobenzoic Acid & $.0001 \mathrm{~g} / \mathrm{L}$ \\
\hline DL-Glutamic Acid & $.2672 \mathrm{~g} / \mathrm{l}$ & D-Pantothenic Acid Ca & $.00002 \mathrm{~g} / \mathrm{L}$ \\
\hline L-Glutamine & $20 \mathrm{~g} / \mathrm{l}$ & Polyoxyethylenesorbitan Monoolate & $.04 \mathrm{~g} / \mathrm{l}$ \\
\hline Glycine & $.10 \mathrm{~g} / \mathrm{L}$ & Pyridoxal HCI & $.00005 \mathrm{~g} / \mathrm{L}$ \\
\hline L-Histidine $\mathrm{HCl} \mathrm{H}_{2} \mathrm{O}$ & $.04376 \mathrm{~g} / \mathrm{L}$ & Pyridoxine $\mathrm{HCl}$ & $.00005 \mathrm{~g} / \mathrm{L}$ \\
\hline L-Hydroxyproline & $.02 \mathrm{~g} / \mathrm{L}$ & Retinol Acetate & $.00028 \mathrm{~g} / \mathrm{L}$ \\
\hline DL-Isoleucine & $.08 \mathrm{~g} / \mathrm{L}$ & Riboflavin & $.00002 \mathrm{~g} / \mathrm{l}$ \\
\hline DL-Leucine & $.24 \mathrm{~g} / \mathrm{L}$ & Ribose & $.001 \mathrm{~g} / \mathrm{L}$ \\
\hline L-Lysine $\mathrm{HCl}$ & $.14 \mathrm{~g} / \mathrm{L}$ & Thiamine $\mathrm{HCl}$ & $.00002 \mathrm{~g} / \mathrm{L}$ \\
\hline DL-Methionine & $.06 \mathrm{~g} / \mathrm{L}$ & Thymine & $.0006 \mathrm{~g} / \mathrm{L}$ \\
\hline DL-Phenylalanine & $10 \mathrm{~g} / \mathrm{L}$ & Uracil & $.0006 \mathrm{~g} / \mathrm{L}$ \\
\hline L-Proline & $.08 \mathrm{~g} / \mathrm{l}$ & Xanthine $\mathrm{HCl}$ & $.00069 \mathrm{~g} / \mathrm{L}$ \\
\hline DL-Serine & $.10 \mathrm{~g} / \mathrm{L}$ & Calcium Chloride $2 \mathrm{H}_{2} \mathrm{O}$ & $.265 \mathrm{~g} / \mathrm{L}$ \\
\hline DL-Threonine & $.12 \mathrm{~g} / \mathrm{L}$ & Ferric Nitrate $9 \mathrm{H}_{2} \mathrm{O}$ & $.00144 \mathrm{~g} / \mathrm{L}$ \\
\hline DL-Tryptophan & $.04 \mathrm{~g} / \mathrm{L}$ & Magnesium Sulfate (anhydrous) & $1.2 \mathrm{~g} / \mathrm{t}$ \\
\hline L-Tyrosine $2 \mathrm{Na}$ & $.11532 \mathrm{~g} / \mathrm{L}$ & Potassium Chloride & $.40 \mathrm{~g} / \mathrm{L}$ \\
\hline DL-Valine & $.10 \mathrm{~g} / \mathrm{L}$ & Sodium Acetate (anhydrous) & $.10 \mathrm{~g} / \mathrm{L}$ \\
\hline Adenine Hemisulfate & $.02 \mathrm{~g} / \mathrm{L}$ & Sodium Chloride & $6.8 \mathrm{~g} / \mathrm{L}$ \\
\hline Adenosine Triphosphate $2 \mathrm{Na} 2 \mathrm{Na}$ & $.002 \mathrm{~g} / \mathrm{L}$ & Sodium Phosphate Monobasic (anh) & $.224 \mathrm{~g} / \mathrm{L}$ \\
\hline Adenylic Acid & $.0004 \mathrm{~g} / \mathrm{L}$ & D-Glucose & $2.0 \mathrm{~g} / \mathrm{L}$ \\
\hline Alpha Tocopherol Phosphate $2 \mathrm{Na}$ & $.00002 \mathrm{~g} / \mathrm{L}$ & Insulin & $.01 \mathrm{~g} / \mathrm{L}$ \\
\hline spnumAscorbic Acid & $.001 \mathrm{~g} / \mathrm{L}$ & Bovine Serum Albumin & $30 \mathrm{~g} / \mathrm{L}$ \\
\hline D-Biotin & $.00002 \mathrm{~g} / \mathrm{L}$ & Sodium Bicarbonate & $4.4 \mathrm{~g} / \mathrm{L}$ \\
\hline Calciferol & $.0002 \mathrm{~g} / \mathrm{L}$ & Pyruvate & $.22 \mathrm{~g} / \mathrm{L}$ \\
\hline Cholesterol & $.0024 \mathrm{~g} / \mathrm{L}$ & Transferin & $.10 \mathrm{~g} / \mathrm{L}$ \\
\hline Choline Chloride & $.001 \mathrm{~g} / \mathrm{L}$ & Serum & $10 \mathrm{ml}$ \\
\hline Deoxyribose & $.001 \mathrm{~g} / \mathrm{L}$ & B-cyclodextrin & $.50 \mathrm{~g} / \mathrm{L}$ \\
\hline Folic Acid & $.00002 \mathrm{~g} / \mathrm{L}$ & Chondroitin sulfate B & $.004 \mathrm{~g} / \mathrm{L}$ \\
\hline Glutathione (reduced) & $.0001 \mathrm{~g} / \mathrm{L}$ & Acidic fibroblast growth factor & $.02 \mathrm{~g} / \mathrm{L}$ \\
\hline Guanine $\mathrm{HCL}$ & $.0006 \mathrm{~g} / \mathrm{L}$ & heparin & $.18 \mathrm{~g} / \mathrm{L}$ \\
\hline Hypoxanthine & $.0006 \mathrm{~g} / \mathrm{L}$ & & \\
\hline
\end{tabular}


principles of laboratory animal care according to NIH standards. Excised kidneys were divided into five groups:

$\begin{array}{ll}\text { Group } 1(n=5) & 24 \mathrm{hrs} \text { organ culture }\left(32^{\circ} \mathrm{C}\right) \text { and reimplantation } \\ \text { Group } 2(n=2) & 48 \mathrm{hrs} \text { organ culture }\left(32^{\circ} \mathrm{C}\right) \text { and reimplantation } \\ \text { Group } 3(n=10) & \begin{array}{l}6 \mathrm{hrs} \text { organ culture }\left(32^{\circ} \mathrm{C}\right) \text { and reimplantation } \\ \text { Group } 4(n=2)\end{array} \\ \begin{array}{l}6 \mathrm{hrs} \text { organ culture without oxygen carrier }\left(32^{\circ} \mathrm{C}\right) \text { and } \\ \text { reimplantation }\end{array} \\ \text { Group 5 }(n=2) & \begin{array}{l}6 \mathrm{hrs} \text { organ culture without albumin }\left(32{ }^{\circ} \mathrm{C}\right) \text { and } \\ \text { reimplantation }\end{array}\end{array}$

The mean reanastomosis time was 28 minutes, ranging from 22-32 minutes. Contralateral nephrectomy was performed prior to reperfusion of preserved kidneys. The contralateral kidneys were used in the NOS blocking studies. NOS was either not inhibited (control; $n=3$ ), inhibited by L-NAME $(100 \mu \mathrm{M} ; \mathrm{n}=3)$; inhibited by iNOS specific dexamethason $(15 \mu \mathrm{M} ; n=3)$; or inhibited by iNOS specific L-NIL $(100 \mu \mathrm{M} ; n=3)$. Values are expressed as the mean with standard deviation for each experimental group.

\section{Posttransplant graft function}

Blood samples for BUN and serum creatinine were analyzed using an ACE analyzer (Schiapparelli Biosystems, Inc., Fairfield, NJ, USA). Serum creatinine was considered normal with values $<2.0 \mathrm{mg} / \mathrm{dL}$.

Ad5.CMVS-GFP

Ad5.CMV5GFP serotype 5 particles expressing the Green Fluorescent Protein gene using modified Cytomegalovirus-I E promoter/enhancer were employed (Quantum, Biotechnologies, Inc. Montreal Quebec, Canada). The vector was administered into the perfusion path at a concentration of $1 \times 10^{6}$ $\mathrm{VP} / \mathrm{g}$ of kidney and recirculated for 24 hours.

\section{RESULTS}

Organ culture of human kidneys

Human kidneys were placed in organ culture at $32^{\circ} \mathrm{C}$ and resulting metabolism and function were evaluated (Figure 1). Evaluation of the kidneys at 1,4, $8,16,24,36$ and 48 hours demonstrated that human kidneys could be main- 


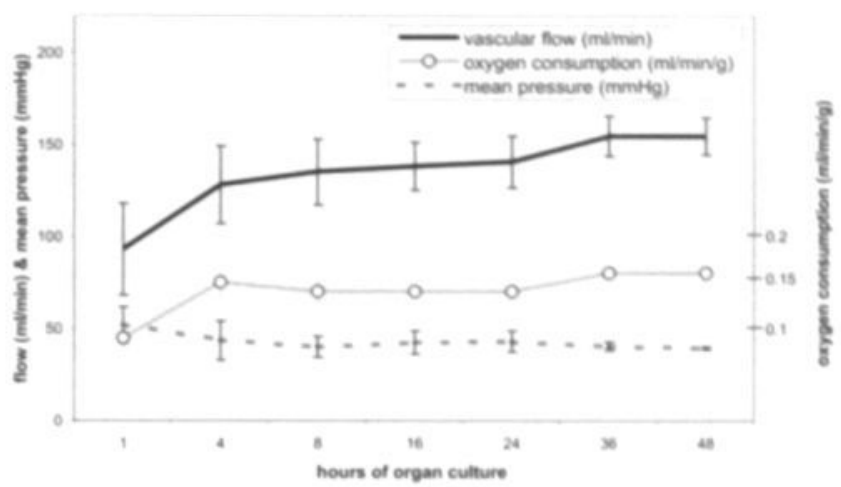

FIGURE 1. Perfusion characteristic of the human kidneys $(n=6)$ following upto 48 hours of whole organ culuture.

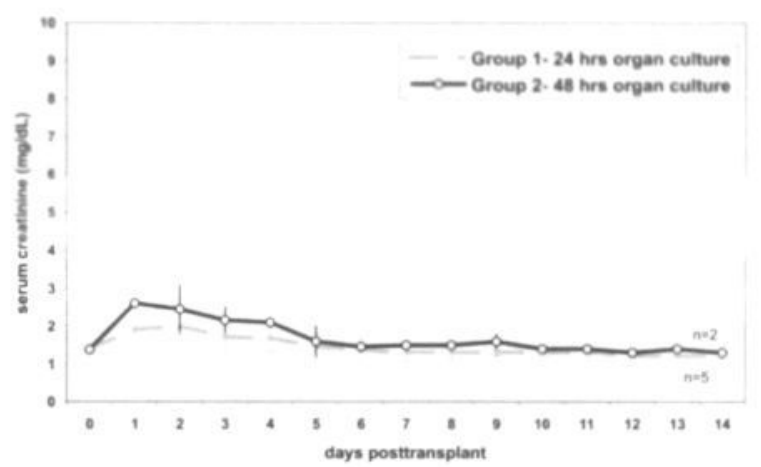

FIGURE 2. Serum creatinine concentration following renal transplantation of kidneys subjected to 24 hours (Group 1) and 48 hours (Group 2) of whole organ culture. Values are expressed as the mean with standard deviation for each experimental group.

tained stably ex vivo in the acellular environment of organ culture. During the culture period, $\mathrm{O}_{2}$-consumption remained stable. Similarly, perfusion pressures and vascular flow rates remained stable throughout the experiment. Urine flow was in all cases reestablished during organ culture with the ending diuresis increased over initial rates, demonstrating the feasibility of maintaining isolated human kidneys in organ culture for 48 hours.

\section{Transplantation following organ culture}

To demonstrate the results obtained with the culture of human kidneys represented preservation of renal cellular and functional integrity, a canine kidney autotransplant model was used (Figure 2). Kidneys were placed in organ culture for 24 or 48 hours. All kidneys reperfused well upon reimplantation, 


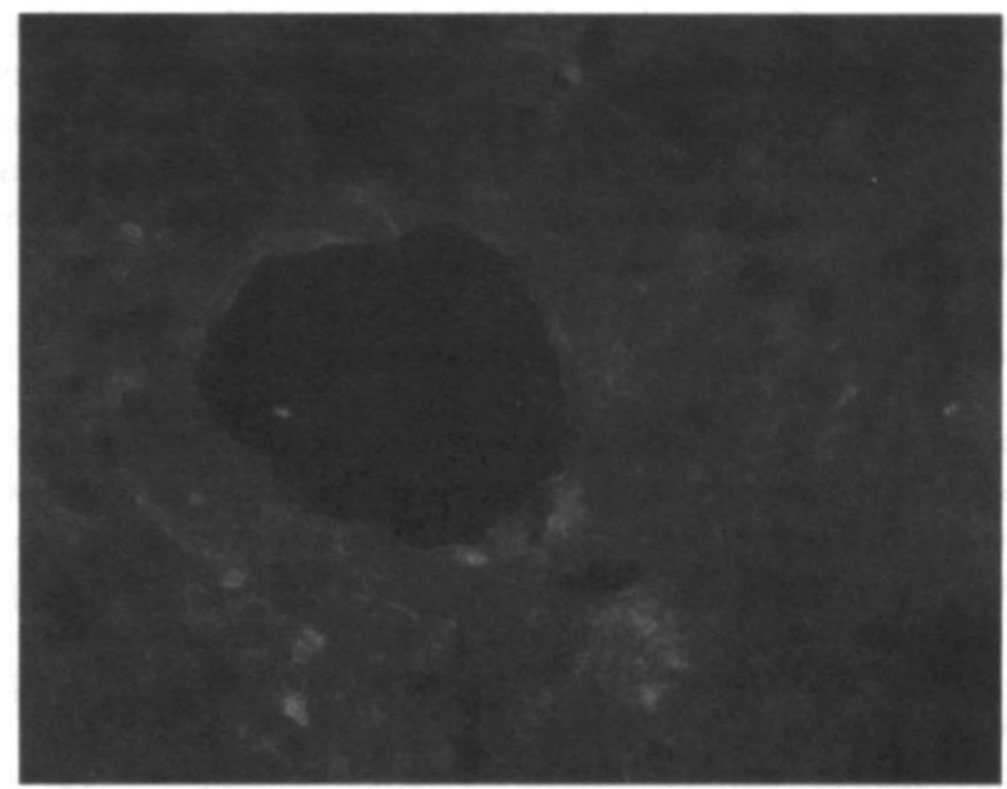

FIGURE 3C

FIGURE 3A,B,C. Fluorescent light microscopy (200x). Evaluation of frozen sections from a kidney transfected during 24 hours of whole organ culture with Ad5.CMV5GFP. Expression of green fluorescent protein limited to the intima of all blood vessels can be observed (Figure $3 a, b)$. The human control kidney that was perfused but not transfected was negative (Figure 3c).

with restored urine flow within minutes of reperfusion. All dogs survived with normal serum chemistries, normal urine and histologically normal kidneys. These results demonstrate the feasibility of maintaining intact isolated organs in a metabolically active state in the cell culture-like organ system.

De novo synthesis of proteins during organ culture

Metabolism during culture was evaluated for the ability to support protein synthesis ex vivo (Figure $3 a, b$ and $c$ ). De novo synthesis was evaluated using a transfected exogeneous gene, since there would be no possibility of an endogenous cellular reservoir contributing the protein, in three human kidneys. Ad5.CMV5GFP; Adenovirus serotype 5 (Ad5) particles expressing the Green Fluorescent Protein (GFP) was the viral vector. An additional human kidney served as a control placed in organ culture but not transfected. The human test 
kidneys were transfected with $1 \times 10^{6} \mathrm{VP} / \mathrm{g}$ during a 24-hour period of organ culture. Evaluation of frozen sections made from the test kidneys demonstrated positive fluorescence limited to the intima of the blood vessels examined. (Figure $3 a, b$ ) The human control kidney not transfected was negative. (Figure $3 c$ ) These results demonstrate de novo synthesis of proteins during a 24-hour period of organ culture.

\section{Underlying mechanism preserving vascular integrity}

The maintenance of stable perfusion dynamics without the development of edema ( $<15 \%$ net weight gain) during organ culture suggested preservation of the vascular wall barrier functions $(25,26)$ (Figure 4$)$. A stable by-product of nitric oxide synthase (NOS) isoforms, $\mathrm{NO}_{3}$, was found to accumulate in the medium during the culture period suggesting the continued flux of $\mathrm{NO}$ in organ culture. We evaluated if NOS played a regulatory role during organ culture.

Blocking the induction of NOS by adding L-NAME ( ${ }^{6}$-nitro-L-arginine methyl ester; $100 \mu \mathrm{M}$ ) at the start of the organ culture lead to the development of interstitial edema with a mean net weight gain of $350 \%$ and significant increases in perfusion pressures. Likewise, the addition of L-NAME significantly inhibited $\mathrm{NO}_{3}$ accumulation.

Additional studies using $i N O S$ specific inhibitors dexamethasone $(15 \mu \mathrm{M})$ and L-NIL (L-N-(1-iminoethyl lysine hydrochloride; $100 \mu \mathrm{M}$ ) confirmed a central role for NOS during the culture of organs. Similar to the results using L-NAME, dexamethasone and L-NIL blockade of iNOS also resulted in marked edema ( $276 \%$ and $206 \%$ respectively). In contrast to L-NAME, introduction at the start of the culture period did not affect perfusion pressures or vascular flow rates.

The absence of edema in conjunction with accumulation of $\mathrm{NO}_{3}^{-}$(mean $4.6 \pm 0.4 \mathrm{mg} / \mathrm{L}$ ) in the kidneys without NOS inhibitors following 24 hours of organ culture was in contrast to the edematous test kidneys where the L-NAME, dexamethasone and L-NIL groups had lower $\mathrm{NO}_{3}$ accumulation $(0.16 \pm 0.1 \mathrm{mg} / \mathrm{L} ; 0.18 \pm 0.1 \mathrm{mg} / \mathrm{L} ;$ and $0.51 \pm 0.2 \mathrm{mg} / \mathrm{L}$ respectively, $P<0.05))$. These results suggest a central role for NOS in the preservation of vascular integrity during organ culture.

\section{Underlying metabolic mechanism}

Two critical carrier functions intrinsic to supporting metabolism during organ culture consist of oxygen and albumin carriers (Figure 5). The amount 


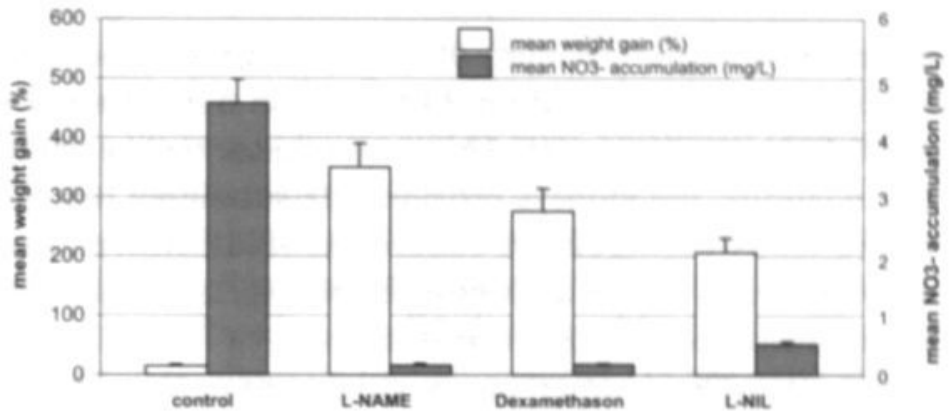

FIGURE 4. Mean net weight gain of kidneys and mean NO3- accumulation in the perfusate seen following 24 hours of whole organ culture. NOS was either not inhibited (control; $n=3)$, inhibited by L-NAME $(100 \mu \mathrm{M} ; \mathrm{n=3})$; inhibited by iNOS specific dexamethason ( $15 \mu \mathrm{M} ; n=3)$; or inhibited by iNOS specific L-NIL $(100 \mu \mathrm{M} ; \mathrm{n}=3)$.

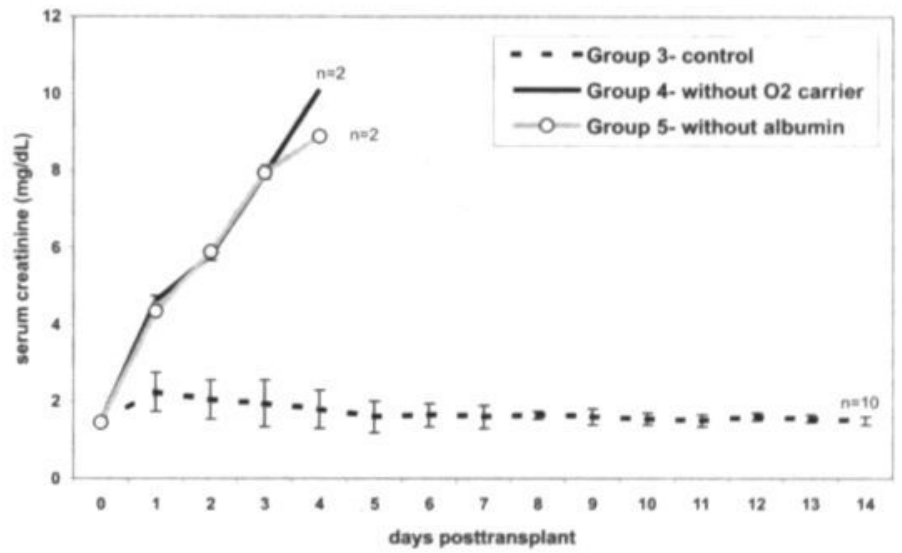

FIGURE 5. Serum creatinine concentration following renal transplantation of kidneys subjected to 6 hours of organ culture (Group 3; $n=10$ ); organ culture without oxygen $\left(\mathrm{O}_{2}\right)$ carrier (Group $\left.4 ; n=2\right)$; and organ culture without albumin (Group $5 ; n=2$ ). Values are expressed as the mean with standard deviation for each experimental group.

of oxygen that is dissolvable in an aqueous solution is insufficient to support oxidative metabolism in an organ during ex vivo perfusion. Chemically modified hemoglobin was used to augment oxygen delivery during organ culture. Because of its unique structure, albumin accommodates a large number of molecules, making it a universal carrier. Eliminating either carrier from the medium during 6 hours of organ culture, resulted in non-viable kidneys. 
These results demonstrate the feasibility of maintaining intact kidneys during acellular perfusions with a cell culture-like medium administered via the vascular bed for 48 hours. Moreover, when canine kidneys were reimplanted following organ culture, the kidneys provided life-sustaining function. The metabolic rate sustained during ex vivo culture was of sufficient magnitude to support de novo protein synthesis as assessed by the expression of the reporter gene product following ex vivo gene transfection.

Protective mechanisms during organ culture appear to include the continued flux of $\mathrm{NO}$ by constitutive NOS, as well as activation of the inducible isoform, iNOS. Blockade of NOS by L-NAME, dexamethasone or L-NIL resulted in profound edema during organ culture. The literature is replete with reports of the versatility of this critical signaling messenger, demonstrating both protective and adverse effects. It appears likely that NO generated by the constitutive isoform found in endothelial cells, as well as inducible isoform of NOS, provides signaling pathways during organ culture. The continued function of constitutive NOS isoform during organ culture is suggested by the increased dysfunction observed with L-NAME blockade targeting multiple NOS isoforms in comparison to specific blockade of iNOS. L-NIL is approximately 28 -fold more selective for iNOS in comparison to the constitutive endothelial NOS isoform (26). Similarly, dexamethasone inhibits the induction of iNOS without affecting constitutive isoforms (27). While the edema was more severe in the kidneys perfused with the addition of L-NAME, blockade of iNOS also leads to profound edema supporting the function of iNOS during organ culture.

Induction of iNOS may be attributable to generalized modulatory mechanism when organs are removed from their physiologic setting and adapted to an altered state of equilibrium (28). However, the NO produced during organ culture was not cytotoxic since the canine kidneys provided normal serum chemistries with immediate resumption of urine flow upon reimplantation.

Interfacing directly with a metabolizing and functioning organ could provide expanded research opportunities over either animal models or cell culture. The ability to study heterogeneous cell populations that constitute complex tissues with preservation of normal cell-cell and cell-extracellular matrices integrity holds the potential to better understand cellular interactions. Among the potential medical applications that may be developed, one of the most intriguing would be the possibility of repairing damaged organs. The application of cell culture principles to an isolated organ in combination with adequate growth factor signaling could provide the basis for cellular 
repair mechanisms; since optimized cell culture systems can support population doublings in $<24$ hours. The repair ex vivo would be distinct from the physiologic processes involved in wound repair because wound repair involves coagulation and inflammation, with a migratory/adhesion phase. Since organ culture is acellular and ex vivo, any repair represents the cellular recovery that occurs with restoration of metabolism. The de novo synthesis that occurred in the human kidneys during 24 hours of culture demonstrates the potential for synthetic functions supporting cellular reparative processes.

Other potential medical applications would include using ex vivo metabolism to modulate allograft immunogenicity. In the near term, prognostic testing during organ culture could form the basis for expanding the donor pool with organs from marginal and non-heartbeating donors.

The ability to perform gene transfection, with accompanying denovo protein synthesis of the reporter gene product ex vivo, could provide new opportunities. The current approach has been to administer viral vectors in situ where transfer rates can be low, targeting specific sites is difficult and immunologic responses can negatively affect the outcomes (29-32). Alternatively, transfection has been attempted during hypothermic perfusion $\left(4-8^{\circ} \mathrm{C}\right)$ where the rate of transfection is low and the hypothermia limits transgene expression since hypothermic preservation is predicated upon inhibition of cellular metabolism (33-37). The ability to target delivery of an exogenous gene to the vascular endothelium during ex vivo perfusion could potentially optimize the effect of a given therapeutic.

Tissue engineering represents an interdisciplinary field that combines the principles of engineering with those of the biologic sciences to develop composites that would substitute for tissues and organs $(38-42)$. The major obstacle to developing bioengineered organs is the inherent complexity of tissues that require metabolism and function be maintained. An acellular perfusion system capable of delivering nutrients and removing accumulating by-products to the cells at the inner most core of these organs could provide a the solution.

Perhaps most importantly, the ability to maintain organs in cell culture-like conditions would present the opportunity to eliminate the art factual cell proliferation that is a concomitant feature of using dissociated cells for experimentation. Therefore, ex vivo testing based upon intact organs represents an intermediate phase between in vivo animal models and the dissociative state of isolated cell populations derived in cell culture. 


\section{REFERENCES}

1. Pedanius Dioscorides, First Century B.C., De Materia Medica I, Introduction, translated by John Goodyear 1655 in R. T. Gunther, The Greek Herbal of Dioscorides Oxford, 1934

2. Walcott GD (general editor), A Source Book In Greek Science, New York, NY 1948

3. Translation by Spencer WG, Celsus, Introduction 74.75

4. Temkin O, Straus W. Bulletin of the History of Medicine. 1946: 19:167

5. Schiller J. J Hist Med 1967: 22:246

6. Ryder R. Victims of Science. London Davis-Poynter 1975

7. Burnett M. Auto-Immunity and Auto-Immune Disease, Davis Philadelphia 1972: 243

8. Mordes JP, Desemone J, Rossini AA. Diabetes/Metab Rev 1987: 3(3):725

9. Makino S, Kunimoto K, Muraoka Y et al. Breeding of non-obese, diabetic strain of mice. Jikken Dobutsu 1980: 29(1):1

10. Butler L, Guberski DL, A.A. Like, In Frontiers in Diabetic Research: Lessons From Animal Diabetes II. Shafrir E and Renold AE (eds) Libbey, London 1988: 74

11. Carrel A. J. Exp. Med. 1912: 15:516

12. Southard JH. Cryobiology 1989: 26(3):232

13. Couch NP, Cassie GF, Murray JE. Surgery 1958: 44:666

14. Belzer FO, Ashby BS, Dunphy JE. Lancet 1967: 2(7515):536

15. Benjamin JL, Sell KW. Transpl 1972: 14:501

16. Folkman J, in Norman, Organ Perfusion and Preservation, Appleton-CenturyCrofts, NY 1968

17. Benjamin JL, Sell KW. Transpl Proc 1971: 8:616

18. Telander RL. Surgery Gyn Obstet 1964: 118:347

19. Belzer FO, Hoffmann RM, Southard JH. Transpl 1982: 33:322

20. Collins GM, Bravo-Shugarman M, Terasaki PI. Lancet 1969: 2(7632):1219

21. Hoffmann RM, Southard JH, Lutz M et al. 1983: 118(8):919

22. Squifflet JP, Pirson Y, Gianello P et al. 1981: 13(1 Pt 2):693

23. Brasile L, Stubenitsky BM, Booster MH et al. Am J Transplant 2001: 1:316

24. Brasile L, Stubenitsky BM, Booster MH et al. Transpl 2002: 73:6:897

25. Gabbai FB, Boggiano C, Peter T et al. J Immunol 1997: 159(12):6266

26. Radomski MW, Palmer RM, Moncada S. Proc Natl Acad Sci USA. 1990: $87(24): 10043$

27. Di Rosa M, Radomski M, Carnuccio R et al. Biochem Biophys Res Commun 1990: 172(3):1246

28. Miller MJ, Sandoval M. Am J Physiol 1999: 276:G795

29. Springer CJ, Niculescu-Duvaz. J Clin Invest 2000: 105:1161

30. Kojima A, Hackett NR, Ohwada A et al. J Clin Invest 1998: 101:1789

31. Lubberts E, Joosten LAB, Chabaud M et al. J Clin Invest 2000: 105:1697

32. Gahery-Segard H, Molinier-Frenkel V, Le Boulaire C et al. J Clin Invest 1997: 100(9):2218 
33. Chia SH, Geller DA, Kibbe MR et al. Transpl 1998: 66:1545

34. Vickers SM, Sampson LS, Phillips JO et al. Arch Surg 1997: 132:1006

35. Gojo S, Niwaya K, Taniguchi S et al. Ann Thorac Surg 1998: 65:647

36. Shiraishi M, Kusano T, Hara J et al Transplant Int 1997: 10:202

37. Zwacka RM, Zhou W, Zhang Y et al. Nature Med 1998: 4:698

38. Sachs DH, Colvin RB, Cossimi AB. Nature Med 1998: 4:372

39. Langer R, Vacanti JP. Science 1993: 260(5110):920

40. Hering BJ, Browatzki CC, Schulz A et al. Cell Transplant 1993: 2(4):269

41. Vacanti JP, Langer R. Lancet 1999: 354 Suppl 1:S132-4. Review.

42. Putman AJ, Mooney DJ. Nature Med 1996: 2:824 

CHAPTER 9

Conclusions and future applications

Summary

Samenvatting

Acknowledgements

Curricuclum vitae 


\section{Conclusions and future applications}

Transplantation medicine represents our best hope for the continuation of a normal life when end-stage organ failure occurs. While not all of the obstacles facing this discipline have been overcome sufficiently to make transplantation a permanent cure, it nonetheless represents the best option available. It is logical to assume that the demand and indications for organ transplantation will continue to grow. For the past thirty years organ procurement efforts have been based upon the heartbeating donor using neurologic criteria of death, whenever a living-related donor was not available. The results of the organ procurement activity during the past decade have demonstrated that the current organ donor pool is unlikely to expand. Clearly alternative sources of organs must be developed to meet the increasing demand for transplantation.

Although organ donation from expatients by cardiopulmonary criteria was the source of transplantable kidneys prior to the introduction of brain death legislation, less than one percent of kidneys are currently being procured from this group today, in all but a few transplant centers. The nonheartbeating donor represents the best hope for a short-term solution to the growing demand for transplantable organs. One of the major barriers to the effective use of non-heartbeating donors is not enough time. Not enough time between being a patient to being designated an expatient or donor. Not enough time to obtain consent from next-of-kin for organ donation. Not enough time to conveniently excise the kidneys. And not enough time to store hypothermically without substantially increasing both the delayed graft function and primary non-function rates. Technology that would provide more time could provide the foundation for the effective utilization of non-heartbeating donors. Technology that overcomes extended warm ischemic exposure upon cardiac arrest would likewise provide a mechanism to substantially expand the indications for organ donation. An important concordant goal would be the development of effective prognostic testing. Without the ability to differentiate delayed graft function from primary non-function, with a high degree of confidence, the widespread resistance to using non-heartbeating donor kidneys will continue.

None of these issues can be effectively addressed using hypothermia to preserve organs. Hypothermic preservation is predicated upon reducing the metabolic requirements of an organ. The inhibition of cellular metabolism 
precludes the possibility of effective prognostic testing. Most importantly, the cold itself is damaging and the consequences of inhibiting metabolism is that at some point it becomes irreversible. Proof of this concept is that organs can only be preserved for short periods, i.e. six hours for hearts, without the cold damage leading to permanent impairment of the organ's function.

\section{Potential of warm perfusion}

The most logical approach to developing technology capable of overcoming the technical obstacles that limits access to the non-heartbeating donor is a warm temperature preservation technology. A near normothermic perfusion technology would be more physiologic, theoretically would better preserve cellular integrity and if cell metabolism was adequately supported, it would be non-damaging. Continued cellular metabolism during an ex vivo phase could also present important new opportunities in medicine.

Warm perfusion technology holds the potential to achieve long-term organ preservation. The current time frames in organ preservation represent a limited opportunity to alter tissues via therapies such as gene transfection. Long-term warm perfusion also holds the potential of repairing warm ischemically damaged organs. With adequate nutrient delivery and growth factor signaling via membrane receptor specific mechanisms, signal transduction may be sufficient to initiate repair mechanisms ex vivo. The results of the studies in this thesis demonstrate the feasibility of repairing the cellular consequences of warm ischemia. Continued metabolism in an organ being stored ex vivo could provide the basis for developing prognostic testing. Prognostic testing would be important for identifying organs with irreversible damage. Just as important will be the ability to monitor any repair process to ensure functionality. All three components: ability to maintain a metabolizing organ ex vivo, the ability to repair warm ischemically damaged organs and the diagnostic capability to prospectively evaluate organs, represents integral components for successful utilization of expanded organ donor criteria.

The results of the studies described in this thesis provide evidence for the feasibility of achieving a clinically relevant warm temperature perfusion technology. Over the course of the past nine years, incremental work has been accomplished that builds a case for the potential of a more physiologic perfusion technology. The unique feature of the EMS technology is that it represents an extension of tissue culture principles to an intact organ.

The ability to maintain an intact organ in tissue culture-like conditions is predicated upon two major principles: 
1. It provides adequate support of metabolism by providing all the necessary nutrients and substrates to support continued metabolism, including oxygen.

2. It maintains vascular integrity by preserving the normal barrier functions of the blood vessel wall.

While incredibility sometimes accompanies the introduction of EMS technology, its basis is in fact quite logical. We maintain normal mammalian cells in tissue culture for many passages over the course of many months. Therefore, why cannot an intact organ be maintained in a similar fashion?

\section{Future applications}

The potential for a warm perfusion technology may be significant. For example, it was demonstrated in this thesis that gene transfer could be achieved during EMS perfusion. More startling was the observation that denovo synthesis of the reporter gene product could likewise be achieved ex vivo during the perfusion period with the acellular EMS solution. Just as significant was the ability to target the transfected gene expression to the blood vessel wall. These results provide evidence for the potential introduction of novel immunomodulating therapies. Immunomodulation via a warm temperature perfusion would have the added benefit of being able to simultaneously monitor metabolism and function.

Future bioengineering technologies must able to address the functional complexity of organs in terms of the interactions required with the rest of the physiologic system and with the organ's regulatory role(s). Such biohybrids will have to consist of cells in combination with synthetically engineered materials to develop complex three-dimensional artificial organs. The complex biohybrids will also have to contain the heterogeneous cell types necessary to approximate the physiologic functions of the organ it is intended to replace. The ability to develop biohybrids capable of replacing organs will be dependant upon a warm perfusion technology to deliver nutrients, remove waste products and maintain the cells within the core of the three-dimensional constructs.

The work described in this thesis represents the potential of a warm perfusion technology in its infancy. The potential applications that could be attempted with the next generations of this technology are enormous. A short list could include developing targeted drug delivery systems to minimize systemic toxicity, such as in the case of chemotherapy. In situ techniques could be developed that target resuscitation and repair of tissue damaged 
down-stream from a thrombotic event thereby expanding the opportunities for thrombolytic therapies or even to support the development of effective gene transfer technologies minimizing the immunologic consequences of administering virus systemically. Another application could entail utilizing warm perfusion to isolate specific cell types within organs and tissues.

In conclusion, this work demonstrates the feasibility of ex vivo warm perfusion using an acellular technology based upon the principles of cell culture. The real visionary of this technology was one of the founding fathers of clinical organ preservation technology, Folkert Belzer, who in 1982 predicted that the future of organ preservation would be at a warmer, more physiologic temperature. 


\section{Summary of results}

The studies comprising this thesis were designed to address whether the EMS technology that had in previous studies demonstrated the feasibility of preserving organs in situ or ex vivo for short periods, could be further developed to address one the major obstacles facing transplantation medicine today-the organ shortage.

Chapter 1 is a brief overview of the two major problems facing transplantation today: the organ shortage and chronic rejection. It addresses the need to develop a new approach to solving these problems. It also serves as an introduction to this thesis.

Chapter 2 is a historical overview of cadaveric organ donation. Emphasis was placed on the relative outcomes of the early experience using non-heartbeating donors and the transition to the heartbeating donors in comparison to the current experience with expanded indications for donation.

Chapter 3 is an overview of approaches and technologies that hold the potential to solve the organ shortage. The relative chance of success for each technology is discussed, with the identification of repairing warm ischemically damaged organs as the best near-term solution.

Chapter 4 describes the underlying principles and functions of a new perfusion technology currently being developed called Exsanguineous Metabolic Support (EMS) technology.

Chapter 5 is comprised of the studies that were performed to identify the limiting factor(s) in expanding the organ donor pool. Canine kidneys were subjected to varying periods of warm ischemia followed by either cold preservation or warm preservation or a combination of both. The results clearly identify cold ischemia as a major barrier to utilizing warm ischemically damaged kidneys.

Chapter 6 is a study indicating that a controlled perfusion with an acellular, near-normothermic technology can ameliorate reperfusion injury following 30 minutes of warm ischemic insult. This finding is significant for the development of reliable prognostic testing, since it is imperative that no further damage be encountered between the time of organ assessment and reimplantation for a prospective test to be effective. The ability to effectively reduce reperfusion injury could bridge prospective organ evaluation with posttransplant outcomes. 
Chapter 7 demonstrates the potential to repair organs during ex vivo EMS perfusion. In canine kidneys that were damaged by either 45 or 120 minutes of warm ischemia, repair mechanism were sufficient to render the kidneys capable of supporting life. Control kidneys were not viable following the same warm ischemic insult. The results suggest that ex vivo repair of damaged organs may be feasible and could theoretically provide a mechanism to increase the number of transplantable kidneys.

Chapter 8 demonstrates the potential long-term ex vivo survival of canine and human kidneys in a metabolically active state. The results of this study demonstrate the ability to maintain stable metabolism and vascular integrity for up to 48 hours ex vivo. Also demonstrated in this study is the ability to perform gene transfection with accompanying denovo protein synthesis of the reporter gene product during ex vivo warm perfusion. Transfection was accomplished using an adenoviral vector encoding GFP with demonstration of a dose dependant effect in both human and canine kidneys. The results of this study supports the effective viral transfer during the perfusion period with corresponding internalization, nuclear trafficking and expression of the GFP marker.

Chapter 9 contains the general discussion of the thesis research and corresponding results, in the context of its potential role in transplantation. A summary of each chapter is included along with the potential of the EMS technology in other future applications. 


\section{Samenvatting}

In dit proefschrift worden meerdere studies beschreven waarbij ex vivo herstel van orgaanmetabolisme middels warme perfusie op de voorgrond staat.

Hoofdstuk 1 vormt de algemene introductie voor dit proefschrift. Het geeft een overzicht van de voornaamste obstakels in de hedendaagse klinische transplantatiegeneeskunde-1) het tekort aan organen voor transplantatie en 2 ) de chronische afstoting van getransplanteerde organen. Tevens wordt de noodzaak voor en de mogelijkheid tot het oplossen van deze obstakels middels ex vivo warme perfusie besproken.

In hoofdstuk 2 wordt een historisch overzicht van de orgaandonatic voor transplantatie gegeven. Hierbij worden de vroegere ervaringen en resultaten met non-heartbeating donoren (ischemisch beschadigde nieren) en de overgang naar heartbeating donoren (ischemisch onbeschadigde nieren) beschreven.

Hoofdstuk 3 bespreekt de verschillende theorieën en ontwikkelingen binnen de wetenschap die pogen een oplossing te vinden voor het tekort aan organen voor transplantatie. Gekeken wordt naar de haalbaarheid en de kans op succes van de verschillende theorieën en ontwikkelingen, waarbij het ex vivo herstel van ischemisch beschadigde organen wordt gezien als de meest haalbare oplossing in de nabije toekomst.

Hoofdstuk 4 bespreekt het oorspronkelijke concept hetgeen ten grondslag ligt aan de ontwikkeling van warme perfusie met 'Exsanguinous Metabolic Support' (EMS) technologie. EMS werkt via het ondersteunen van twee, tijdens preservatie, kritieke processen: te weten het cellulair metabolisme en de vasculaire integriteit teneinde respectievelijk de functionaliteit van de niercellen en de barrière functies van het vaatbed te behouden.

Indien aan deze twee voorwaarden is voldaan, lijkt het haalbaar een orgaan te bewaren bij een bijna fysiologische temperatuur onder omstandigheden die gelijk zijn aan die van cellen in een celkweek. De perfusie vloeistof en het perfusie systeem komen in detail aan de orde.

Middels een kritisch auto-transplantatie model bij honden worden in hoofdstuk 5 de beperkende factoren voor het uitbreiden van de bestaande donorpool geidentificeerd. De nieren worden onderworpen aan warme ischemie, gevolgd door koude preservatie en/of warme perfusie. De bevin- 
dingen identificeren de koude ischemie tijdens koude preservatie als voornaamste obstakel voor het gebruik van warm ischemisch beschadigde nieren.

Hoofdstuk 6 (auto-transplantatie model bij honden) beschrijft een significante vermindering van de reperfusieschade door ex vivo herstel van niermetabolisme voor transplantatie. Dit gegeven is belangrijk voor de ontwikkeling van betrouwbare voorspellende kwaliteitstesten naar de levensvatbaarheid van nieren, aangezien er idealiter geen aanvullende schade mag optreden tussen het tijdstip van evaluatie en het tijdstip van transplantatie.

Hoofdstuk 7 bespreekt de mogelijkheid van herstel tijdens ex vivo warme perfusie bij ernstige ischemisch beschadigde nieren $(120 \mathrm{~min}$. warme ischemie). Deze bevindingen wijzen op de mogelijkheid om door herstel het aantal geschikte donornieren voor transplantatie te vergroten.

Hoofdstuk 8 toont aan dat langdurige ex vivo warme perfusie mogelijk is. Hierbij wordt het metabolisme van de nier en de vasculaire integriteit gedurende 48 uur succesvol in stand gehouden. Tevens wordt aangetoond dat transfectie van genen, met bijbehorende genexpressie, mogelijk is gedurende ex vivo warme perfusie.

In hoofdstuk 9 worden de algemene conclusies besproken en geïnterpreteerd. Mogelijke nieuwe ontwikkelingen voortvloeiend uit de behaalde resultaten worden in de context van de transplantatiegeneeskunde besproken. 


\section{Acknowledgements}

It is with profound gratitude that I thank Professor Kootstra for this opportunity; I will always be grateful. Since our first lunch in New York City, I have been inspired by his keen intellect, ability to see the big picture and his calculated risk-taking when he believes in an undertaking. Thank you, Professor

A special thanks goes to Bart Stubenitsky, my adopted son and kindred spirit in research endeavors. You made this work infinitely more bearable. I have appreciated our synergy, where we were always more productive together than the simple sums of our efforts.

Thank you Maurits for your input - your superb surgical expertise, the long hours and the hard work, we make a great team.

Two of the most important people in my life have been instrumental in accomplishing this work. My daughter Breean has endured as much as she has given. Being forced to grow up with this project, she can perfuse organs, perform chemistries and postop care like a pro and lived with the perpetual presence of cow urine in the refrigerator. Of course being exposed to all of this for so long, so young explains why she hates science! Yet, during the "hopeless" phase it was you who prevented me from quitting, thank you. My partner in life and work, Ernie, made this work possible. Since the earliest days, through the tough ones and now during the good times, you believed in me and supported me, even with the crazy ideas.

To Carl, thank you for all your support, collaborations, surgeries and always being the main reference man. Thank you for never thinking warm perfusion was a stupid idea; although I sometimes did.

Liza thanks for all your help, I thought I'd drive you crazy! Jordan my other son, thank you for quietly always doing what was needed, I never had to ask. Tina my other daughter, thank you for all the babysitting, help building the clean-room and believing in me.

And, thanks to everyone in North Carolina, you supported this work over the long haul. Most importantly, through the periods of initial failures you always provided what was needed. A special thanks to Debbie, Dorian, Corinne, Peggy and Anita. 



\section{Curriculum Vitae}

Lauren Brasile was born in Springfield, Massachusetts in 1952. After receiving her Bachelor of Science degree, she assumed responsibilities in the Histocompatibility Testing Program and subsequently as supervisor of the Transplantation Research Labs for the Department of Surgery at Ohio State University Transplantation Program. She left Ohio to accept a position as Director of the Transplantation Research Laboratories for the Department of Surgery at Albany Medical Center Albany, New York. Her experience includes the formation of a regional genetic testing service for the State of New York through which she was called upon numerous times to provide expert professional testimony in civil and criminal proceedings.

In 1986 Lauren Brasile began her business career when she founded Vec Tec Inc., a biotech startup company. In 1996 she left Vec Tec to create Breonics, Inc. where presently she is Executive Vice President and Chief Scientific Officer (C.S.O.). She is the inventor of 12 patents that cover Breonics' EMS and Immunosuppression technologies with over 20 years experience in transplantation immunology and organ preservation, is author of approximately 60 publications in medical journals and 3 chapters in textbooks. Ms. Brasile is the recipient of several Small Business Innovation Research awards from the National Cancer Institute and the National Institute For Diabetes, Digestive and Kidney Diseases and was honored in 1998 as "Inventor of the Year" by the Eastern New York State Intellectual Property Law Association. 
W.

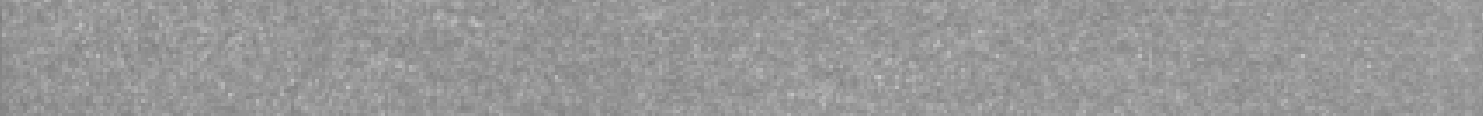
P. 325: Q W.1.

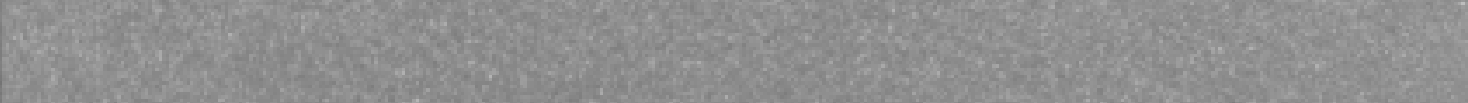

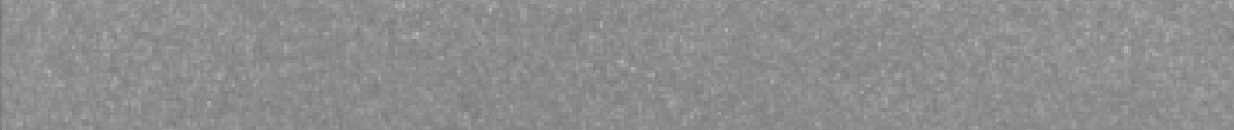

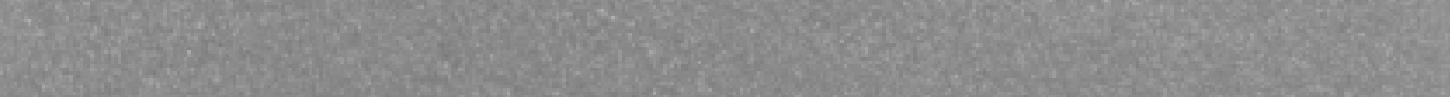

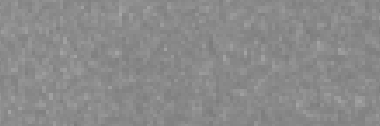
(H) 20. (x) 